\title{
Deliberate Self-Persuasion and Forgiveness
}

Irene Cheung, The University of Western Ontario

Supervisor: Dr. James Olson, The University of Western Ontario

A thesis submitted in partial fulfillment of the requirements for the Doctor of Philosophy degree in Psychology

(C) Irene Cheung 2012

Follow this and additional works at: https://ir.lib.uwo.ca/etd

Part of the Social Psychology Commons

\section{Recommended Citation}

Cheung, Irene, "Deliberate Self-Persuasion and Forgiveness" (2012). Electronic Thesis and Dissertation Repository. 421.

https://ir.lib.uwo.ca/etd/421

This Dissertation/Thesis is brought to you for free and open access by Scholarship@Western. It has been accepted for inclusion in Electronic Thesis and Dissertation Repository by an authorized administrator of Scholarship@Western. For more information, please contact wlswadmin@uwo.ca. 


\section{DELIBERATE SELF-PERSUASION AND FORGIVENESS}

(Spine title: Deliberate Self-Persuasion and Forgiveness)

(Thesis format: Monograph)

by

Irene O. L. Cheung

Graduate Program in Psychology

A thesis submitted in partial fulfillment of the requirements for the degree of Doctor of Philosophy

The School of Graduate and Postdoctoral Studies

The University of Western Ontario

London, Ontario, Canada

(C) Irene Cheung 2012 
THE UNIVERSITY OF WESTERN ONTARIO

School of Graduate and Postdoctoral Studies

\section{CERTIFICATE OF EXAMINATION}

$\underline{\text { Supervisor }}$

Dr. James Olson

$\underline{\text { Supervisory Committee }}$

Dr. Clive Seligman $\underline{\text { Examiners }}$

Dr. Gordon Hodson

Dr. Wonkyong Beth Lee

Dr. Chris Roney

The thesis by

\section{Irene Oy-Ling Cheung}

entitled:

\section{Deliberate Self-Persuasion and Forgiveness}

is accepted in partial fulfillment of the requirements for the degree of

Doctor of Philosophy

\section{Date}

Chair of the Thesis Examination Board 


\begin{abstract}
After being hurt by a romantic partner, individuals may feel ambivalent towards their partner. Specifically, individuals' feelings about their partner after a transgression (current attitudes) may be discrepant from how they want to feel about their partner (desired attitudes). When individuals are aware of such a discrepancy, they may be motivated to resolve it by using mental strategies (e.g., focusing on the positive characteristics of the partner or focusing on events that are not related to the transgression) that bring their current attitudes more in line with their desired attitudes, a process that has been labeled deliberate self-persuasion (Maio \& Thomas, 2007). In three studies, we empirically tested the deliberate self-persuasion process within a forgiveness context. In Study 1, participants recalled a transgression within the last six months in which they were harmed by their romantic partner and indicated their responses to the transgression. In Study 2, participants imagined a hypothetical scenario in which they were harmed by their romantic partner and reported how they would respond to the transgression. In Study 3, participants who were transgressed against by their romantic partner within the last week were asked to indicate their reactions to the transgression over a three-week period. In general, more ambivalent feelings toward the transgressor were associated with more need to resolve the ambivalence. In turn, the need to resolve the discrepancy was sometimes associated with more use of deliberate self-persuasion strategies and was consistently associated with greater discussion of the transgression with the partner. Although the results indicated that participants may not always resolve their feelings of ambivalence using deliberate self-persuasion strategies, strategies predicted forgiving responses in all three studies. In addition, the use of deliberate self-persuasion strategies was associated in Study 3 with greater increases in forgiveness over time. The results from the current studies provide some empirical support for a deliberate self-persuasion model of
\end{abstract}


forgiveness.

Keywords: deliberate self-persuasion; forgiveness; transgressions 


\section{Acknowledgments}

First and foremost, I would like to express my gratitude to my advisor, Dr. Jim Olson, who has supported me throughout my graduate experience with his expertise, enthusiasm, patience, and understanding. There are not enough words to describe the appreciation that I feel for the amount of wisdom and knowledge that he has imparted to me over the years.

The research presented here would not be possible with the help of many people. I am grateful to Lisa Gallen, Belinda Hammoud, Jane Liao, Natasha Thoennes, Billy Tzavaras, and Katy Torgovnikov for their assistance with data collection, and to Chester Kam and Taylor Kohut for their guidance in SEM. I am also grateful to Drs. Lorne Campbell, Chris Roney, and Clive Seligman for their insightful comments and suggestions on my dissertation research, and to Drs. Gordon Hodson and Beth Lee for graciously agreeing to be my examiners.

There are many people who have added considerably to my graduate experience. I thank Caroline Bennett-AbuAyyash, Paula Brochu, Bethany Butzer, Paul Conway, Tim Jackson, Sandra Lackenbauer, Etienne LeBel, Matthew Maxwell-Smith, Alex McIntyreSmith, Andrew Szeto, and Chris Wilbur for their friendship, support, and encouragement.

I am indebted to my parents, my sister and brother, and my parents-in-law for their love and encouragement during my graduate studies, and especially to my husband, Glen Gorman for his unwavering support. And last but not least, I thank Dr. Deb Matthews for her generosity and giving me a place to call home in London. 


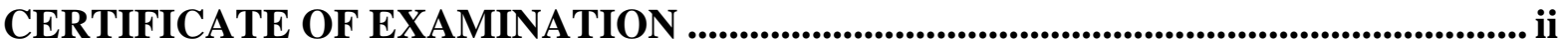

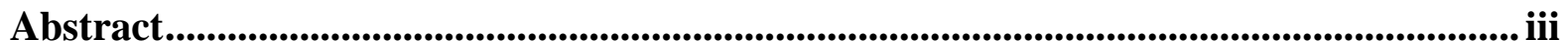

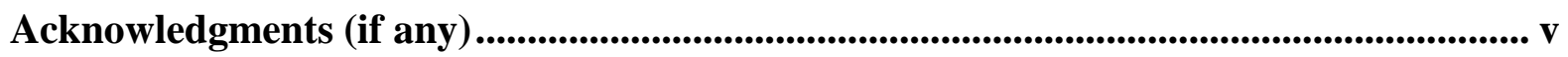

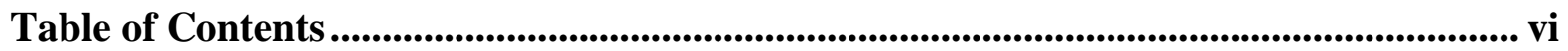

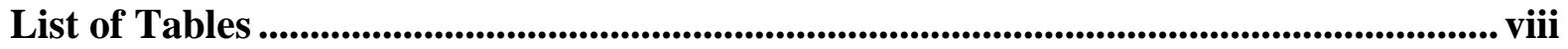

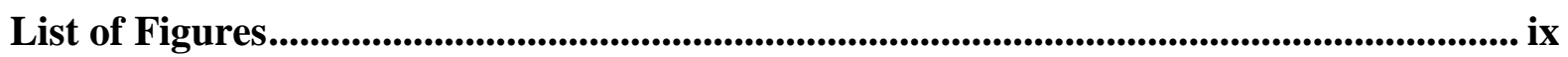

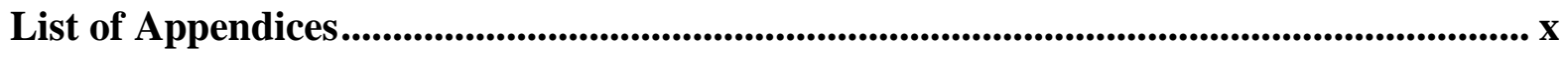

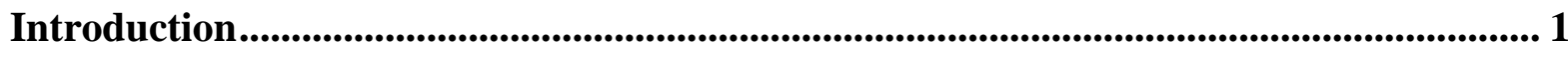

Theory and Research on Forgiveness …..............................................................................................2

Self-Persuasion..............................................................................................................................................................8

Deliberate Self-Persuasion .............................................................................................................................11

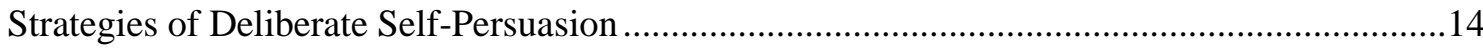

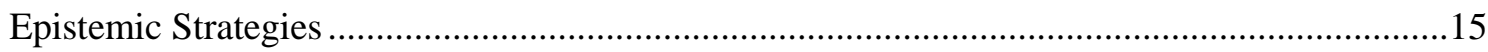

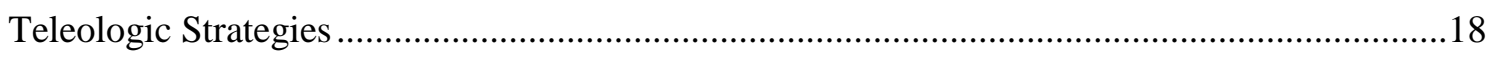

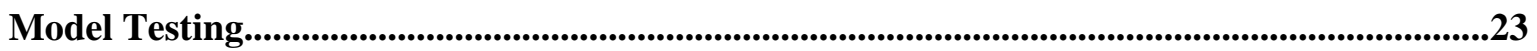

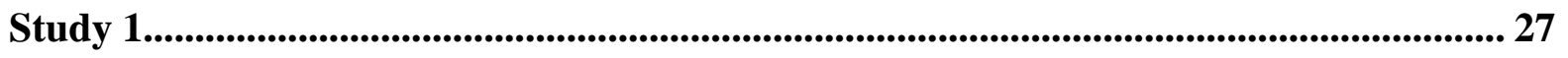

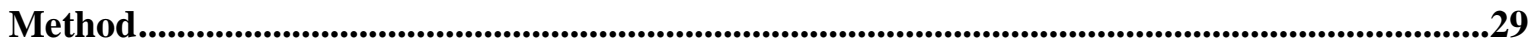

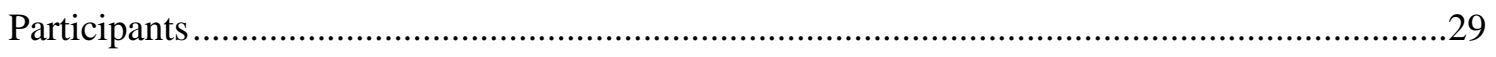

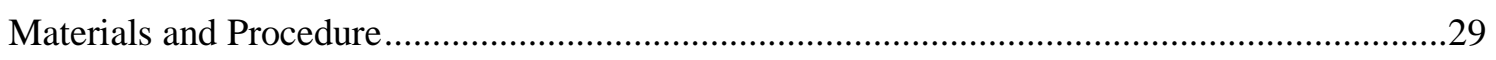

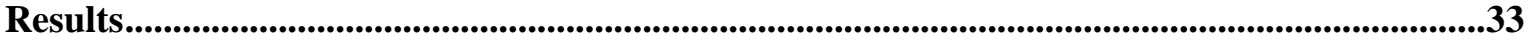

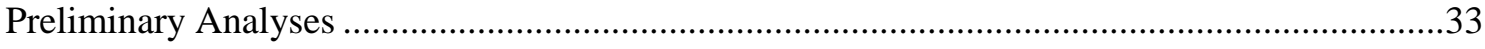

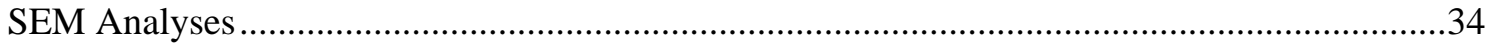

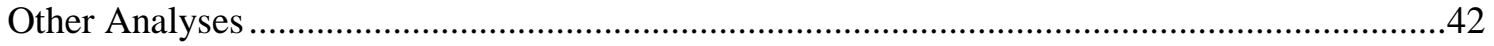

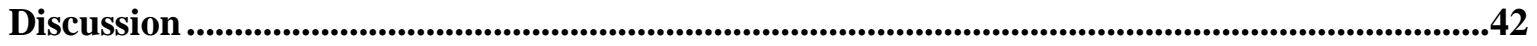

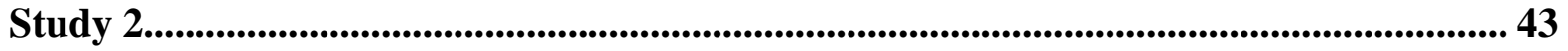

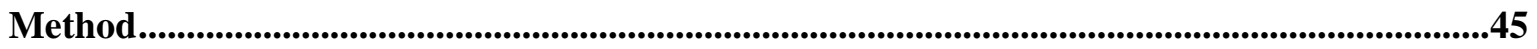

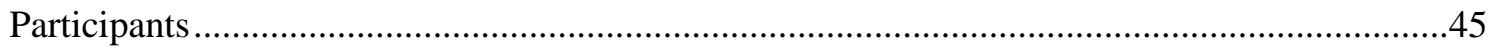

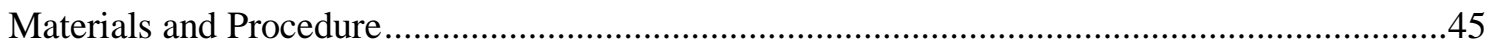




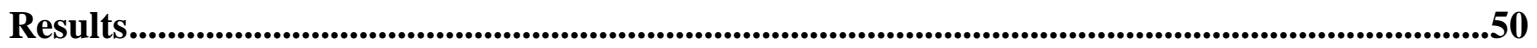

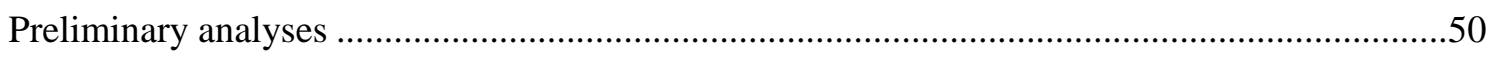

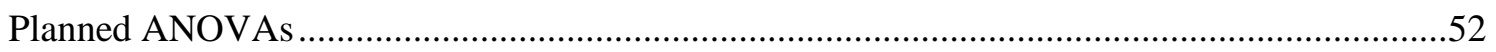

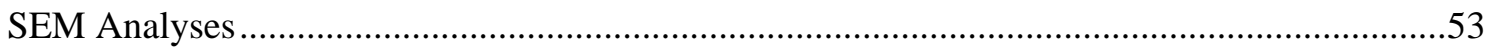

Discussion ........................................................................................................................................................................60

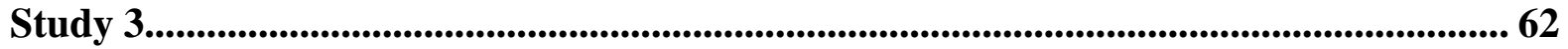

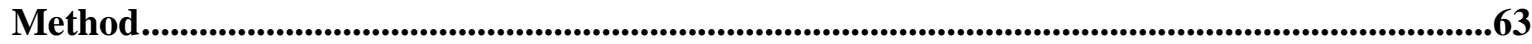

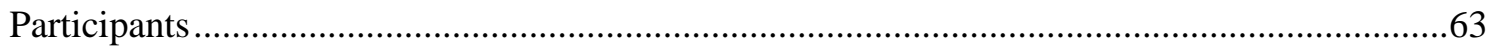

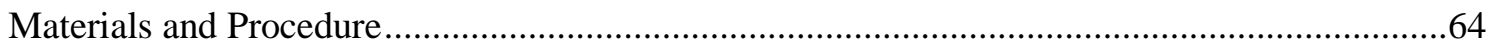

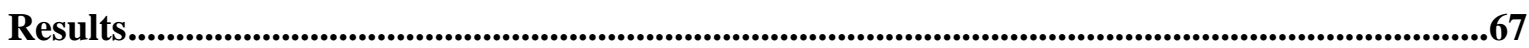

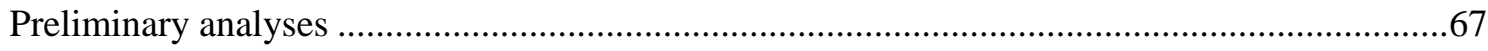

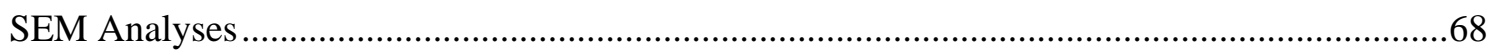

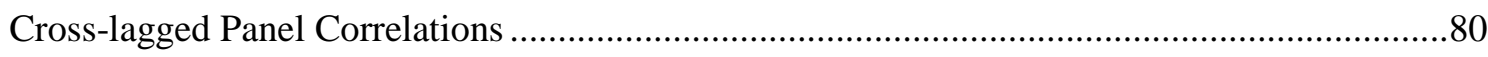

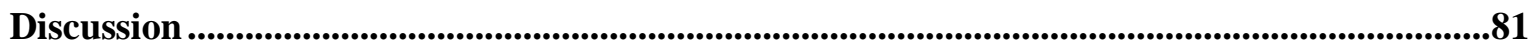

General Discussion................................................................................................................. 82

Summary of Findings ............................................................................................................................82

Contributions and Implications .........................................................................................................84

Limitations and Directions for Future Research ....................................................................................87

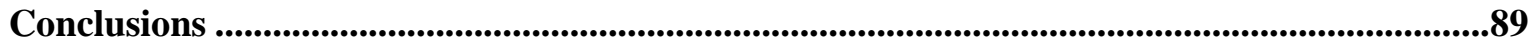

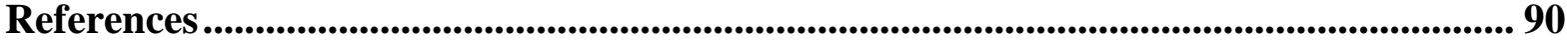

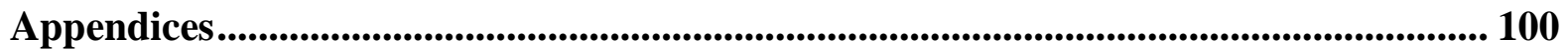

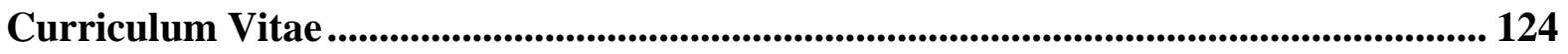




\section{List of Tables}

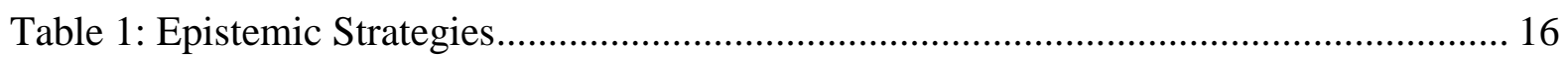

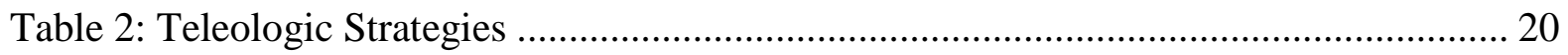

Table 3: Study 1 Internal Consistency Reliabilities, Zero-Order Variable Correlations, and

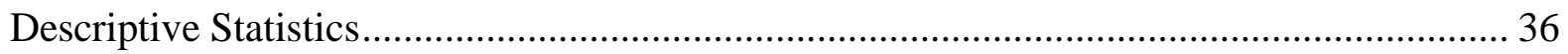

Table 4: Study 1 Partial Correlations Controlling for Transgression Severity, Relationship

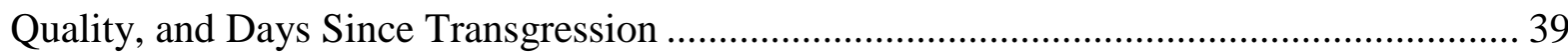

Table 5: Study 2 Internal Consistency Reliabilities, Zero-Order Variable Correlations, and

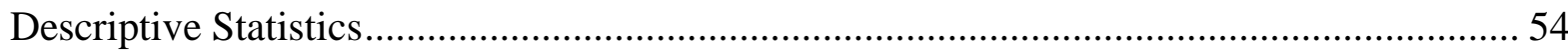

Table 6: Study 2 Partial Correlations Controlling for Transgression Severity and Relationship

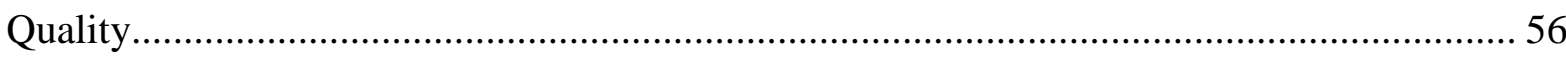

Table 7: Study 3 Internal Consistency Reliabilities, Zero-Order Correlations, and Descriptive

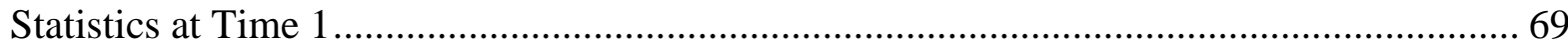

Table 8: Study 3 Variable Descriptive Statistics at Time 1, 2, 3, and 4 ........................... 70

Table 9: Study 3 Partial Correlations Controlling for Transgression Severity, Relationship

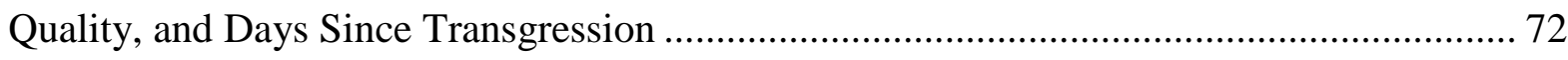

Table 10: Study 3 Bootstrapping Results for Tests of Indirect Effects of Need to Resolve on Forgiveness via Discussion and Strategies for Forgiveness at Time 1 ............................ 78

Table 11: Study 3 Bootstrapping Results for Tests of Indirect Effects of Need to Resolve on Forgiveness via Discussion and Strategies for Changes in Later Forgiveness ..................... 79 


\section{List of Figures}

Figure 1. An indirect effects deliberate self-persuasion model of forgiveness.................... 25

Figure 2. A full effects deliberate self-persuasion model of forgiveness. ......................... 26

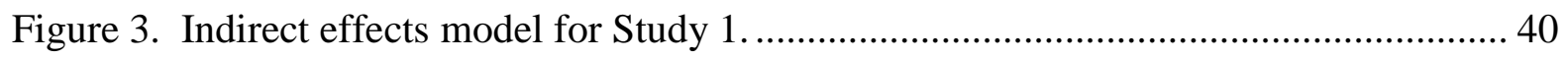

Figure 4. Full effects model for Study 1 .................................................................. 41

Figure 5. Indirect effects model for Study 2 .......................................................... 58

Figure 6. Full effects model for Study 2 ............................................................. 59

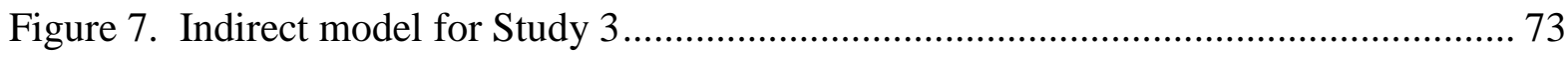

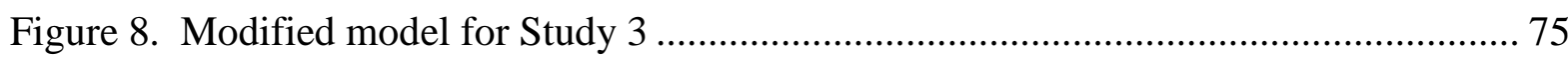

Figure 9. Simple latent growth curve model.......................................................... 117

Figure 10. Hypothesized latent growth curve model with feelings of discrepancy, need to resolve, discussion, and strategies at Time 1 as predictors........................................... 119 


\section{List of Appendices}

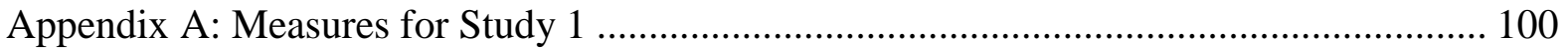

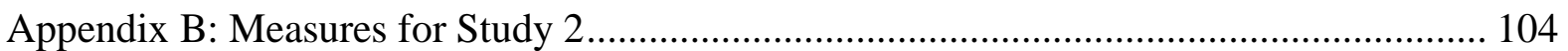

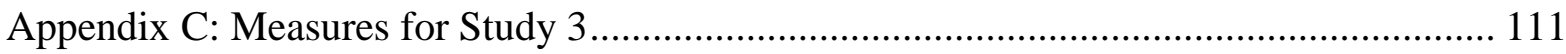

Appendix D: Latent Growth Curve (LGM) Modeling for Study 3 ................................. 116

Appendix E : Ethics Approval Forms for Studies 1, 2, and 3........................................ 121 


\section{Deliberate Self-Persuasion and Forgiveness}

Even in the closest of relationships, family members, friends, and partners can hurt each other in ways that have significant consequences for the relationship. For example, parents can be overly critical of their children; friends can reveal each others' secrets to others without discretion; and partners can ridicule each other in the presence of others. These situations can be extremely stressful because individuals want to feel positively about those who are close to them. After being hurt by a close other, individuals' positive feelings may be tempered, leading to a mix of both positive and negative feelings, which can make forgiving responses difficult. One way for victims to get past the harm may be to convince themselves that the actions of the transgressor were not as bad as they had initially thought, so they can forgive the transgressor and continue with the relationship. Forgiveness can be defined as prosocial change toward a transgressor, such that negative feelings and motivations are reduced and replaced with neutral or positive feelings and motivations (e.g., Aquino, Grover, Goldman, \& Folger, 2003; McCullough, Worthington, \& Rachal, 1997; McCullough, Rachal, Sandage, Worthington, Brown, \& Hight, 1998; McCullough \& Root, 2006; Tangney, Wagner, Hill-Barlow, Marschall, \& Gramzow, 1996).

Researchers have theorized that when individuals feel ambivalent about an attitude object, but have a specific attitudinal preference, they can intentionally induce attitude change toward the object in a way that is consistent with the preferred attitude (Maio \& Thomas, 2007). This covert mental process has been labeled deliberate selfpersuasion. The goal of the proposed research is to provide an empirical test of the deliberate self-persuasion process as one way that some individuals facilitate forgiveness. 
To my knowledge, this issue has not been examined in previous research. Thus, the proposed research empirically examines several components of deliberate self-persuasion and explores how they fit into the forgiveness process.

\section{Theory and Research on Forgiveness}

Forgiveness researchers have not always used equivalent definitions of forgiveness, but they tend to agree that it involves an increase in prosocial motivation toward someone who has caused harm. Forgiveness is distinct from pardoning (which seems more relevant to legal contexts), condoning (which suggests that the transgression is somehow warranted), and excusing (which suggests that the transgression occurred for a good reason; see McCullough, 2001). Forgiveness is also different from reconciliation, which involves the restoration of a relationship. Instead, forgiveness can be perceived as parallel to "canceling a debt." Different forgiveness researchers have differed in the extent to which they characterize forgiveness as an intrapersonal versus an interpersonal phenomenon (e.g., Finkel, Rusbult, Kumashirio, \& Hannon, 2002; Rusbult, Hannon, Stocker, \& Finkel, 2005).

As an intrapersonal phenomenon, researchers largely focus on victims' experiences in the forgiveness process, such as how they come to forgive their transgressors and the outcomes associated with forgiving responses. Some of this research has illuminated various personality traits, cognitions, emotions, and personal values that are associated with forgiveness. For example, some personality traits have been shown to correlate positively with forgiveness, such as agreeableness (e.g., Ashton, Paunonen, Helmes, \& Jackson, 1998; McCullough \& Hoyt, 2002) and emotional stability (e.g., Ashton et al., 1998; Berry, Worthington, Parrott, O’Connor, \& Wade, 2001). When 
individuals forgive, they tend to make generous attributions about and evaluations of the transgressor and the transgression (e.g., Bradfield \& Aquino, 1999; Fincham, 2000; Shapiro, 1991). Other research has shown that forgiving responses have positive outcomes for victims, including reduction of negative emotions, better physical health (Witvliet, Ludwig, \& Vander Laan, 2001), and improved mental health (Burnette, Davis, Green, Worthington, \& Bradfield, 2009; Coyle \& Enright, 1997; Freedman \& Enright, 1996). Studying forgiveness using a victim-based approach has been informative, but may be better suited to situations wherein the victim and perpetrator are strangers or have no interest in continuing a relationship, because the onus is then on the victim to move on from the transgression (Finkel et al., 2002; Rusbult et al., 2005).

In contrast, forgiveness as an interpersonal phenomenon focuses on the interaction between the victim and the perpetrator, so that both parties contribute to the forgiveness process (Finkel et al., 2002; Hannon, Rusbult, Finkel, \& Kumashiro, 2010; Rusbult et al., 2005). The interdependent nature of the forgiveness process is based on the key principles of interdependence theory (Kelley, Holmes, Kerr, Reis, Rusbult, \& Van Lange, 2003; Kelley \& Thibaut, 1978; Thibaut \& Kelley, 1959). For social relationships, the interaction that occurs between two people is a function of each person's attitudes, goals, and motives in a specific situation of interdependence. In the context of forgiveness, adopting an interdependence framework highlights the importance of considering both the victim and the perpetrator in the forgiveness process, especially in ongoing relationships, where individuals have a history together and are likely to continue their relationship in the future. This quality makes it extremely important to acknowledge and resolve transgressions, as failing to do so can have serious 
consequences for the relationship. It is unlikely that the forgiveness process will be reliant on the victim alone; the perpetrator can act in ways that either facilitate or impede the process (Finkel et al., 2002; Hannon et al., 2010; Rusbult et al., 2005). It is important to note that although forgiveness is typically perceived as being beneficial for relationships, recent research has shown that forgiveness can be detrimental in some relationships, such as those in which one party frequently engages in negative behaviour (e.g., McNulty, 2010, 2011). The goal of the present research is not to examine the costs/benefits of forgiveness but to understand the components of deliberate selfpersuasion within a forgiveness context.

Drawing from interdependence theory, a transgression can be perceived by the victim, and perhaps by the perpetrator, as an event that intentionally violates the norms of their relationship and consequently hurts the victim (Finkel et al., 2002; Hannon et al., 2010; Rusbult et al., 2005). Rusbult and Van Lange (2003) characterize these norms as a set of rules that partners implicitly or explicitly agree to follow that are assumed to govern their relationship. For example, when friends share personal information with each other, the expectation is that the information will not be disclosed to others. When individuals depart from these norms, they not only harm their friend in the process, but they also violate their moral obligations to their friend. Consequently, victims of these transgressions typically feel a sense of righteous indignation and often perceive the incident as having negative repercussions for the relationship (Leary, Springer, Negal, Ansell, \& Evans, 1998).

When individuals are the victim of a transgression, their immediate gut-level reactions may include negative responses to the perpetrator, such as holding a grudge or 
feeling the need for vengeance. Victims may experience a wide range of negative emotions, including anxiety, hurt, sadness, anger, and hostility (e.g., Leary et al., 1998; Ohbuchi, Kameda, \& Agarie, 1989). They may also experience negative patterns of cognitions, such as being confused about the transgression and what it means for the relationship, thinking obsessively about the events that are relevant to the transgression, being inclined to make blameful attributions, and reinterpreting pre-transgression behaviour (Baumeister, Stillwell, \& Wotman, 1990; Boon \& Sulsky, 1997; Stillwell \& Baumeister, 1997). Furthermore, victims may exhibit negative behavioural tendencies toward the perpetrator, such as avoiding the perpetrator, holding a grudge, seeking vengeance, and demanding atonement or retribution (e.g., Fagenson \& Cooper, 1987; Kremer \& Stephens, 1983; McCullough, Fincham, \& Tsang, 2003).

Similarly, perpetrators can also develop negative response patterns to the transgression. When perpetrators behave in ways that are hurtful to the victim, such as behaving selfishly or otherwise violating the norms of their relationship, they may feel shame, sadness, or guilt. In general, feelings of guilt promote perpetrators to behave in ways that encourage forgiveness, such as being more likely to confess, apologize, and offer amends (Baumeister, Stillwell, \& Heatherton, 1996; Tangney et al., 1996). Perpetrators may also construe transgressions differently from victims, and the inability to see eye-to-eye on the matter can lead to negative response tendencies. For example, perpetrators tend to construe their transgression as meaningful, comprehensible, and an isolated incident. In contrast, victims tend to perceive the transgression as arbitrary, incomprehensible, and having long-lasting implications for the relationship. These differences in perception can lead perpetrators to perceive victims' angry responses as 
unwarranted overreactions to the incident (Baumeister et al., 1990). Perpetrators can also develop defensive cognitions to explain and validate their hurtful actions in response to victims' negative attributions about them (e.g., Gonzales, Manning, \& Haugen, 1992; Stillwell \& Baumeister, 1997). Thus, both victims and perpetrators can construe the transgression in a self-serving manner (Baumeister et al., 1990; Kearns \& Fincham, 2005; Zechmeister \& Romero, 2002).

The empirical literature also shows that victim responses tend to be moderated by the characteristics of the transgressions. For instance, victims experience more distress, such as greater anxiety, hostility, avoidance, and need for vengeance, when the transgressions are more severe, perceived as devaluing the relationship, and viewed as controllable and intentional (McCullough et al., 2003; Smolen \& Spiegel, 1987). Properties of the victim-perpetrator relationship can also moderate victim responses. For example, researchers have shown that when the victim and the perpetrator are in a close and committed relationship, the victim tends to have more benign cognitions, affect, and behavioural responses toward the perpetrator (e.g., Finkel et al., 2002). In addition, when victims and perpetrators are in a highly committed relationship, they experience greater psychological well-being following forgiving responses (Karremans, Van Lange, Ouwerkerk, \& Kluwer, 2002). The interactions between the victim and the perpetrator can also have consequences for victim responses. For instance, past research has shown that couples who try to resolve conflict in an open and direct manner tend to develop a more accurate understanding of their partner's thoughts and feelings compared to those who avoid conflict (Knudson, Sommers, \& Golding, 1980). In addition, past research has shown that discussing an issue openly can clarify misunderstandings about why an event 
occurred (e.g., Gottman, 1994; Hilton 1990). Thus, the interactions between the victim and the perpetrator can lead to changes in responses toward the perpetrator, which can subsequently influence forgiveness.

Given that both victims and perpetrators can have intense negative responses to transgressions, how does forgiveness occur? Interdependence theory describes individuals' immediate gut-level reactions as given preferences, which centre on selforiented outcomes. These given preferences do not always drive behaviour, however. A transformation of motivation can allow victims to diverge from self-oriented outcomes to consider broader goals, such as the welfare of the perpetrator and the relationship. Behaviour is then guided by these psychologically transformed preferences, labeled as effective preferences (Kelley \& Thibaut, 1978). The transformation process can sometimes be automatic and guided by habitual patterns of interactions. For example, married couples may automatically reason that their partner's harsh criticism of them is only meant to help them become better people, allowing the couple's interactions to return to normal. Thus, the transformation process does not have to involve extensive mental activity. Sometimes, however, the transformation process is mediated by internal cognitive and affective processes. Cognitive processes can include considering what the situation entails, the needs and motives of oneself and the perpetrator, and what interactions with the perpetrator will be like in the future. For example, during the transformation process, the victim may think about any potential extenuating circumstances leading to the transgression or things that he or she may have done to elicit the transgression. The victim may subsequently construe the transgression more benevolently and reduce the blame attributed to the perpetrator. Researchers have shown 
that victims are more inclined to forgive if they develop more benign attributions about what may have caused the transgressor to commit the harm, but less inclined to forgive if they ruminate more about the transgression and can remember a greater number of past transgressions (Brown, 2003; Fincham et al., 2002; McCullough et al., 2001, 2003). Affective processes associated with the transformation process can include positive changes in affect, such as reductions in rage and anger and increases in empathy and caring for the perpetrator (Rusbult et al., 2005). According to interdependence theory, the transformation of motivation can occur relatively automatically. However, in a forgiveness context, the transformation process may not happen immediately after an interpersonal transgression, but rather after some time has elapsed. The amount of time required for the transformation process to occur is dependent on both the victim and the perpetrator, because both parties can interact in ways that either promote or impede the process (e.g., Rusbult et al., 2005). Thus, we use interdependence theory to understand the motivations that individuals may experience after an interpersonal harm (i.e., shift from self- to relationship-focused goals), which may influence forgiving responses, but we diverge from the theory in that the amount of time needed for the transformation of motivation after a transgression may take some time (rather than occur immediately), and the amount of time can depend on various factors, such as the relationship between the victim and perpetrator and the severity of the transgression.

\section{Self-Persuasion}

Persuasion can be defined as the process of inducing someone to hold a particular belief or perform a particular behaviour through reasoning or argument (Concise Oxford English Dictionary, 2008). Social psychological research on persuasion has typically 
focused on inducing attitude change by using direct communication and has primarily examined three classes of factors: the nature of the message, the characteristics of the individuals delivering the message, and the characteristics of the individuals receiving the message (e.g., Cialdini, 1984; Petty \& Wegener, 1999; Pratkanis \& Aronson, 1992). Persuasion can also take the form of self-persuasion, however, whereby individuals persuade themselves to adopt a particular belief or to act in a specific manner (Aronson, 1999).

The theory that best informs the phenomenon of self-persuasion is Festinger's cognitive dissonance theory (Aronson, 1999; Festinger, 1957). In brief, cognitive dissonance theory is premised on the idea that when an individual behaves in a way that is inconsistent with his or her own beliefs, a state of dissonance (unpleasant affect) is aroused. Individuals will try to reduce the dissonance by making their incompatible cognitions more in line with each other, which can be accomplished by changing or rationalizing their beliefs, attitudes, and/or behaviours. For example, in a classic study demonstrating cognitive dissonance (Aronson \& Mills, 1959), individuals volunteered to be part of a discussion group and endured either a mild or severe initiation. As it turned out, the discussion group was not interesting. It was predicted and found that individuals who experienced a severe initiation were more successful in persuading themselves that the discussion group was relatively interesting than those who experienced a mild initiation. Presumably, individuals who went through a severe initiation only to become part of a boring discussion group experienced stronger dissonance, as this contradicted the belief that they were sensible people. To reduce the dissonance, individuals focused 
on the positive aspects of the discussion group, which coincided with their belief that they were sensible (Aronson \& Mills, 1959).

An extensive amount of social psychological research has focused on dissonanceinduced self-persuasion (for a review, see Olson \& Stone, 2005). One conclusion that has been drawn is that individuals may not be consciously aware of why they experienced dissonance or realize that they changed or justified their choices to relieve the dissonance.

There are also instances, however, in which individuals may consciously recognize that their evaluation of an object is discrepant with how they would like to evaluate the object (Maio \& Thomas, 2007). ${ }^{1}$ For example, individuals may feel ambivalent towards a partner who betrayed their trust because they want to feel positively about their partner, but their partner also transgressed against them. These ambivalent attitudes can lead individuals to engage in a variety of mental strategies that will help them feel good about their partner again, but only if they have both the ability and the motivation to do so. The strategies that might be utilized involve balancing the need to come to the "correct" attitude (e.g., how individuals "should" feel toward their partner) and the need to come to the desired attitude (e.g., how individuals want to feel about their partner). This process, which has received relatively little attention, is known as deliberate self-persuasion.

\footnotetext{
1 Throughout this paper, discrepancies between actual and desired attitudes will also be referred to as ambivalent attitudes, because evaluations of the attitude object contain both desirable and undesirable attitude elements.
} 


\section{Deliberate Self-Persuasion}

Deliberate self-persuasion can be defined as a process that involves "self-directed, intentional attitude change" (Maio \& Thomas, 2007, p. 2). Individuals can engage in deliberate self-persuasion to resolve their ambivalent attitudes towards an attitude object in a way that is consistent with how they want to evaluate the object. This process seems compatible with an interpersonal model of forgiveness, because in ongoing relationships, the interaction between the victim and the perpetrator after a transgression can facilitate or impede the ease with which the victim can reach a desired attitude toward the transgressor. As implied in the definition of deliberate self-persuasion, there are prerequisites in order for the process to occur: (1) individuals must be consciously aware that there is a discrepancy between their current and desired attitudes toward an attitude object; (2) individuals must be motivated to resolve the discrepancy; and (3) individuals must have the ability to resolve the discrepancy (for a review, see Maio \& Thomas, 2007).

The first prerequisite of deliberate self-persuasion is that individuals must be consciously aware that there is an inconsistency between how they currently evaluate aspects of an attitude object and how they want to evaluate it. For example, in one study, Murray and Holmes (1993) asked participants to list the similarities and differences between themselves and their dating partners that were important for making their relationships successful. Participants were then led to believe that they had little awareness of some significant differences between themselves and their partners. Then, ostensibly in an unrelated study, participants in the experimental condition read an article describing the importance of partners' willingness to recognize and acknowledge their 
differences as being associated with a more mature form of intimacy, which was intended to challenge participants' a priori theories that similarities are diagnostic of intimacy. Therefore, this article served to threaten experimental participants' positive convictions about their relationship by associating inattention to significant differences with a less mature form of intimacy. In contrast, participants in the control group read a filler article about a topic unrelated to romantic relationships. Results showed that when participants were given an opportunity to provide additional details about the similarities and differences that they had listed earlier, participants in the experimental group were more likely to reinterpret the similarities between themselves and their partner as founded on some underlying difference than those in the control condition. For instance, individuals who perceived themselves and their partner as equal on intellectual ability might have added that they are different with respect to how much time they spend on school work. In addition, experimental participants were more likely to exaggerate the importance of any existing differences and more likely to bolster the significance of similarities in promoting intimacy than control participants. Experimental participants' effort to revise their construal of reported similarities and differences indicates that they were aware of the discrepancy between what is desired for an intimate dating relationship (i.e., a more mature form of intimacy by acknowleding differences) and the nature of their current dating relationship (i.e., a less mature form of intimacy by not acknowleding differences).

Two final points about the role of awareness are important (Maio \& Thomas, 2007). First, holding the desired attitude must be a personal goal above and beyond others' expectations. If the desired attitude is not a personal goal, then the outward expression of the attitude toward the object may simply be altered to please others. 
Second, although deliberate self-persuasion requires conscious awareness of the discrepant evaluations of the object, as well as the intention to change the evaluation of the object, individuals may not be aware of the processes that they use to move toward the desired evaluation.

Two other prerequisites for deliberate self-persuasion are that individuals must have the motivation and ability to reduce the discrepancy between their current and desired attitudes toward objects, people, or issues (Maio \& Thomas, 2007). There may be occasions when the current attitude is so salient and compelling that the desired attitude moves toward the currently held attitude. For example, in one study, satisfied couples in the beginning of their romantic relationships changed their ideal partner standards so that the attributes of their current partner matched those standards (Fletcher, Simpson, \& Thomas, 2000a). It is also possible for individuals to accept the discrepancy if there is nothing that can be done, or if they are not highly motivated to change it (Maio \& Thomas, 2007). Whether deliberate self-persuasion is successful or not is dependent on both subjective and objective ability (i.e., perceived and actual ability). For example, even when individuals are high in objective ability to self-persuade, they may not do so if they perceive low ability (e.g., low self-efficacy). Similarly, even when individuals are high in subjective ability, factors such as unintended distraction, time constraints, or arousal can inhibit their objective ability. For example, research on forgiveness has shown that when individuals are motivated to forgive their relationship partner, but do not have sufficient time to think about the positive aspects of their partner, they are less likely to forgive (Kachadourian, Fincham, \& Davila, 2005). 


\section{Strategies of Deliberate Self-Persuasion}

As conceptualized by Maio and Thomas (2007), deliberate self-persuasion is always driven by the motive to seek the desired conclusion. Sometimes, there may be a co-occuring motive to seek the correct conclusion, but this accuracy motive does not drive deliberate self-persuasion. When the only goal is accuracy (i.e., the individual does not have a preferred conclusion), deliberate self-persuasion is irrelevant because accuracy means drawing conclusions based on whatever the relevant information might say. As such, the attitude can change or stay the same depending on what leads to a more valid conclusion. Therefore, what is unique to the process of deliberate self-persuasion is the conscious, deliberate pursuit of a specific attitude - that is, an attitude that is consistent with what is desired.

Individuals can employ multiple strategies to engage in deliberate self-persuasion, which can be categorized as either epistemic or teleologic (Maio \& Thomas, 2007). In general, epistemic tactics strive for both a desired as well as an accurate attitude. This can be accomplished by reinterpreting the meaning of undesired attitude elements to undermine their perceived validity and by bolstering the perceived validity of desired attitude elements. The extent to which individuals can exert biased reasoning processes is constrained by reality, such that desired and current attitudes cannot be too disparate. In contrast, teleologic tactics are not constrained by validity concerns and use mental control processes to attain a desired attitude by reducing the accessibility of undesired attitude elements and increasing the accessibility of desired attitude elements. Maio and Thomas suggest that people often start with deliberate self-persuasion via epistemic strategies because they can try to balance the goals of reaching a desired and an accurate 
attitude, which should be more preferable than either goal alone. When epistemic strategies do not yield the desired attitude, however, people then turn to teleologic strategies.

\section{Epistemic Strategies}

There are six epistemic tactics: motivated interpretation, motivated integration, motivated attribution, motivated hypothesis testing, changing comparators, and changing dimensions (Maio \& Thomas, 2007). For a summary of the epistemic strategies, see Table 1. 
Table 1

Epistemic Strategies

Strategy

Description

Motivated interpretation

Interpret undesired attributes as more desired attributes

Motivated integration

Integrate undesirable attributes with desirable attributes

Motivated attribution

Attribute undesired attributes to more benign causal factors

Motivated hypothesis testing

Test the validity of undesired attributes

Changing comparators

Change the standard of comparison for evaluating the attitude object

Changing dimensions

Change the dimensions of the comparison

Note. This table was adapted from Maio and Thomas (2007, p. 6). 
First, individuals may be motivated to reinterpret their current attitudes, such that undesired attributes may be perceived as more desired attributes. For example, as discussed earlier, dating couples can reinterpret aspects of their relationship in order to bolster the perception that their dating relationship reflects a more mature form of intimacy (Murray \& Holmes, 1993). Second, individuals may be motivated to integrate undesirable attributes with desirable attributes, which is analogous to a "yes, but..." approach. Seeing the undesirable attributes in a broader context, as opposed to grouping attributes as either positive or negative, can often downplay the undesired attribute. For example, the characteristic "jealousy" may seem more favourable when it is combined with attributes like "committed" and "caring"; pairing jealousy with commitment (a positive attribute) versus selfishness (a negative attribute) yields different connotative meanings. Individuals who pair in memory undesirable attributes with desirable ones tend to hold more positive views about their partner and have more stable relationships compared to those who cluster their partner's attributes in memory by valence (positive with positive; negative with negative; see Murray \& Holmes, 1999). Third, individuals may be motivated to attribute undesirable elements to benign factors. For example, in relationships, individuals often perceive inexpressiveness as a significant fault in their partners' personality. These individuals, however, can downplay the significance of the fault by attributing it to a benign factor. As an illustration, one participant reported that his partner's inexpressiveness reflected her ability to think about things in a different way (for a review, see Murray, 1999). Fourth, people may be motivated to test specific hypotheses that confirm their desired attitude. For example, if individuals want to see themselves as an introvert, they may try to confirm this self-label. Sanitioso, Kunda, and 
Fong (1990) found that when participants were motivated to see themselves as introverted, they tended to recall more introverted than extroverted behaviours, whereas when participants were motivated to see themselves as extroverted, they recalled more extroverted than introverted behaviours. These patterns presumably reflected a tendency to seek evidence consistent with the valued attribute. Fifth, individuals may change the standard of comparison to view the undesired attributes more favorably. The standard can shift to another individual, group, or the self at another point in time (e.g., Albert, 1977). For example, students may use downward social comparisons to feel better about themselves following poor performance, or use upward social comparisons to motivate self-improvement (e.g., Collins, 1996). Sixth, individuals can reweigh particular dimensions, such as increasing or decreasing the perceived self-relevance or importance of specific attributes. For example, couples can maintain a positive view of their relationship by emphasizing the positive qualities and devaluing the negative qualities of their relationship (Neff \& Karney, 2003). In sum, these epistemic tactics work to weaken the undesired elements and strengthen the desired elements of the attitude object, while being concerned about obvious invalidity.

\section{Teleologic Strategies}

There are four teleologic strategies, which utilize one of two regulatory methods, operating versus monitoring systems (similar to extant models of regulatory focus; e.g., Carver \& Scheier, 1998; Higgins \& Spiegel, 2004). The operating system activates specific thoughts, feelings, and behaviours, whereas the monitoring system senses the intrusion of other thoughts, feelings, and behaviours. Teleologic processes also involve one of two regulatory goals, either excluding undesired elements out of awareness or 
bringing desired elements into awareness. For a summary of the teleologic strategies, see Table 2.

One teleologic tactic is attitudinal suppression, which involves monitoring undesired thoughts, feelings, and behaviours, and keeping them out of awareness. For example, victims of an interpersonal transgression may try not to think about the transgression when it comes to mind. Research has shown that suppressing unwanted thoughts, feelings, and behaviours can lead to ironic effects, such that when people have low cognitive resources, the undesired elements may actually become more accessible (e.g., Wegner, Erber, \& Zanakos, 1993). However, other research has shown that attitudinal suppression can be effective (e.g., Simpson, Ickes, \& Blackstone, 1995).

A second teleologic strategy is attitudinal distraction, which uses the operating system to activate thoughts, feelings, and behaviours that are unrelated to the undesired attitude (Maio \& Thomas, 2007). For example, people may go on vacation to "take their mind off things." This strategy can be effective if the distraction lasts long enough for the undesired attitude elements to fade, which makes the desired attitude elements relatively more accessible.

A third tactic is attitudinal concentration, which uses the operating system to pursue thoughts, feelings, and behaviours that are relevant to the desired attitude, with low vigilance to thoughts, feelings, and behaviours that are irrelevant to the desired attitude. For example, if victims want to focus on the positive qualities of their transgressor, they may selectively recall past experiences or process new information about the transgressor that is consistent with their desired attitude. 
Table 2

Teleologic Strategies

\begin{tabular}{lcc}
\hline & \multicolumn{2}{c}{ Regulatory Method } \\
\cline { 2 - 3 } Regulatory Goal & Operating System & Monitoring System \\
\hline $\begin{array}{l}\text { Keeping undesired elements out } \\
\text { of awareness }\end{array}$ & Attitudinal Distraction & $\begin{array}{c}\text { Attitudinal } \\
\text { Suppression }\end{array}$ \\
$\begin{array}{l}\text { Keeping desired elements in } \\
\text { awareness }\end{array}$ & Attitudinal Concentration & Attitudinal Preemption \\
\hline
\end{tabular}

Note. This table is adapted from Maio and Thomas (2007, p. 10). 
Finally, a fourth tactic is attitudinal preemption, which uses the monitoring system to avoid specific thoughts, feelings, and behaviours that could weaken or disconfirm the desired attitude. For example, individuals may not tell their friends about a harm that was committed by their partner because the discussion could elicit negative reactions to their partner. These negative reactions, in turn, might make it difficult to reinforce individuals' desired attitude about their partner.

Epistemic and teleologic strategies both strive to move from an ambivalent attitude to a more desired attitude, but do so in different ways (Maio \& Thomas, 2007). At the most basic level, the former seek to reinterpret undesired attitude elements more positively within reality constraints, whereas the latter inhibit the accessibility of undesired attitude elements and increase the salience of desired attitude elements.

\section{The Present Research}

Interdependence theory provides a framework for understanding when deliberate self-persuasion might occur in the forgiveness process. As described earlier, deliberate self-persuasion requires that individuals are aware of a discrepancy between their current and desired attitudes toward an attitude object, and that they are motivated and have the ability to change their current attitude (Maio \& Thomas, 2007). Within the context of forgiveness, being hurt by a close other can lead to ambivalent attitudes toward the transgressor, such that victims' attitudes toward the transgressor are less favourable than they would like them to be. Given that individuals want to see their close relationships in a positive light (e.g., Van Lange \& Rusbult, 1995), victims may be motivated to resolve any discrepancies they experience between their current and desired attitudes. 
The motivation or need to resolve the discrepancy between current and desired attitudes is unlikely to occur immediately following a transgression. As previously discussed, victims' initial responses to a transgression tend to reflect their gut-level reactions, such as experiencing negative emotions, patterns of cognitions, and behavioural tendencies, as well as seeking self-oriented outcomes (e.g., Leary et al., 1998; Ohbuchi et al., 1989). It is expected that victims would be less likely to engage in immediate deliberate self-persuasion because their reactions would most likely be focused on anger, sadness, or ruminating over the details of the transgression (e.g., Fagenson \& Cooper, 1987; Kremer \& Stephens, 1983; McCullough et al., 2003). Deliberate self-persuasion may be more likely to occur, however, during the transformation process, wherein victims become less concerned with self-oriented goals and more concerned with broader goals, such as the well-being of their relationship with the perpetrator. In contrast to interdependence theory, we do not expect the transformation process to occur immediately, but most likely after some time has elapsed. When individuals strive towards a positive outcome for the relationship, it can encourage the use of mental processes to make the desired thoughts, feelings, and behaviours more accessible and the undesired thoughts, feelings, and behaviours less accessible or reinterpreted in a more positive light. The interaction between the victim and the perpetrator can also promote or impede the extent to which the desired attitude elements are made salient. For instance, when perpetrators show more care and concern for victims as a way to repair the relationship, victims may perceive the perpetrator's gestures as support for their desired conclusion. In addition, the victim and perpetrator may discuss the transgression to clarify any misunderstandings or to understand each 
other's perspective about the transgression. Thus, open communication about the transgression can lead to more support for the victim's desired attitude toward the perpetrator.

The purpose of the present studies is to examine empirically some of the components of the deliberate self-persuasion process within the context of forgiveness. Study 1 asked participants in a romantic relationship to recall a past transgression that was committed by their romantic partner. An autobiographical narrative and questionnaire method was used to examine the extent to which feelings of discrepancy and the need to resolve the discrepancy, two requirements of deliberate self-persuasion, were associated with forgiveness. Study 2 involved asking participants to imagine a hypothetical scenario in which they were transgressed against by their romantic partner and how they would actually respond to the transgression. Study 3 utilized a longitudinal design to look at how the components of deliberate self-persuasion predict changes in forgiveness over time. In all three studies, discussion of the transgression with the perpetrator and use of deliberate self-persuasion strategies were examined as possible mediators of the relation between the motivation to resolve the discrepancy and forgiveness. Although our discussion has focused on forgiveness as an interpersonal process, the variables that we used to test our model and the operationalizations of those variables were more individualistic in nature.

\section{Model Testing}

In all of our studies, we tested a deliberate self-persuasion model of forgiveness using Structural Equation Modeling (SEM) procedures. Two different models were 
tested, the first being an indirect effects model (see Figure 1) and the second being a full effects model (see Figure 2).

We reasoned that individuals can experience feelings of discrepancy toward their partner after being harmed by them, and in turn, these feelings can lead to a need to resolve them. In the indirect effects model, the extent to which individuals discuss the transgression with their transgressor and the use of deliberate self-persuasion strategies were hypothesized to mediate the relation between need to resolve feelings of discrepancy and forgiveness. Based on our reasoning, need to resolve, but not feelings of discrepancy, would be related to discussion of the transgression and use of deliberate self-perusasion strategies because simply being aware of the discrepancy is unlikely to drive individuals to change their attitudes toward their perpetrator. We argue that individuals must feel the need to resolve the discrepancy in order for them to feel motivated to engage in various tactics, such as discussion of the transgression with the perpetrator and/or use of deliberate self-persuasion strategies, to reduce the inconsistency between their current and desired attitudes toward the transgressor. Thus, the paths from feelings of discrepancy to discussion, strategies, and forgiveness and the path from need to resolve to forgiveness were set to zero and were not included in the model (see Figure $1)$.

In the full effects model, feelings of discrepancy and need to resolve directly related to discussion, strategies, and forgiveness. This model is considered a full effects model because both feelings of discrepancy and need to resolve were allowed to be directly related to forgiveness and indirectly related to forgiveness via discussion and strategies (see Figure 2). 


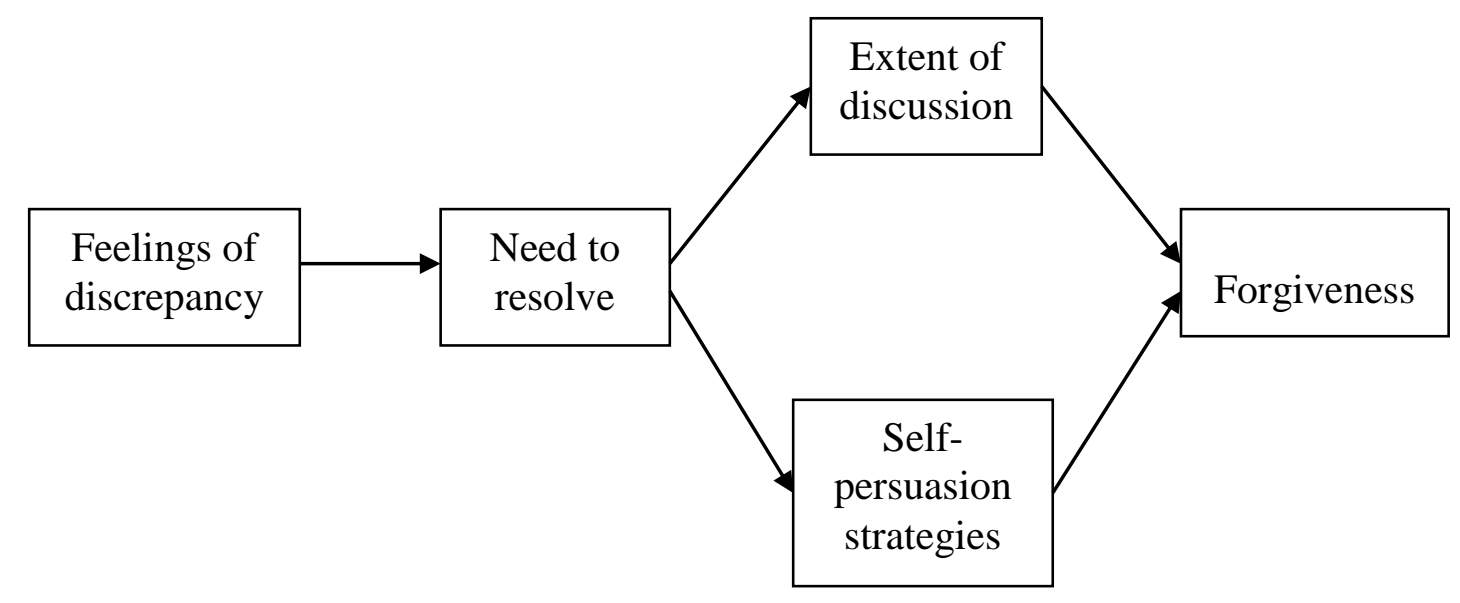

Figure 1. An indirect effects deliberate self-persuasion model of forgiveness. 


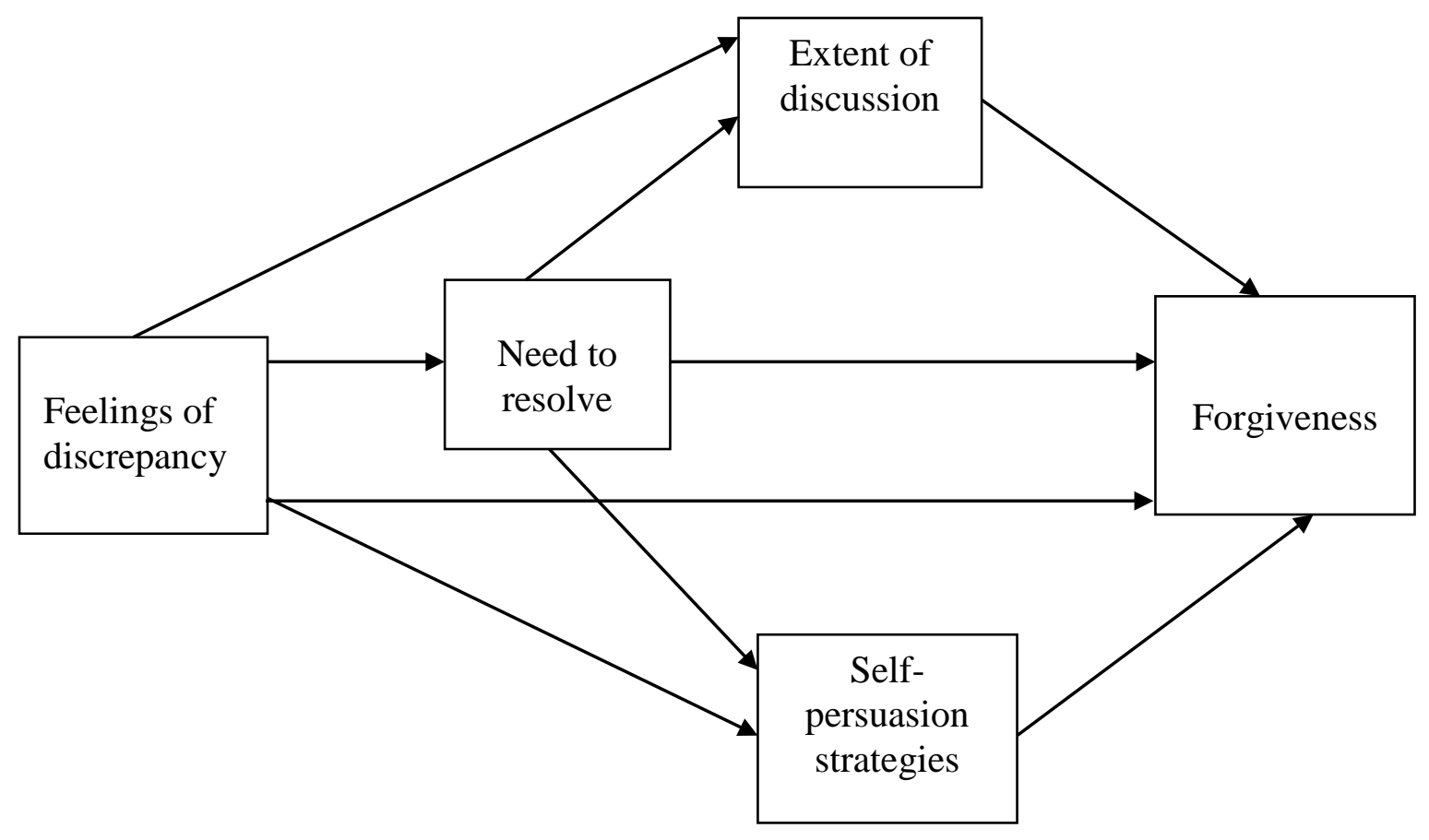

Figure 2. A full effects deliberate self-persuasion model of forgiveness. 
Consistent with our hypothesized relations of the variables, we predicted that the indirect effects model would be the most parsimonious model and that the fit of the indirect effects model would not be significantly worse than the fit of the full effects model. It should be noted that in SEM, simpler models typically fit the data less well than more complex models because there are more constraints in the model, and thus fewer components to maximize fit. To determine whether the indirect or full effects model is a better fit, we conducted chi-square difference tests and examined the parameter estimates (i.e., significance levels of path coefficients). All models were tested using Amos 18.0.

\section{Study 1}

Study 1 provided an initial test of the components involved in deliberate selfpersuasion by asking individuals in romantic relationships to recall a time when their partner committed a transgression against them. We recruited individuals who were involved in a romantic relationship because it was expected that they would generally want to see their partners in a positive light, and after being hurt by their partner, they would have more incentive to use deliberate self-persuasion.

Study 1 also included a manipulation of transgression severity to examine whether deliberate self-persuasion would be more likely to occur in severe versus mild transgressions. We expected transgressions that were severe in nature to be more consequential in a relationship and, therefore, to make the negative attitude elements toward the transgressor more salient and more significant in the relationship. Thus, the discrepancy between current and desired attitudes toward the transgressor should be greater, compared to mild transgressions, and victims may be more likely to use 
deliberate self-persuasion to reduce the discrepancy. In contrast, mild transgressions should be less consequential to a relationship, leading to a smaller discrepancy between current and desired attitudes toward the transgressor, and therefore require less need to engage in deliberate self-persuasion to resolve the discrepancy.

Two hypothesized prerequisites of deliberate self-persuasion were measured: the extent to which participants experienced discrepancy between their current and desired attitudes toward their partner and their need to resolve the discrepancy. The extent to which participants discussed the transgression in detail with their partner, as well as the extent to which they used deliberate self-persuasion strategies, were assessed. Participants' forgiveness of their partner was also measured. It was hypothesized that the opportunity to discuss the transgression with their partner would be associated with more forgiveness. We also expected that greater use of deliberate self-persuasion strategies would be associated with more forgiveness because these strategies would help participants come to a more desired attitude about their partner.

Based on the assumption that people generally want to hold positive thoughts and feelings about their partners, it was predicted that more ambivalent attitudes would be associated with more need to resolve the ambivalence. This, in turn, should lead to behaviours that encourage a resolution, such as talking about what happened and using deliberate self-persuasion strategies. Finally, talking about the transgression and using deliberate self-persuasion strategies were expected to encourage greater forgiveness. 


\section{Method}

\section{Participants}

Participants were 50 undergraduate students (14 men and 36 women) enrolled in an introductory psychology course at the University of Western Ontario, who received course credit in exchange for their participation. Participants had indicated in earlier mass testing that they were currently involved in a romantic relationship of at least three months duration. On average, participants were involved with their partner for 17.27 months ( $S D=14.73$; range from 3 to 71 months), and almost all participants were in an exclusive relationship with their partner (47 were dating exclusively, 1 was engaged, 1 was married, and 1 was not dating exclusively). In addition, most participants (48 out of 50) were not co-habiting with their partner. Participants were 17 to 26 years of age $(M=$ $18.86, S D=1.97)$.

\section{Materials and Procedure}

Participants were told that the study was about recalling interactions with their romantic partners. They arrived at the lab in groups ranging from 1 to 5 persons and were randomly assigned to one of two experimental conditions (recall a severe vs. mild transgression in which their partner was the transgressor). Participants answered all of the questions on computers in separate cubicles.

In the first part of the study, participants were asked to provide some general information about themselves and their current romantic relationship. They provided demographic information, such as their age and gender, and indicated how long they had been dating their partner, their relationship status, and whether they resided with their partner. Participants then answered the Perceived Relationship Quality Component 
(PRQC) Inventory (Fletcher, Simpson, \& Thomas, 2000b), which assessed six components of perceived relationship quality: relationship satisfaction (e.g., "How satisfied are you with your relationship?"), commitment (e.g., "How committed are you to your relationship?"), intimacy (e.g., "How intimate is your relationship?"), trust (e.g., "How much do you trust your partner?"), passion (e.g., "How passionate is your relationship?"), and love (e.g., "How much do you love your partner?”). Each component was assessed by three items and were all measured on a 7-point rating scale ranging from 1 (not at all) to 7 (extremely). The 18 items were averaged to form a composite measure of relationship quality $(\alpha=.85)$.

Transgression severity manipulation. Next, participants were asked to think about instances over the past three months in which their partner had transgressed against them and were randomly assigned to describe either the most severe or the most mild transgression in more detail. Specifically, participants were given the following instructions (adapted from Kammrath \& Dweck, 2006):

Even in the best of relationships, people do things at times that make one another upset or angry. Please think back over the last 3 months and recall times when your romantic partner did something that upset you. Of the incidents that come to mind, select the one that made you the most [least] upset. In the space below, please describe the incident fully so that we can understand what it was like for you.

Participants then answered three open-ended questions that were intended to encourage them to think about the transgression in more detail: "How did you feel?"; "What did you do?"; and "What did you think and feel about your partner at the time?". Next, participants indicated the month and date that the incident occurred. 
Manipulation check. As a manipulation check, participants answered four questions that assessed the severity of the transgression they described. They were asked how severe, serious, painful, and harmful the transgression was on 7-point rating scales ranging from 1 (not at all) to 7 (extremely). These items were averaged to form a composite score for transgression severity $(\alpha=.89)$. See Appendix A for all of the dependent measures.

Forgiveness measures. Participants were then asked to answer two measures to assess whether they had forgiven their partner for the harm. The first was a single-item measure of forgiveness, "To what extent have you forgiven your partner?". The question was answered on a 7-point rating scale ranging from 1 (I have not forgiven at all) to 7 (I have completely forgiven). The second measure was the 18-item Transgression-Related Interpersonal Motivations (TRIM) Inventory (McCullough, Root, \& Cohen, 2006). The TRIM assesses victims' avoidance, revenge, and benevolence motivations toward their transgressor. The assumption is that forgiveness is associated with a reduction in negative motivations and an increase in positive motivation. All items were answered on a 5-point rating scale from 1 (strongly disagree) to 5 (strongly agree). The avoidance subscale consisted of 7 items (e.g., "I keep as much distance between us as possible"; "I live as if my partner doesn't exist, isn't around"), the revenge subscale consisted of 5 items (e.g., "I'll make my partner pay"; "I wish that something bad would happen to my partner"), and the benevolence subscale consisted of 6 items (e.g., "Even though my partner's actions hurt me, I still have good will for him/her"; "Despite what my partner did, I want us to have a positive relationship again"). The 19 forgiveness items (the single-item and the 18 items from the TRIM, with the items from the avoidance and 
revenge subscales reverse-scored) were each standardized and then averaged to form a composite measure of forgiveness $(\alpha=.92)$.

Feelings of discrepancy and need to resolve measures. Next, participants answered nine items that were designed to measure their immediate post-transgression feelings of discrepancy toward their partner and need to resolve the discrepancy after the transgression occurred. Five items assessed participants' feelings of discrepancy toward their partner by asking them the extent to which they simultaneously experienced both positive and negative thoughts and feelings toward their partner (e.g., "It was stressful to have both positive and negative feelings about my partner"; "I wanted to stay away from my partner and spend time with my partner at the same time"; $\alpha=.88$ ). Four items assessed participants' need to resolve the discrepancy (e.g., "It was important for me to change things, for the better, between my partner and I"; "It was important to me that my partner and I talked about what happened so our relationship could get back to normal"; $\alpha$ $=.86$ ). All items were answered on a 7-point rating scale from 1 (strongly disagree) to 7 (strongly agree). ${ }^{2}$

Discussion of transgression. The next set of questions was designed to gauge the extent to which participants had discussed the transgression. First, participants were asked to indicate who initiated a conversation about the transgression, with the following

\footnotetext{
${ }^{2}$ Some of the items from the need to resolve subscale are similar to the items from the benevolence subscale of the TRIM Inventory. We examined the correlation between these two variables in all three studies, controlling for transgression severity, relationship quality, and time since the transgression, variables that are typically controlled in forgiveness research. There was a correlation between need to resolve and benevolence in Study $1, r(45)=.35, p=.02$, but these variables were not correlated in any of the other studies, so this relation will not be addressed further.
} 
response options: you, partner, someone else, and did not talk about the transgression. Then participants rated the detail (or depth) of their discussion of the transgression using a 7-point rating scale from 1 (not detailed at all) to 7 (extremely detailed) and indicated whether their partner had apologized for the harm with yes and no as response options.

Deliberate self-persuasion strategies. Next, we designed a series of questions to capture some of the deliberate self-persuasion strategies that participants might have used (see Maio \& Thomas, 2007). Specifically, six items assessed the extent to which participants tried to use some of the strategies (e.g., "I thought about my partner's good qualities"; "I tried to reinterpret the transgression in a more positive way"; $\alpha=.77$ ). Participants indicated their responses on a 7-point rating scale from 1 (not at all) to 7 (a great deal).

\section{Results}

\section{Preliminary Analyses}

Relationship quality. Analyses on the PRQC were first conducted to test whether there were differences in relationship quality between the two transgression severity conditions. Analyses indicated that participants in the mild $(M=6.21, S D=.58)$ and severe conditions $(M=5.85, S D=.79)$ did not differ significantly in relationship quality $t(48)=-1.80, p=.08$.

Time since transgression. Fifteen participants recalled transgressions that occurred more than three months previously (outside the suggested period). A $t$-test indicated, however, that the number of days since the transgression did not differ between 
the severe $(M=86.48, S D=74.58)$ and mild $(M=80.44, S D=74.58)$ conditions, $t(48)=$ $.28, p=.78$, so all 50 participants were included in the analyses.

Severity manipulation. As predicted, the severity manipulation check showed that participants in the mild condition rated their transgressions as less severe $(M=3.05$, $S D=1.36)$ than those in the severe condition $(M=3.92, S D=1.46), t(48)=2.18, p=$ .035. The transgression severity manipulation did not affect any of our main dependent measures, however, including: forgiveness, participants' feelings of discrepancy toward their partner, participants' need to resolve the feelings of discrepancy, and the extent to which participants discussed the transgression with their partner (all $p \mathrm{~s}>.30$ ). There was a marginal main effect of severity on the use of deliberate self-persuasion strategies, such that participants in the mild condition $(M=4.09, S D=1.27)$ reported using the strategies somewhat more than those in the severe condition $(M=3.42, S D=1.35), t(48)=-1.82, p$ $=.08$. There were no effects of condition on the other dependent measures, all $p \mathrm{~s}>.05$. Because the severity manipulation had so few effects, subsequent analyses collapsed across condition, but we controlled for subjective ratings of transgression severity.

\section{SEM Analyses}

To test our proposed model of deliberate self-persuasion within a forgiveness context, we used Structural Equation Modeling procedures. It was hypothesized that participants would experience a discrepancy between their current and desired attitudes about their partner. In turn, this should motivate participants to try to resolve the discrepancy. The discrepancy may be resolved by the extent to which participants discussed the transgression with their partner and the use of deliberate self-persuasion strategies, which can then lead to more forgiveness. A model that included both the 
extent of discussion and use of deliberate self-persuasion strategies as mediators was tested. Table 3 presents the internal consistency reliabilities as indexed by Cronbach's alpha, the zero-order correlations, and the descriptive statistics for the variables included in the model.

To evaluate model fit, three indices were used: the comparative fit index (CFI; Bentler, 1990), the nonnormed fit index (NNFI; Bentler \& Bonett, 1980), and the root mean square error of approximation (RMSEA; cf. Browne \& Cudeck, 1992). These fit indices are less sensitive to sample size in comparison to other indices (Fan, Thompson, \& Wang, 1999). For CFI and NNFI, values greater than .95 indicate that the model is a good fit. Values greater than 1.00 are possible, but should be interpreted as 1.00. For RMSEA, values less than .05 indicate a close fit; values between .05 and .08 indicate a reasonable fit; values between .08 and .10 indicate mediocre fit; and values greater than .10 indicate unacceptable fit (see Browne \& Cudeck, 1992). The chi-square omnibus test is also reported. 
Table 3

Study 1 Internal Consistency Reliabilities, Zero-Order Variable Correlations, and Descriptive Statistics

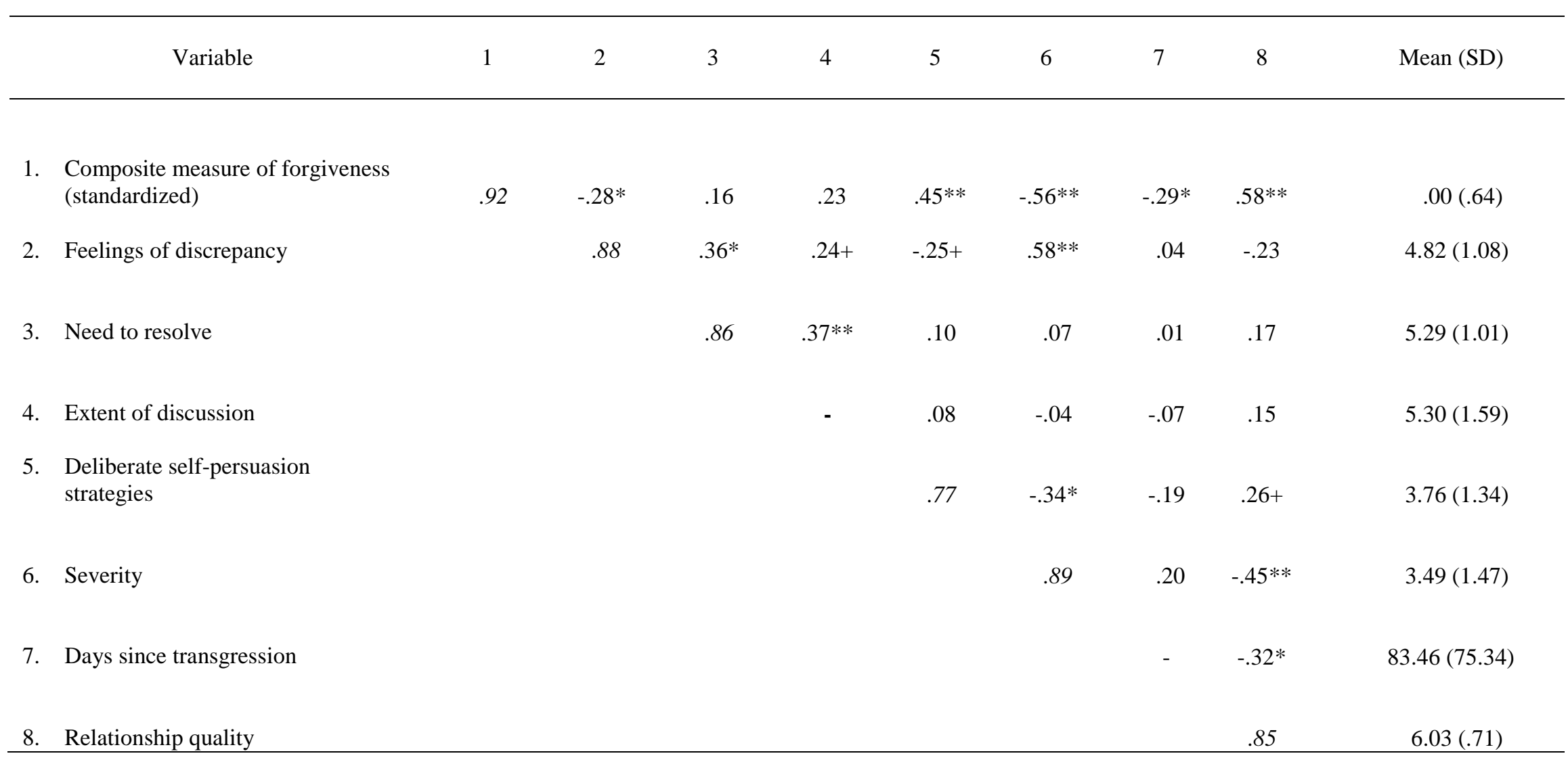

Note. Italicized values on the diagonal represent coefficient alpha internal consistency estimates. Values above the diagonal represent correlations among variables. ${ }^{* *} p<.01 .{ }^{*} p<.05 .{ }^{+} p<.10$. 
First, we tested the indirect effects model (as shown in Figure 1). Overall the model was not a good fit, $\chi^{2}(5)=10.94, p=.05, \mathrm{CFI}=.79, \mathrm{NNFI}=.58$, and RMSEA $=$ $.16(90 \% \mathrm{CI}<.001, .28)$. All paths were significant except for two paths. Contrary to our predictions, the path from need to resolve the discrepancy to the use of deliberate self-persuasion strategies and the path from discussion to forgiveness were not significant. The variables in the model explained $23 \%$ of the variance in forgiveness. Second, we tested the full effects model (as shown in Figure 2). Overall, the model was a good fit, $\chi^{2}(1)=.39, p=.53, \mathrm{CFI}=1.00, \mathrm{NNFI}=1.21$, and $\mathrm{RMSEA}<.001(90 \% \mathrm{CI}<$ $.001, .32$ ). All paths were significant except for the path from discussion to forgiveness, the path from resolve to strategies, and the path from resolve to forgiveness. The variables in the model explained $31 \%$ of the variance in forgiveness. A chi-square difference tests indicates that the indirect effects model fit significantly worse than the full effects model, $\chi_{\text {diff }}^{2}(4)=10.55, p=.03$

One reason why we may have obtained a poor fit of the indirect effects model is that extraneous variables related to forgiveness responses were not accounted for in the model. We therefore controlled for three variables in another test of the indirect effects model, which have been shown to influence forgiveness in prior research and were highly correlated with forgiveness in the present study. Prior to testing the fit of the model, the control variables were partialed out of the variables in the model to account for their influence. The control variables were not explicitly modeled for simplicity due to the small sample size. Thus, the unstandardized residual for each of the variables was used to test the model. Table 4 presents the partial correlations (controlling for perceived 
transgression severity, number of days since the transgression, and relationship quality) for the variables included in the model.

When the control variables were taken into account the indirect effects model was a good fit, $\chi^{2}(4)=3.10, p=.54, \mathrm{CFI}=1.00, \mathrm{NNFI}=1.14$, and $\mathrm{RMSEA}<.001(90 \% \mathrm{CI}<$ $.001, .19)$. All paths were significant except for the path from discussion to forgiveness and the path from need to resolve to the use of strategies. The variables in the model explained $13 \%$ of the variance in forgiveness. This model is shown in Figure $3 .^{3}$

The full effects model was also tested partialing out the control variables, and the model was also a good fit, $\chi^{2}(1)=.09, p=.77, \mathrm{CFI}=1.00, \mathrm{NNFI}=1.58$, and RMSEA $<$ $.001(90 \% \mathrm{CI}<.001, .25)$. The same paths were significant as in the indirect effects model with the addition of a significant path from feelings of discrepancy to discussion. All other new paths were not significant. This model is presented in Figure 4.

A chi-square difference test indicated that the two models, after partialing out the control variables, did not differ in fit, $\chi^{2}$ diff $(4)=3.35, p=.50$. Because forgiveness was highly correlated with perceived transgression severity, when the transgression occurred, and relationship quality, we reasoned that it was important to take these variables into account when testing our model to ensure that our findings were not attributable to those variables. Given that the indirect and full effects models both fit the data well, the more parsimonious indirect effects model seems preferable as the model of choice.

\footnotetext{
3 The model being tested assumed mediation, but based on the size and significance of the path coefficients, it is unlikely.
} 
Table 4

Study 1 Partial Correlations Controlling for Transgression Severity, Relationship

Quality, and Days Since the Transgression

\begin{tabular}{|c|c|c|c|c|c|}
\hline Variable & 1 & 2 & 3 & 4 & 5 \\
\hline $\begin{array}{l}\text { 1. Composite measure of } \\
\text { forgiveness (standardized) }\end{array}$ & - & .03 & .18 & .21 & $.30 *$ \\
\hline 2. Feelings of discrepancy & & - & $.39 * *$ & $.31 *$ & -.09 \\
\hline 3. Need to resolve & & & - & $.36^{*}$ & .12 \\
\hline 4. Extent of discussion & & & & - & .05 \\
\hline 5. Self-persuasion strategies 4 & & & & & - \\
\hline
\end{tabular}

Note. ${ }^{* *} p<.01 .{ }^{*} p<.05,{ }^{+} p \leq .10$.

${ }^{4}$ For exploratory purposes, we examined whether the different types of strategies were associated with forgiveness. The items used to assess deliberate self-persuasion strategies fall into four kinds of strategies: attitudinal concentration (average of items 1,2, and 3), attitudinal suppression (item 4), motivated interpretation (item 5), and motivated hypothesis testing (item 6). None of the correlations (controlling for severity, days since transgression, and relationship quality) were significant, $p \mathrm{~s}>.13$, except for motivated hypothesis testing $r(45)=.42, p=.003$. 


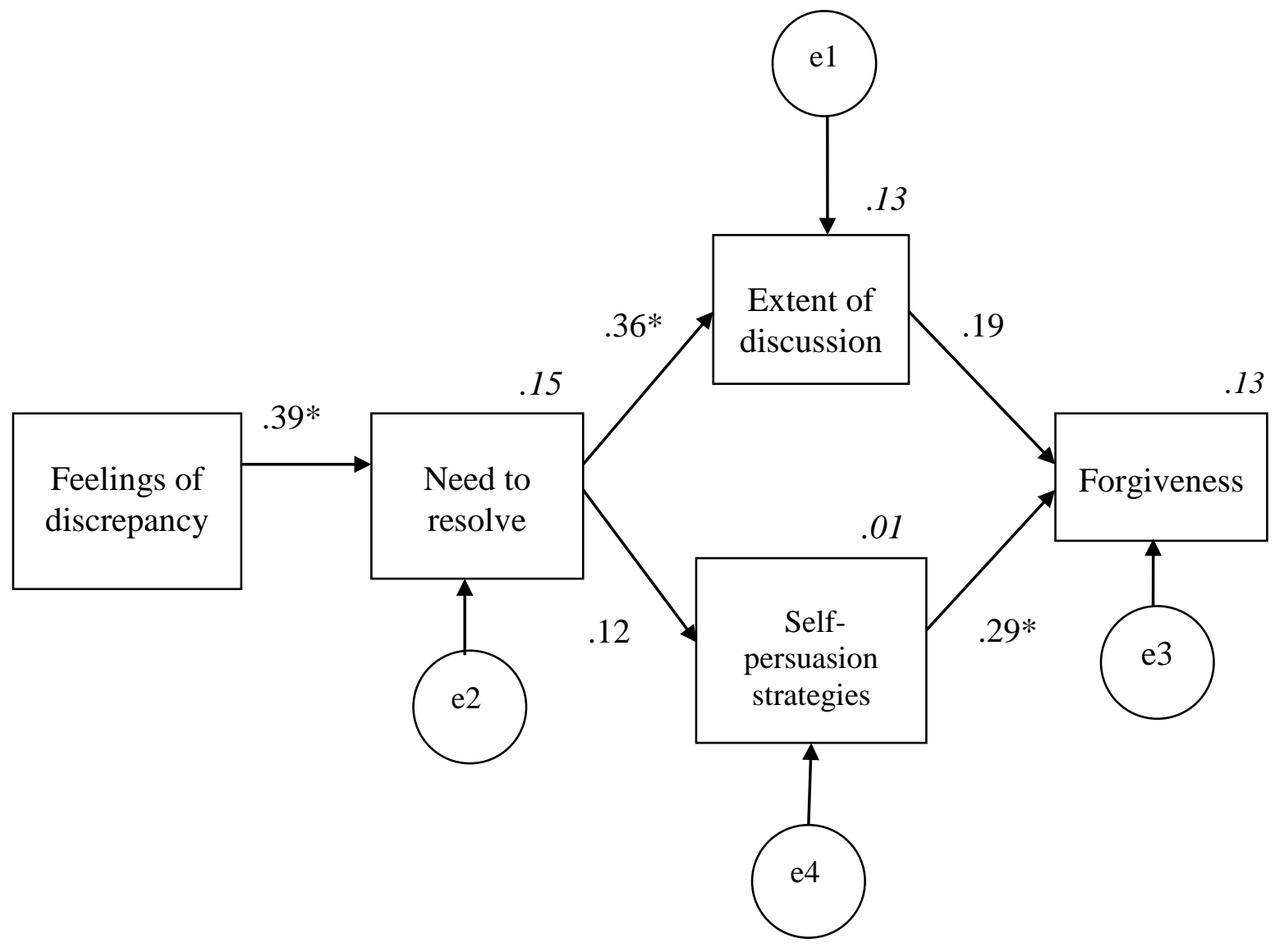

Figure 3. Indirect effects model for Study $1, \chi 2(5)=3.46, p=.63, \mathrm{CFI}=1.00, \mathrm{NNFI}=$ 1.20 , and RMSEA $<.001(90 \% \mathrm{CI}<.001, .16)$. The model controls for time since the transgression, perceived relationship quality, and perceived transgression severity. Rectangles represent measured variables and circles (e1 to e4) represent measurement error. Italicized values on the endogenous variables represent the percentage of variance explained by predictors in the variable (squared multiple correlations). Path coefficients are the standardized regression weights. $* * p<.01{ }^{*} * p<.05$. 


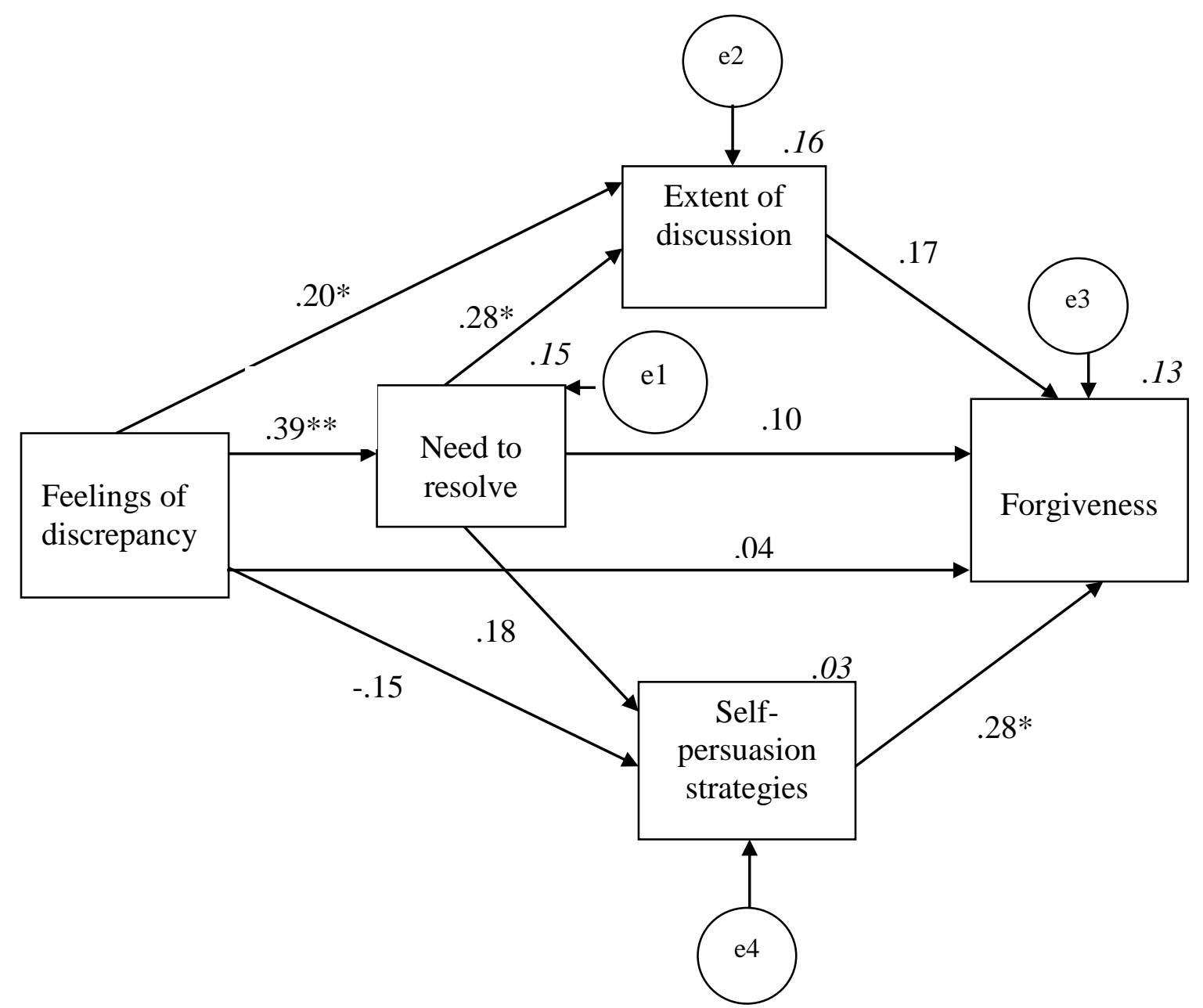

Figure 4. Full effects model for Study $1, \chi 2(1)=.09, p=.77, \mathrm{CFI}=1.00, \mathrm{NNFI}=1.58$, and RMSEA $<.001(90 \% \mathrm{CI}<.001, .25)$. The model controls for time since the transgression, perceived relationship quality, and perceived transgression severity. Rectangles represent measured variables and circles (e1 to e4) represent measurement error. Italicized values on the endogenous variables represent the percentage of variance explained by predictors in the variable (squared multiple correlations). Path coefficients are the standardized regression weights. $* * p<.01$. $* p^{*}<.05$. 


\section{Other Analyses}

A discussion of the transgression was most often initiated by the perpetrator $(\mathrm{n}=$ 35) or a third party $(n=11)$. Only three participants initiated the discussion, and only one participant reported that he or she did not talk about the transgression. Out of the total sample, 39 participants received an apology and 11 did not receive an apology for the transgression. ${ }^{5}$

\section{Discussion}

The findings from Study 1 provide some preliminary evidence consistent with a deliberate self-persuasion analysis of forgiveness. Although the findings are only correlational in nature, they suggest that some individuals do feel ambivalent towards their partner following a transgression and are aware of their ambivalence, as indicated by self-reports of both positive and negative thoughts, feelings, and behaviours toward their partner. In addition, the more participants reported feeling ambivalent toward their partner, the more they reported the need to resolve the discrepancy; Maio and Thomas (2007) hypothesized that being conscious of the discrepancy and being motivated to resolve it are necessary prerequisites for deliberate self-persuasion. The results also suggest the importance of communication between the victim and the perpetrator; the more individuals were motivated to resolve the feelings of discrepancy, the more they talked to their partner about the transgression. However, the extent to which participants discussed the transgression with their partner did not influence forgiveness. Thus,

5 An ANCOVA with apology as the independent variable, forgiveness as the dependent variable, and transgression severity as the covariate was conducted. Results indicated that there were no differences in forgiveness between those who did and did not receive an apology, $F(1,47)=.29, p=.59$. 
discussion did not mediate the relation between need to resolve and forgiveness. Finally, greater use of self-persuasion strategies was associated with more forgiveness toward the partner, but did not mediate the relation between need to resolve and forgiveness.

\section{Study 2}

The primary purpose of Study 2 was to experimentally manipulate the salience of feelings of discrepancy toward the perpetrator and the need to resolve the discrepancy to examine their effects on forgiveness in order to establish the causal direction of the components of deliberate self-persuasion. In Study 2, dating participants were asked to read an article about how couples should resolve problems in their relationship. To manipulate the need to resolve feelings of discrepancy, participants were randomly assigned to read and evaluate one of two versions of the article. In the high need to resolve condition, participants read that it is important to discuss conflicts with their partner in detail to establish trust in the relationship and to avoid similar situations from occurring in the future. In the low need to resolve condition, participants read that it is not always important to discuss their conflicts in detail with their partner because sometimes talking about the conflict can make things worse. Then participants were asked to imagine a hypothetical scenario in which their partner transgressed against them. To manipulate the salience of feelings of discrepancy, participants were randomly assigned to answer one of two sets of questions. In the high salience condition, participants answered questions about the extent to which their partner would have failed to meet their expectation if the scenario they imagined were to actually occur. In the low salience condition, participants answered questions that were unrelated to the hypothetical scenario, instead assessing the extent to which they used various 
communication tools. Afterwards, participants answered questions about the extent to which they would use deliberate self-persuasion strategies, whether they would discuss the transgression with their partner, and the extent to which they would forgive their partner. It was predicted that in the low need to resolve condition, participants would be less likely to use deliberate self-persuasion strategies and discuss the transgression with their partner regardless of whether the salience of the discrepancy was high or low. It was reasoned that when there is low need to resolve feelings of discrepancy, participants would invest little effort to downplay the negative aspects of the partner and the relationship. However, in the high need to resolve condition, it was predicted that when the salience of the discrepancy was high, participants would be more likely to discuss the transgression with their partner and more likely to use deliberate self-persuasion strategies, compared to when the salience of the discrepancy was low. Thus, the high need to resolve and high salience of discrepancy condition was expected to elicit the greatest motivation from participants to discuss the transgression, to devalue the negative aspects, and to enhance the positive aspects of their partner and relationship. Predictions for forgiveness were less clear. On the one hand, greater discussion and greater use of self-persuasion strategies might be expected to produce more forgiveness, in which case the "high/high" condition should produce the most forgiveness. On the other hand, the high salience of the discrepancy condition might increase the perceived severity of the transgression, in which case it may be easier for participants in the low salience condition to forgive their partner (because the partner's transgression is perceived as less severe and therefore easier to forgive). 


\section{Method}

\section{Participants}

Participants were 97 (32 men, 65 women) undergraduate students enrolled in an introductory psychology course at the University of Western Ontario, who received partial course credit for their participation. Ten participants were excluded from the analyses due to an error in the computer program during the study session. The final sample consisted of 87 (27 men, 60 women) students. In an earlier mass testing session, participants indicated that they were currently involved in a romantic relationship for at least three months. On average, participants were involved with their partners for 16.41

months $(S D=12.76 \text {; range from } 1 \text { to } 48 \text { months })^{6}$, and almost all participants were in an exclusive relationship with their partner (80 were dating exclusively, 2 were commonlaw, and 5 were dating their partner and others). Participants were between the ages of 18 to 23 years $(M=18.68, S D=.96)$.

\section{Materials and Procedure}

Participants in a dating relationship were invited to participate in a study about communication in romantic relationships. They arrived at the lab in groups ranging from 1 to 5 persons and were randomly assigned to one of four experimental conditions. Participants completed all of the questions on a computer in individual cubicles.

In the first part of the study, participants were asked to provide some demographic information about themselves and their current romantic relationship, as in Study 1.

6 Two participants were in a relationship for less than three months and seven participants did not indicate the length of their relationship. Analysis of the data including and excluding these nine participants did not differ. Therefore, these nine participants were included in the final analyses. 
Participants then completed the PRQC Inventory (Fletcher et al., 2000b), as in Study 1. The 18 items in the PRQC Inventory were averaged to form a composite measure of relationship quality $(\alpha=.93)$.

Need to resolve manipulation. To manipulate the need to resolve feelings of discrepancy, participants were asked to read one of two versions of an article about how to solve problems in relationships, which was allegedly written by a clinical psychologist who specialized in couple's therapy. Participants were instructed to read the article carefully so that they could evaluate its contents afterwards, which would help researchers understand how information about relationships can be communicated effectively. In the high need to resolve condition, participants read that when couples experience conflict, it is important for both partners to be honest with each other. Here is an excerpt from the high need to resolve version (see Appendix B for the measures used in Study 2):

"Many people believe that honesty is the best policy, and this is absolutely true. When people are dealing with issues, it is extremely important for both partners to communicate their needs and expectations to each other." She goes on to add, "When people feel like they have been 'hurt' by their partners, they tend to have biased perceptions of the situation. They may see the situation in a more selfcentered way and are unable to take into account situational factors that might have led to their partner's behavior. Because of this, it's better for people to discuss their conflicts and communicate clearly with their partner, so that a similar situation does not happen in the future."

In the low need to resolve condition, participants read that when conflict occurs among couples, it is not always necessary to bring the issues into the open to resolve them.

Below is an excerpt from the low need to resolve version of the article: 
"Many people believe that honesty is the best policy, and sometimes this is true, but other times it's not. Sometimes, when people are dealing with issues, bringing them into the open can create tension and unhappiness in the relationship." She goes on to add, "When people feel like they have been 'hurt' by their partners, they tend to have biased perceptions of the situation. They may see the situation in a more self-centered way and are unable to take into account situational factors that might have led to their partner's behavior. Because of this, it's often times safer to let things go and not discuss the conflict at all."

Then participants answered three questions, which asked them to indicate the extent to which the article was easy to understand, well-written, and effective on 7-point rating scales from 1 (not at all) to 7 (extremely). The items were reliable, $\alpha=.81$, and were therefore averaged to form a composite measure of participants' evaluation of the article.

Hypothetical scenario. In the next part of the study, participants were asked to imagine a hypothetical scenario in which their partner transgressed against them. Specifically, participants were told to imagine how they would think and feel if the scenario were to actually occur. Participants read the following scenario (adapted from Berry, Worthington, Parrott, O’Connor, \& Wade, 2001):

Imagine that your partner offers to drop off a scholarship application for you at the post office by the deadline for submission. A week later, you get a letter from the scholarship granting agency saying that your application could not be considered because it was postmarked after the deadline and they had a very strict policy about this. Your partner said that he or she ran into old friend, went to dinner, and lost track of time. When he or she remembered the package, it was close to closing time at the post office, and he or she would have needed to rush frantically to get there; he or she decided that deadlines usually aren't that strictly enforced, so he or she waited until the next morning to deliver the package.

Feelings of discrepancy salience manipulation. After imagining the hypothetical scenario, participants were presented with the feelings of discrepancy salience manipulation. In the high salience condition, participants were asked to indicate their agreement with 10 statements about their perceptions of their partner if the scenario were to actually occur (e.g., "My partner's behaviour would be different from my 
expectations of him or her"; "What I would have wanted my partner to do and what (s)he did were very different") on 7-point rating scales from 1 (strongly disagree) to 7

(strongly agree), $\alpha=.81$. In the low salience condition, participants answered questions that were unrelated to the hypothetical scenario, instead reporting the frequency with which they used various communication tools (e.g., "How often do you use text messaging?"; "How often do you use email?") on 7-point rating scales from 1 (never) to 7 (very frequently), $\alpha=.65$.

Manipulation checks. Next, participants answered 10 items that measured their feelings of discrepancy and their need to resolve the discrepancy toward their partner if the hypothetical scenario were to occur. Nine of the items were the same as in Study 1, but we added one more item ("My partner's behavior would be different from what I expect from him or her"); six items assessed feelings of discrepancy $(\alpha=.84)$ and four items assessed need to resolve feelings of discrepancy $(\alpha=.75)$. The items for each subscale were aggregated to form a composite measure of feelings of discrepancy and need to resolve feelings of discrepancy.

Deliberate self-persuasion strategies. In the next part of the study, participants reported the extent to which they would engage in deliberate self-persuasion strategies if the hypothetical scenario occurred. Participants were given a series of statements and told that the statements describe how someone might react to the scenario that they imagined. The items were designed to capture the various strategies outlined by Maio and Thomas (2007). Seven items assessed participants' anticipated use of teleologic strategies (e.g., "I would 'take my mind off things' by thinking about something else”; "I 
would simply try not to think about what happened"; $\alpha=.67$ ). Seven items assessed participants' reported likelihood of using epistemic strategies (e.g., "I would explain my partner's behavior in a more positive way"; "I would try to place more emphasis on the positive qualities of our relationship"; $\alpha=.85)$. All of the items were answered on 5point rating scales from 1 (never) to 5 (always).

Discussion of Transgression. Participants then answered three questions about the likelihood that they would confront their partner about their behaviour (i.e., failing to mail their application on time) and the likelihood that they would bring up what happened, both items rated on a 7-point rating scale from 1 (not likely at all) to 7 (extremely likely). Participants were also asked in how much detail they would talk to their partner about what happened and were asked to respond on a 7-point rating scale with endpoints ranging from 1 (no detail at all) to 7 (in extreme detail). The three items were averaged to form a composite measure of the extent to which they would discuss the transgression with their partner, $\alpha=.86$.

Forgiveness Measures. Participants indicated their willingness to forgive their partner if the transgression were to occur. Participants indicated the extent to which they would want to forgive their partner $(1=$ not at all, 7 = very much $)$, the likelihood that they would actually forgive their partner $(1=$ not likely at all, $7=$ very likely $)$, and how long they think it would take for them to fully forgive their partner $(1=$ not long at all, 7 = an extremely long time, reverse-scored). These items were highly correlated and were averaged to form a composite measure of self-reported forgiveness, $\alpha=.74$. Participants also completed an attitudinal measure of forgiveness (from the Family Forgiveness 
Measure; Maio, Thomas, Fincham, \& Carnelley, 2008). The attitudinal forgiveness measure consists of 8 items (e.g., "I would easily forgive him/her"; "I would see him/her more negatively than I did before", reverse-scored; "I would never really see him/her as positively as before he/she wronged me", reverse-scored) measured on a 7-point rating scale ranging from -3 (strongly disagree) to +3 (strongly agree). The items were averaged to form a composite measure of forgiveness attitudes, $\alpha=.85$. Finally, participants reported their forgiveness motivations toward their partner via the 18 -item TRIM Inventory (McCullough et al., 2006). The items were aggregated (the avoidance and revenge items were reverse-scored) to form a composite measure of forgiveness motivation, $\alpha=.85$.

Transgression Severity. Finally, participants were asked to indicate the extent to which the hypothetical scenario would have the potential to harm their relationship on a 7-point rating scale from 1 (no harm at all) to 7 (extremely harmful).

\section{Results}

\section{Preliminary analyses}

Relationship quality. Participants' responses to the PRQC (Fletcher et al., 2000b) were submitted to a 2-way ANOVA with need to resolve (high, low) and feelings of discrepancy (high, low) as the independent variables. No significant effects were found, indicating that relationship quality was equivalent across conditions, $p \mathrm{~s}>.10$. Across all participants, the mean for relationship satisfaction was $5.77(S D=1.12)$, commitment was $6.30(S D=1.01)$, intimacy was $6.11(S D=.83)$, trust was $6.08(S D=$ $1.10)$, passion was $5.72(S D=1.11)$, and love was $6.21(S D=.96)$. Across all 
participants, the overall mean for relationship quality was 6.03 on the 7-point scale $(S D=$ $.76)$.

Evaluation of the article. A two-way ANOVA with need to resolve (high, low) and feelings of discrepancy (high, low) as the independent variables was conducted on participants' evaluations of the article. Results showed no significant effects, indicating that there were no differences in evaluations of the article among the four conditions, $p \mathrm{~s}>$ .16. On average, participants' rating of the article was fairly positive, $M=5.49$ on the 7 point scale $(S D=.90)$.

Transgression severity. Participants' severity ratings of the hypothetical scenario were submitted to a two-way ANOVA with need to resolve (high, low) and feelings of discrepancy (high, low) as the independent variables. Results showed that there was a marginally significant main effect of feelings of discrepancy, $F(1,83)=3.05$, $p=.084$, such that those in the high discrepancy conditions $(M=3.64, S D=1.53)$ rated the transgression as somewhat more severe than those in the low discrepancy condition $(M=3.14, S D=1.16)$. Results also showed that there was a marginally significant interaction between need to resolve and feelings of discrepancy, $F(1,83)=2.93, p=$ .091. Simple effects tests revealed that among participants in the low need to resolve condition, there were no differences in severity ratings between the high $(M=3.39, S D=$ 1.41) versus low discrepancy conditions $(M=3.38, S D=1.02), F(1,83)=.001, p=.98$. In contrast, among participants in the high need to resolve condition, those in the high discrepancy condition rated the hypothetical transgression as more severe $(M=3.91, S D$ $=1.63)$ than those in the low discrepancy condition $(M=2.90, S D=1.26), F(1,83)=$ 
$5.92, p=.017$. In all subsequent analyses, transgression severity was included as a covariate.

Manipulation checks. To examine whether the need to resolve and salience of discrepancy manipulations were successful, participants' responses to the manipulation check items were each submitted to a 2-way ANCOVA with need to resolve (high, low) and salience of discrepancy (high, low) as independent variables, controlling for transgression severity. For need to resolve, results indicated that there were no significant effects, $p s>.25$, although the means were in the predicted direction, such that those in the high need to resolve condition reported slightly more need to resolve feelings of discrepancy toward their partner $(M=5.90, S D=.73)$ than those in the low need to resolve condition $(M=5.68, S D=1.07)$.

For salience of the discrepancy, participants in the high salience condition actually reported nonsignificantly less feelings of discrepancy toward their partner ( $M=$ $5.06, S D=1.18)$ than those in the low salience condition $(M=5.28, S D=1.07), F(1,82)$ $=3.01, p=.086$, contrary to our predictions. No other significant effects were found.

\section{Planned ANOVAs}

The measures of use of self-persuasion strategies (epistemic and teleologic), extent of discussion, and forgiveness (3 composite measures) were all submitted to twoway ANCOVAs with need to resolve (high, low) and salience of discrepancy (high, low) as independent variables and transgression severity as a covariate. No main effects or interactions were significant in any of these analyses (all $p$ s $>.07$ ). These null results 
may not be surprising given that the manipulation check items indicated that the manipulations were unsuccessful.

\section{SEM Analyses}

Given that the planned ANCOVAs yielded no significant effects, we conducted path analyses using participants' responses to the salience of discrepancy and need to resolve the discrepancy manipulation check items to examine the relations among the variables. In these analyses, all of the items assessing forgiveness were aggregated to form a single composite measure of forgiveness. Items from the measure of forgiveness attitudes (Maio et al., 2008), TRIM Inventory (McCullough et al., 2006), and the three self-report forgiveness items were included for a total of 29 items, $\alpha=.93$. All of the items were standardized prior to being aggregated. The items assessing teleologic and epistemic strategies were also aggregated to form a single measure of deliberate selfpersuasion strategies, $\alpha=.85$. The internal consistency reliabilities, intercorrelations, means, and standard deviations of the principal dependent variables are presented in Table 5. We tested whether the data from Study 2 would fit the same model that was tested in Study 1. First, we tested the indirect effects model. Results indicated that the model was a poor fit, $\chi^{2}(5)=50.35, p<.001, \mathrm{CFI}=.51, \mathrm{NNFI}=.02$, and $\mathrm{RMSEA}=.33$ (90\% CI: .25, .41). As in Study 1, all paths were significant except for the path from resolve to strategies, and the path from discuss to forgiveness. The model accounted for $24 \%$ of the variance in forgiveness. Second, we tested the full effects model. Results indicated that the model was a good fit, $\chi^{2}(1)=.62, p=43, \mathrm{CFI}=1.00, \mathrm{NNFI}=1.04$, and RMSEA <.001 $(90 \%$ CI: <.001, .26). All paths were significant except for the path from resolve to strategies and the path from discuss to forgiveness. 
Table 5

Study 2 Internal Consistency Reliabilities, Zero-Order Variable Correlations, and Descriptive Statistics

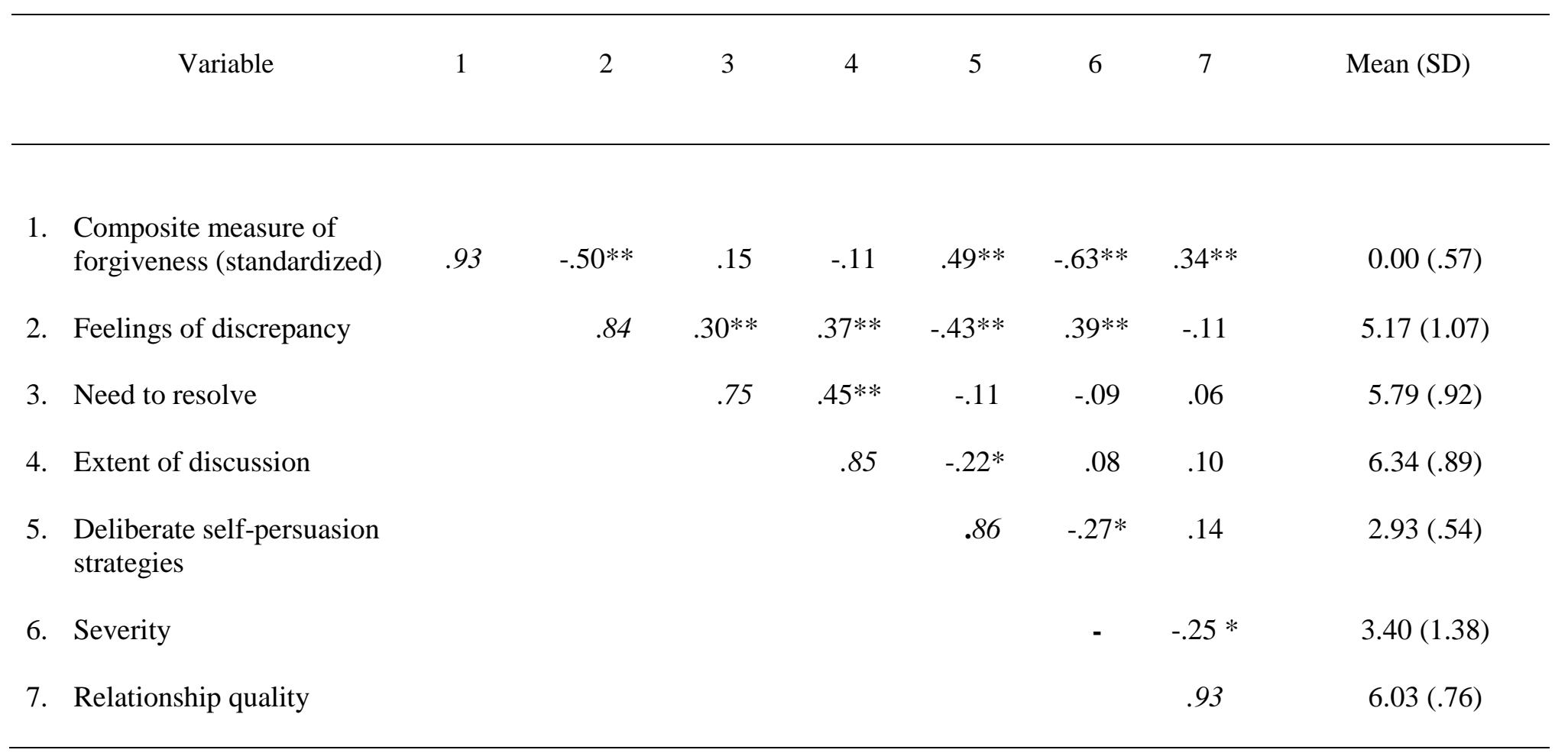

Note. $* * p<.01 . * p<.05 .{ }^{+} p<.10$. 
Four additional paths were also significant: the path from discrepancy to forgiveness, the path from resolve to forgiveness, the path from discrepancy to discussion, and the path from discrepancy to strategies. The model accounted for $44 \%$ of the variance in forgiveness. A chi-square difference test indicated that the data fit the indirect effects model significantly worse than the full effects model, $\chi_{\text {diff }}^{2}(4)=49.73, p<.001$.

Next, we tested both the indirect and full effects models controlling for perceived transgression severity and relationship quality as in Study $1 .^{7}$ These two variables were partialed out of all variables included in the model, because both variables were correlated with forgiveness. Thus, the unstandardized residual for each of the variables was used to test the model. Table 6 presents the correlations among the variables in the model controlling for transgression severity and relationship quality.

\footnotetext{
${ }^{7}$ We also tested the indirect and full effects models controlling for experimental condition in addition to transgression severity and relationship quality. The results were nearly identical, thus we report only the results including severity and relationship quality as control variables.
} 
Table 6

Study 2 Partial Correlations Controlling for Transgression Severity and Relationship

Quality

\begin{tabular}{|c|c|c|c|c|c|}
\hline Study Variables & 1 & 2 & 3 & 4 & 5 \\
\hline $\begin{array}{l}\text { 1. Forgiveness (composite } \\
\text { measure, standardized) }\end{array}$ & - & $-.37 * *$ & .12 & -.11 & $.43^{* *}$ \\
\hline 2. Feelings of discrepancy & & - & $.36^{*}$ & $.38 * *$ & $.37 * *$ \\
\hline 3. Need to resolve & & & - & $.46^{* *}$ & -.14 \\
\hline 4. Extent of discussion & & & & - & $-.22 *$ \\
\hline $\begin{array}{l}\text { 5. Deliberate self-persuasion } \\
\text { strategies }^{8}\end{array}$ & & & & & - \\
\hline
\end{tabular}

Note. $* * p<.01 . * p<.05$.

\footnotetext{
${ }^{8}$ As in Study 1, we examined whether the various individual self-persuasion strategies correlated with forgiveness. Strategies that were assessed with multiple items were aggregated (see Appendix B for the items). Partial correlations (controlling for transgression severity and relationship quality) showed that all of the strategies were positively correlated with forgiveness, all $p s<.05$, except for attitudinal distraction, attitudinal suppression, and changing comparators, which were not correlated with forgiveness, $p \mathrm{~s}>.50$.
} 
Overall, the indirect model was again a poor fit, $\chi^{2}(4)=26.92, p<.001, \mathrm{CFI}=$ $.69, \mathrm{NNFI}=.22$, and RMSEA $=.26(90 \% \mathrm{CI}: .17, .36)$, even after controlling for perceived severity and relationship quality. The results showed that all of the paths were significant, except for the path from need to resolve to deliberate self-persuasion strategies and the path from discussion to forgiveness, contrary to our predictions (but consistent with the results of Study 1). The variables in the model explained 18\% of the variance in forgiveness. This model is shown in Figure $5 .{ }^{9}$

We also tested the full effects model taking the control variables into account (see Figure 6). Results indicated that the model was a good fit, $\chi^{2}(1)=.76, p=.38, \mathrm{CFI}=$ $1.00, \mathrm{NNFI}=1.03$, and RMSEA $<.001(90 \% \mathrm{CI}:<.001, .27)$. All of the paths were significant, except for the same two paths as in the test of the indirect model: the path from need to resolve to strategies, and the path from discussion to forgiveness.

${ }^{9}$ Despite the similarity in magnitude and significance of some of the path coefficients between the models in Study 1 and Study 2 (after partialing out the control variables), the model in Study 2 did not yield a good fit. The main purpose of model testing is to demonstrate how well the hypothesized model and the sample data fit together. Discrepancies between the model and the data can be assessed by examining the standardized residual covariances among the variables. As a general rule of thumb, the standardized residuals should be less than or equal to $|2.58|$ (e.g., Byrne, 2010). Essentially, these values are z-scores that represent the number of standard deviations the observed residuals deviate from zero residuals that would be observed in a perfect fitting model. In Study 1, none of the standardized residual covariances were greater than 2.58 , indicating that it is unlikely the model would improve with additional paths, whereas in Study 2, two of the covariances were greater than the cutoff value, indicating that there are areas in the model that can improve in fit. 


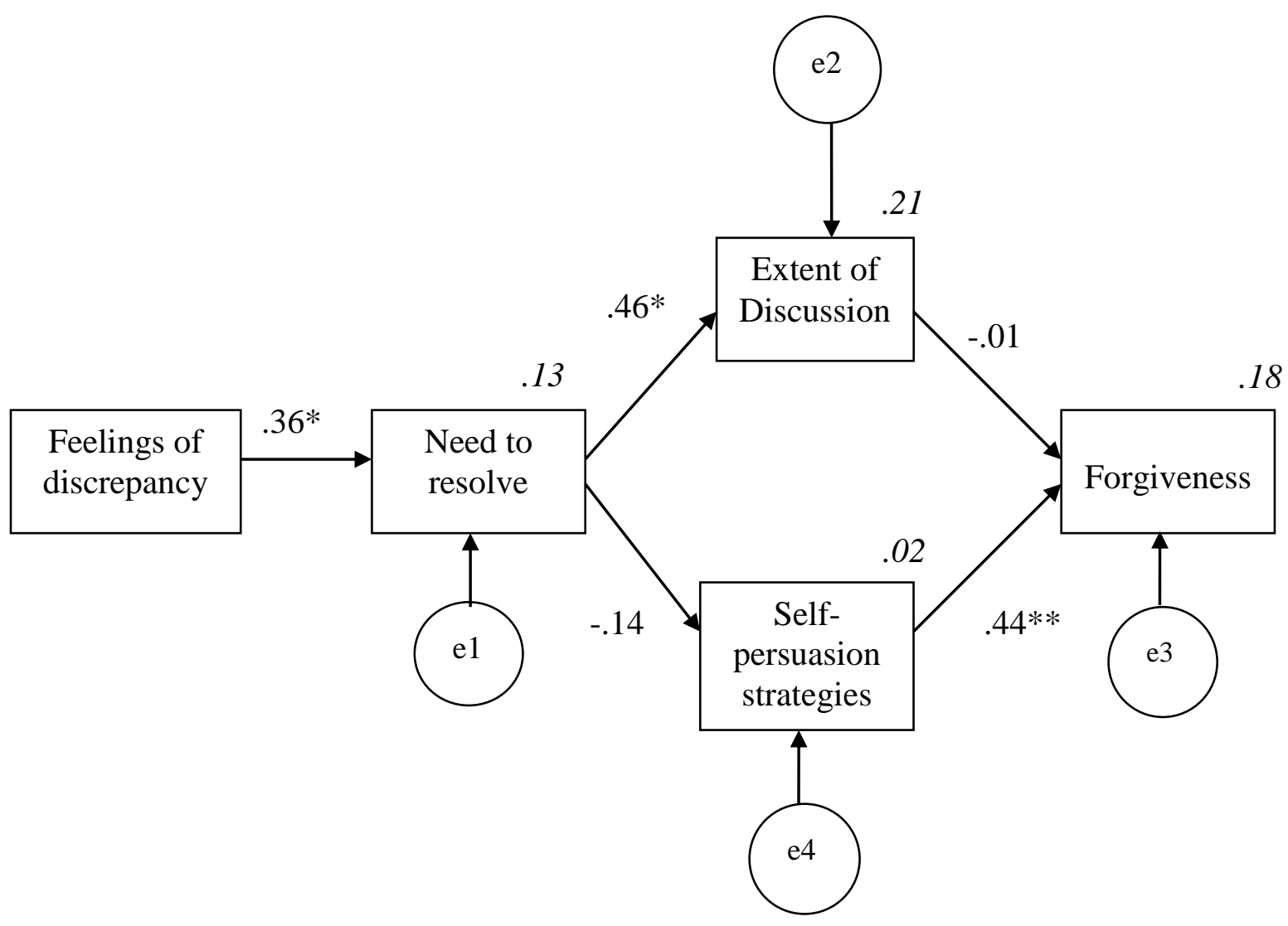

Figure 5. Indirect effects model for Study $2, \chi^{2}(5)=31.53, p<.001, \mathrm{CFI}=.64, \mathrm{NNFI}=$ .28 , and RMSEA $=.25$ (90\% CI: .17, .34). The model controls for perceived transgression severity and perceived relationship quality. Rectangles represent measured variables and circles (e1 to e4) represent measurement error. Italicized values on the endogenous variables represent the percentage of variance explained by predictors in the variables (squared multiple correlations). Path coefficients are the standardized regression weights. $* * p<.01 . * p=.05$. 


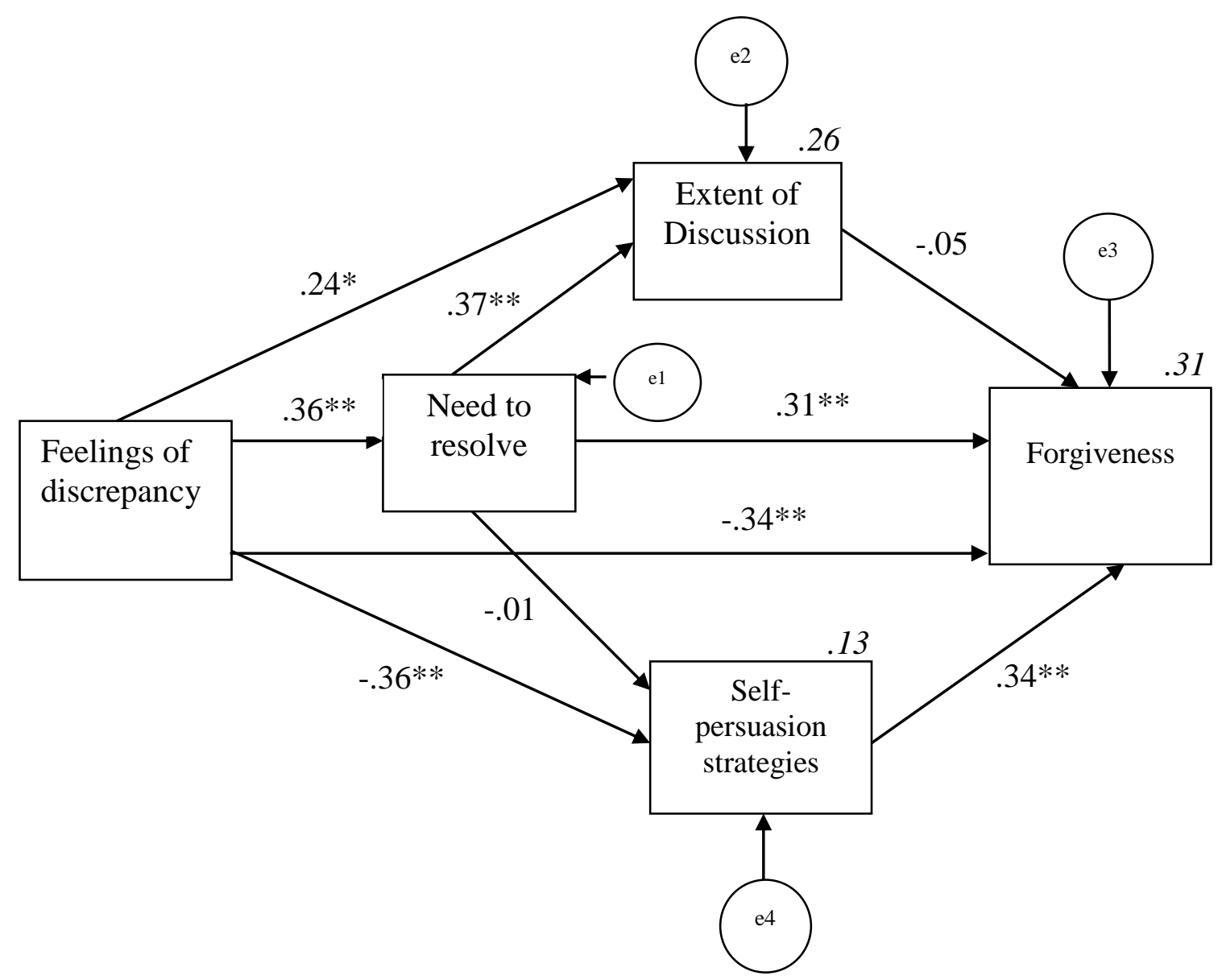

Figure 6. Full effects model for Study $2, \chi^{2}(1)=.76, p=.38, \mathrm{CFI}=1.00, \mathrm{NNFI}=1.03$, and RMSEA <.001 $(90 \% \mathrm{CI}:<.001, .27)$. The model controls for perceived transgression severity and perceived relationship quality. Rectangles represent measured variables and circles (e1 to e4) represent measurement error. Italicized values on the endogenous variables represent the percentage of variance explained by predictors in the variable (squared multiple correlations). Path coefficients are the standardized regression weights. $* * p<.01 . * p=.05$. 
A chi-square difference test indicated that the two models, after partialing out perceived severity and relationship quality, significantly differed in fit, $\chi_{\text {diff }}^{2}(4)=30.77$, $p<.001$. Given that the full model was a better fit than the indirect model (and the full model accounted for more variance in forgiveness than the indirect model, $31 \%$ vs. 18\%), the full effects model seems to be the better representation of forgiveness in Study 2. Again, we reasoned that it is important to account for the control variables because they explain variation in forgiveness responses, as seen in the drop in variance explained by the variables in the model for forgiveness (from $24 \%$ without the covariates to $18 \%$ with covariates for the indirect model and from $44 \%$ to $31 \%$ for the full model).

\section{Discussion}

The purpose of Study 2 was to provide a further test of deliberate self-persuasion in the forgiveness process by showing causal effects of feelings of discrepancy and the need to resolve the discrepancy on tendencies to forgive, mediated by discussion of the transgression and deliberate self-persuasion tactics. Unfortunately, the experimental manipulations of the salience of feelings of discrepancy toward the perpetrator and the need to resolve the discrepancy were unsuccessful. Thus, it was not possible to document their causal effects on forgiveness. The ineffectiveness of the manipulations is somewhat surprising given that participants in all conditions rated their article quite positively. Nonetheless, perhaps it was difficult to manipulate the need to resolve the discrepancy because participants came into the study with clear opinions about the importance of honesty and openness. With regard to the manipulation of salience of the discrepancy, it is possible that low salience participants thought spontaneously about how disappointed 
they would be with their partner even without explicit questions. Clearly, it is important for future researchers to create manipulations of these variables that are more successful.

Using SEM procedures, a test of the indirect effects model showed that the same paths that were significant in Study 1 were also significant in Study 2. However, the analyses indicated that the data from Study 2 did not fit the indirect effects model well (inconsistent with Study 1) and that the data fit the full effects model significantly better. Therefore, a more complex model seemed to be a better fit for the data from Study 2 . The results from the full effects model suggest that the use of strategies mediated the relation between feelings of discrepancy and forgiveness. However, the path from feelings of discrepancy to strategies was negative, such that more feelings of discrepancy was associated with less use of strategies, which seems to be incompatible with Maio and Thomas's (2007) view of the deliberate self-persuasion process. Perhaps participants' reactions were reflective of how they would respond immediately after the transgression occurred, which was unlikely to involve the use of deliberate self-persuasion strategies. Consistent with interdependence theory (Kelley et al., 2003; Kelley \& Thibaut, 1978; Thibaut \& Kelley, 1959) and our interpretation of the deliberate self-persuasion process, it is possible that participants were focused on how they would feel after the transgression, such as feelings of rage and disappointment, and that the passage of time would be necessary for a transformation of motivation in order for participants to shift their focus from self-focused to relationship-focused goals. Nonetheless, both the indirect and full effects models indicated that the use of deliberate self-persuasion strategies positively predicted forgiveness, which is also consistent with Study 1. 


\section{Study 3}

The goal of Study 3 was to extend the findings from the first two studies by examining, in a longitudinal study of actual transgressions, how the components of deliberate self-persuasion influence changes in forgiveness over time. Specifically, participants who had experienced an interpersonal transgression committed by their romantic partner within the last 7 days were invited to take part in an online study (for a similar procedure, see McCullough et al., 2003). Participants first described the transgression and then answered questions about the transgression and their partner. Participants were subsequently contacted three additional times to collect follow-up data. By examining recent transgressions, it was possible to assess how individuals' initial feelings of discrepancy toward the transgressors and their need to resolve the discrepancy, as well as the extent to which they discussed the transgression with their partner and used deliberate self-persuasion strategies, predicted changes in forgiveness. It was hypothesized that more feelings of discrepancy would be associated with more need to resolve those feelings. In turn, the need to resolve would be indirectly related to forgiveness via discussion and strategies. In addition, it was also hypothesized that the extent of discussion and use of strategies at Time 1 would predict changes in forgiveness, such that more discussion and more use of strategies would lead to more increases in forgiveness. 


\section{Method}

\section{Participants}

One hundred and two undergraduate students enrolled in an introductory psychology course at the University of Western Ontario received course credit for their participation. Specifically, participants received half of the research credit for the study after completing the first questionnaire and the other half after completing the follow-up sessions. Participants also earned one entry to win $\$ 100$ for each follow-up questionnaire they completed.

A total of 14 participants were excluded from the analyses. Of these participants, 5 indicated that their responses were not honest (see below for more details), 5 did not indicate when their transgression occurred, and 4 did not follow the instructions (e.g., nominating an event in which they were the transgressor). Thus, the final sample at Time 1 consisted of 88 participants ( 32 men, 56 women). On average, participants were involved with their partner for 16.61 months ( $S D=15.50$; range from 3 to 78 months), and almost all participants were in an exclusive relationship with their partner (82 were dating exclusively, 6 were not dating exclusively). In addition, most participants (85 out of 88) were not co-habiting with their partner. Participants were 17 to 25 years of age ( $M$ $=18.55, S D=1.12$ ). For the follow-up sessions, there were 67 participants at Time $2^{10}$, 64 participants at Time 3, and 60 participants at Time 4.

\footnotetext{
${ }^{10}$ Of the 88 participants who filled out the survey at Time 1, 10 participants canceled their participation, 6 fulfilled all of their research credits after completing the survey at Time 1 and decided not to continue the study, and 5 participants did not provide a reason for not completing the study, leaving 67 participants at Time 2.
} 


\section{Materials and Procedure}

Participants in a romantic relationship were invited to participate in the current

study. Participants were told that the study involved reporting an event and then keeping track of their reactions to the event over a 3-week period. Specifically, participants were asked to complete an online questionnaire once a week over a three-week period for a total of four sessions. The following information was posted on the website of the UWO Psychology Subject Pool:

The event must involve a conflict that you recently experienced with your romantic partner. All of us have expectations about how our partners should treat us. No matter how well-behaved your partner may be in general, from time to time he or she is likely to "break the rules." For example, your partner may tell a friend something that you think should have remained private; your partner may do something that is hurtful behind your back; your partner may flirt with another person; or your partner may otherwise violate the rules that govern your relationship. If something like this happened to you WITHIN THE LAST 7 days, you can sign-up for the study (adapted from Hannon, Rusbult, Finkel, \& Kamashiro, 2010).

\section{Initial Session}

Background information. In the first session, participants were asked to answer some questions about themselves, such as age and gender, as well as some questions about their romantic relationship, including relationship length, dating status, and whether they resided with their partner. Participants then answered the PRQC Inventory $(\alpha=.97$; Fletcher et al., 2000).

Transgression nomination. Next, participants were asked to provide the initials of their partner to ensure that they would think about the same person throughout the study. Then participants were presented with the following instructions: 
We would like for you to describe an event in which your romantic partner wronged you within the last week. That is, we would like you to describe an interpersonal hurt or transgression you experienced between 1 and 7 days ago. Try to visualize in your mind the events and the interactions you had with the person who hurt you. In your description of the event, please try to include as many details as you are comfortable providing. Your responses to this survey will be content-analyzed to assess certain dimensions of wrongful acts. Thus, your honest reporting of the incident is greatly appreciated (adapted from Wohl \& McGrath, 2007).

Then participants were asked to write a keyword or short phrase for the transgression they described. The keyword or short phrase was included whenever the research assistant emailed participants, in order to ensure that they were thinking about the same transgression in the remaining sessions.

Feelings of discrepancy and need to resolve. Next, participants were asked to indicate their current feelings of discrepancy $(\alpha=.89)$ and need to resolve the discrepancy $(\alpha=.92)$ using the same items as in Study 2 but worded in the present tense rather than hypothetically (e.g., "It is stressful to have both positive and negative feelings about my partner"; "It is important for me to know how our future will be affected by what happened") and rated on a 7 -point scale $(1=$ strongly disagree, $7=$ strongly agree $)$.

Deliberate self-persuasion strategies. Participants were then asked to indicate the extent to which they have used each of the deliberate self-persuasion strategies using the same items as in Study 2 (e.g., "I 'take my mind off things' by thinking about something else"; "I focus on all of the good things that my partner has done to me") and rated on a 5 -point scale $(1=$ never, $5=$ always; $\alpha=.83)$.

Extent of discussion. As in Study 1, participants indicated the extent to which they discussed the transgression with their partner $(1=$ not at all, $7=$ very much $)$, and in 
how much detail they discussed it $(1=$ not detailed at all, $7=$ extremely detailed; $\alpha=$ 90). Participants were also asked who initiated the conversation (you, your partner, or other).

Forgiveness. Participants then answered the attitudinal measure of forgiveness (Maio et al., 2008) and the TRIM Inventory (McCullough et al., 2006). All items were rated on 7-point scales ranging from -3 (strongly disagree) to +3 (strongly agree), $\alpha=$ .93 .

Transgression severity and transgression date. Finally, participants were asked whether the transgression had the potential to seriously harm their relationship ( $1=$ not at all, $7=$ very much) and the date of the transgression.

\section{Follow-up sessions}

A research assistant emailed participants with the link to the appropriate questionnaire each week, the day before they were scheduled to complete it. Participants who failed to complete the questionnaire in the allotted time were sent three additional reminders, after which they were not contacted again until the following session. For example, if participants did not complete the second questionnaire after three reminders, they were not contacted again until it was time for them to complete the third questionnaire, at which point they were only given the link to complete the third questionnaire.

The follow-up sessions included all of the questionnaires from the initial session except the background information questionnaire. At the beginning of each follow-up 
session, participants were asked to report the initials of their current partner, the extent to which they were still romantically involved with their partner $(1=$ no, not at all, $7=$ yes, completely involved), and reminded of the keyword or short phrase they used to describe their transgression in the initial session to ensure that they were thinking of the same event.

At the end of the final session, participants were asked to report whether their responses to the study were accurate. Participants were told that students occasionally sign up for studies even though they do not meet the criteria (e.g., are not in a romantic relationship or did not experience a recent negative event with their partner). Participants were told that if their responses were accurate that they should respond to the question with a "yes," and if their responses were not accurate, they should not answer the question. Participants were also told that they would not be penalized if they were not accurate in their responses (a total of 5 participants left the question blank). Finally, participants were thanked and fully debriefed about the purpose of the study.

\section{Results}

\section{Preliminary analyses}

\section{Relationship quality, time of transgression, and severity of transgression.}

Analyses on the PRQC indicated that the average on the scale was $5.78(S D=1.08)$ indicating that participants were high in relationship quality. On average, participants reported a transgression that happened about 10 days ago $(M=9.86, S D=18.17)$, with a 
range from 0 to 103 days ago. ${ }^{11}$ Finally, participants' average reported severity of the transgression was somewhat severe $(M=3.69, S D=1.82)$.

All three variables were highly correlated with forgiveness at Time 1 , such that participants were more forgiving when they reported higher relationship quality, transgressions that occurred further in time, and transgressions that were less severe in nature (see Table 7).

\section{SEM Analyses}

For the SEM analyses, we first report tests of the indirect effects model as in the previous two studies. Given the small sample size, we did not test the full effects model because, with the added measures of forgiveness, it would involve too many variables. Thus, we only tested the indirect effects model. Only participants who completed the questionnaire at all four time points (60 participants) were included in the SEM analyses, because SEM procedures do not allow for missing data. Table 7 presents the internal consistencies and zero-order correlations at Time 1, and Table 8 presents the descriptive statistics for the variables in our model at each of the time points.

\footnotetext{
11 Analyses were conducted including all participants, participants who reported an event within the last two weeks, and participants who reported an event within the last 7 days. The findings for all three sets of analyses were similar, so we retained the full sample.
} 
Table 7

Study 3 Internal Consistency Reliabilities, Zero-Order Variable Correlations, and Descriptive Statistics at Time 1

\begin{tabular}{|c|c|c|c|c|c|c|c|c|c|c|}
\hline & Variable & 1 & 2 & 3 & 4 & 5 & 6 & 7 & 8 & Mean (SD) \\
\hline 1. & $\begin{array}{l}\text { Composite Measure of } \\
\text { Forgiveness }\end{array}$ & .93 & $-.72 * *$ & -.20 & .09 & $.22^{+}$ & $-.56^{* *}$ & $-.29 *$ & $.65^{* *}$ & $1.37(.97)$ \\
\hline 2. & Feelings of discrepancy & & .89 & $.44 * *$ & .07 & -.12 & $.68^{* *}$ & .17 & $-.42^{*}$ & $4.21(1.59)$ \\
\hline 3. & Need to resolve & & & .92 & $.43 *$ & $.21^{+}$ & $.43^{*}$ & .12 & .16 & $5.33(1.49)$ \\
\hline 4. & Extent of discussion & & & & .78 & .06 & $.24^{+}$ & .17 & $.45^{* *}$ & $4.27(1.70)$ \\
\hline 5. & $\begin{array}{l}\text { Deliberate self- } \\
\text { persuasion strategies }\end{array}$ & & & & & .77 & -.31 & .01 & .02 & $3.11(.53)$ \\
\hline 6. & Severity & & & & & & - & $.23^{+}$ & $-.22^{+}$ & $3.78(1.91)$ \\
\hline 7. & Days since transgression & & & & & & & - & -.12 & $8.23(15.56)$ \\
\hline 8. & Relationship quality & & & & & & & & .97 & $5.85(.88)$ \\
\hline
\end{tabular}

Note. $* * p<.001 . * p<.05 .{ }^{+} p<.10 . \mathrm{N}=60$. 
Table 8

Study 3 Variable Descriptive Statistics at Time 1, 2, 3, and 4

\begin{tabular}{|c|c|c|c|c|}
\hline Variable & T1 Mean (SD & T2 Mean (SD) & $\begin{array}{l}\text { T3 Mean } \\
\text { (SD) }\end{array}$ & T4 Mean (SD) \\
\hline 1. Forgiveness & $1.37(.97)$ & $1.52(1.11)$ & $1.54(1.19)$ & $1.59(1.33)$ \\
\hline $\begin{array}{l}\text { 2. Feelings of } \\
\text { discrepancy }\end{array}$ & $4.21(1.59)$ & $3.31(1.40)$ & $2.87(1.51)$ & $2.67(1.48)$ \\
\hline 3. Need to resolve & $5.33(1.49)$ & $4.77(1.54)$ & $4.22(1.86)$ & $3.88(1.92)$ \\
\hline 4. Extent of discussion & $4.27(1.70)$ & $3.89(1.71)$ & $2.82(1.92)$ & $2.63(2.02)$ \\
\hline $\begin{array}{l}\text { 5. Deliberate self- } \\
\text { persuasion strategies }\end{array}$ & $3.11(.53)$ & $3.22(.51)$ & $3.13(.67)$ & $3.01(.73)$ \\
\hline $\begin{array}{l}\text { 6. Degree of } \\
\text { involvement }\end{array}$ & & $5.70(1.71)$ & $5.63(1.86)$ & $5.43(2.29)$ \\
\hline
\end{tabular}

Note. $\mathrm{N}=60$. 
Tests of the indirect model. We examined whether feelings of discrepancy, need to resolve, extent of discussion and use of strategies at Time 1 would predict changes in forgiveness over time. We tested the indirect effects model, which was the same as in Studies 1 and 2, but we also added forgiveness measured at the later time points into the model. Because of the small sample size, we averaged forgiveness responses at Times 2, 3, and 4. Thus, the model consisted of feelings of discrepancy, need to resolve, discussion, strategies, and forgiveness all measured at Time 1, and later forgiveness (average of forgiveness at Times 2,3, and 4). A test of the indirect effects model indicated that it explained the data poorly, $\chi^{2}(7)=54.27, p<.001, \mathrm{CFI}=.60$, $\mathrm{NNFI}=.14$, and RMSEA $=.34(90 \% \mathrm{CI}: .26, .42)$. The variables in the model explained $6 \%$ of the variance in Time 1 forgiveness and $55 \%$ of the variance in later forgiveness.

Next, we tested the indirect effects model again with perceived transgression severity, time since the transgression, and relationship quality partialed out of all variables in the model (see Table 9 for the partial correlations among the variables in the model). Thus, the unstandardized residual for each of the variables was used to test the model. The results indicated that the indirect effects model was a poor fit, $\chi^{2}(7)=22.89$, $p=.002, \mathrm{CFI}=.67, \mathrm{NNFI}=.29$, and RMSEA $=.19(90 \% \mathrm{CI}: .11, .29)$. The variables in the model explained $11 \%$ of the variance in Time 1 forgiveness and $26 \%$ of the variance in later forgiveness. All of the paths in the model were significant except for two paths: the path from discussion to Time 1 forgiveness and the path from discussion to later forgiveness. This model is presented in Figure 7. 
Table 9

Study 3 Partial Correlations Controlling for Severity, Relationship Quality, and Days

Since Transgression at Time 1

\begin{tabular}{|c|c|c|c|c|c|}
\hline Variable & 1 & 2 & 3 & 4 & 5 \\
\hline 1. Forgiveness & .93 & $-.42 * *$ & -.01 & .05 & .15 \\
\hline 2. Feelings of discrepancy & & .89 & $.36^{* *}$ & .00 & .10 \\
\hline 3. Need to resolve & & & .90 & $.26^{*}$ & $.27 *$ \\
\hline 4. Extent of discussion & & & & .78 & .04 \\
\hline $\begin{array}{l}\text { 5. Deliberate self- } \\
\text { persuasion strategies }\end{array}$ & & & & & .77 \\
\hline
\end{tabular}

Note. Coefficient alpha internal consistency estimates appear along the diagonal, and the correlation between variables appear above the diagonal.

$* * p<.001 . * p<.05 .{ }^{+} p<.10$.

${ }^{12}$ For the Time 1 data, we examined whether the various individual strategies correlated with Time 1 forgiveness, controlling for severity, days since the transgression, and relationship quality. As in Study 2, strategies that were assessed with more than one item were aggregated. Results showed that suppression, concentration, and changing dimensions were positively correlated with forgiveness, $p$ s $<.01$. None of the other strategies were significantly correlated with forgiveness at Time 1. Partial correlations between Time 1 strategies and later forgiveness showed that all of the strategies were positively correlated with later forgiveness, all $p$ s $<.05$, except for distraction, suppression, motivated interpretations, and motivated integration, which were not correlated with later forgiveness, $p s>.05$. Thus, some of the strategies may promote forgiveness immediately, whereas other strategies may not be useful right away but accrue benefits over time. 


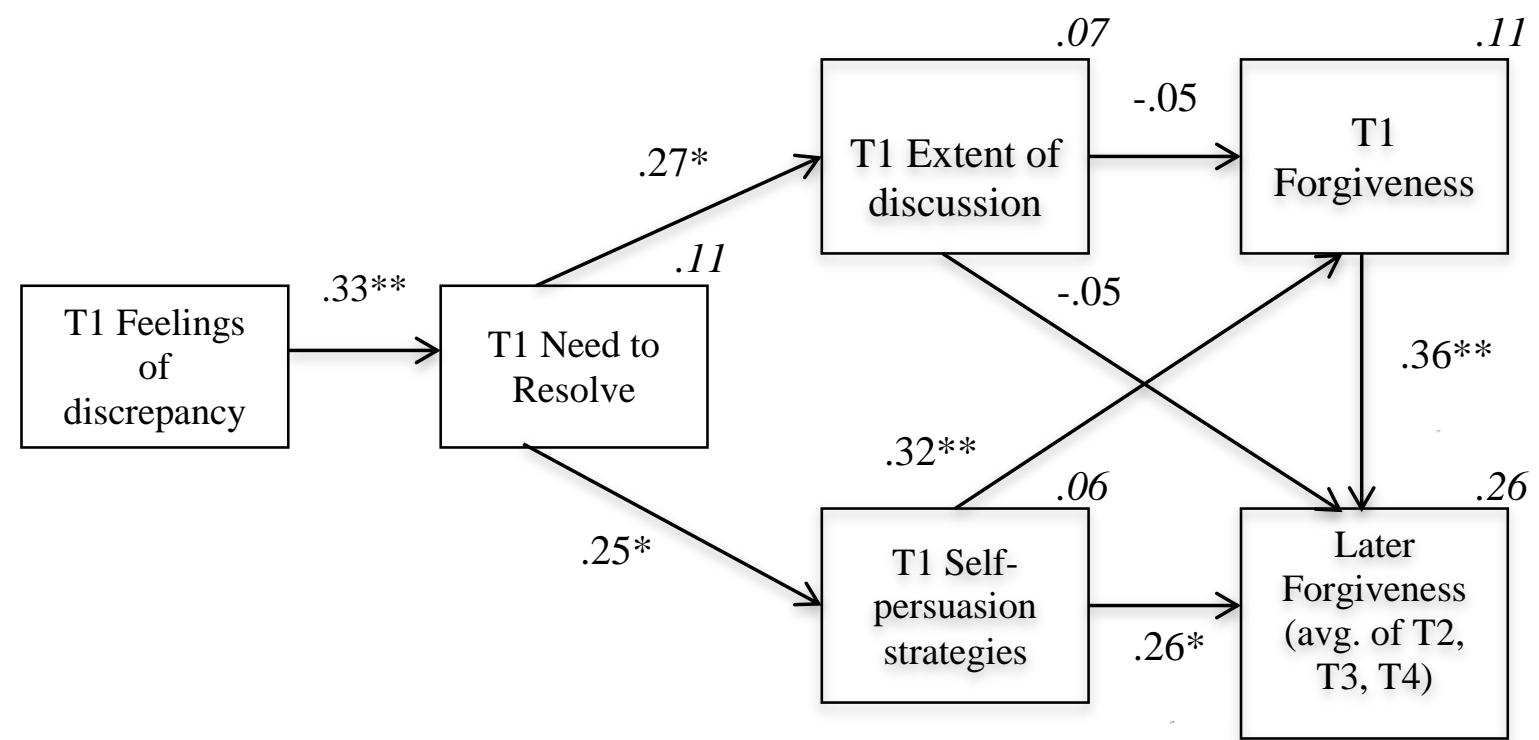

Figure 7. Indirect model for Study $3, \chi^{2}(7)=22.89, p=.002, \mathrm{CFI}=.67, \mathrm{NNFI}=.29$, and RMSEA $=.19(90 \% \mathrm{CI}: .11, .29)$. The model controls for time since the transgression, perceived relationship quality, and perceived transgression severity. Rectangles represent measured variables (error terms are excluded from the figure for simplicity). Italicized values on the endogenous variables represent the percentage of variance explained by predictors in the variable (squared multiple correlations). Path coefficients are the standardized regression weights. $* * p<.01 . * p=.05$. 
Modification indices suggested the addition of a single path from feelings of discrepancy to Time 1 forgiveness. The addition of this path produced a model that explained the data well, $\chi^{2}(6)=6.85, p=.335, \mathrm{CFI}=.98, \mathrm{NNFI}=.96$, and $\mathrm{RMSEA}=.05$ $(90 \%$ CI: <.001, .18). Again all of the paths were significant except for the path from discussion to Time 1 forgiveness and the path from discussion to later forgiveness. The variables in the model explained $28 \%$ and $24 \%$ of the variance in Time 1 forgiveness and later forgiveness, respectively. This model is presented in Figure 8.

A chi-square difference test indicated that the indirect effects model fit the data significantly worse than the modified indirect effects model, $\chi^{2}$ diff $(1)=16.04, p<.001$. Although the indirect model accounted for approximately the same amount of variance in later forgiveness as the modified model (26\% vs. $24 \%)$, the modified model accounted for more variance in forgiveness at Time 1 than the indirect model (28\% vs. $11 \%)$. Given that the indirect model fit the data significantly worse than the modified model and that the additional path from feelings of discrepancy to forgiveness at Time 1 was highly significant, the modified model seems to be the best representation of changes in forgiveness. 


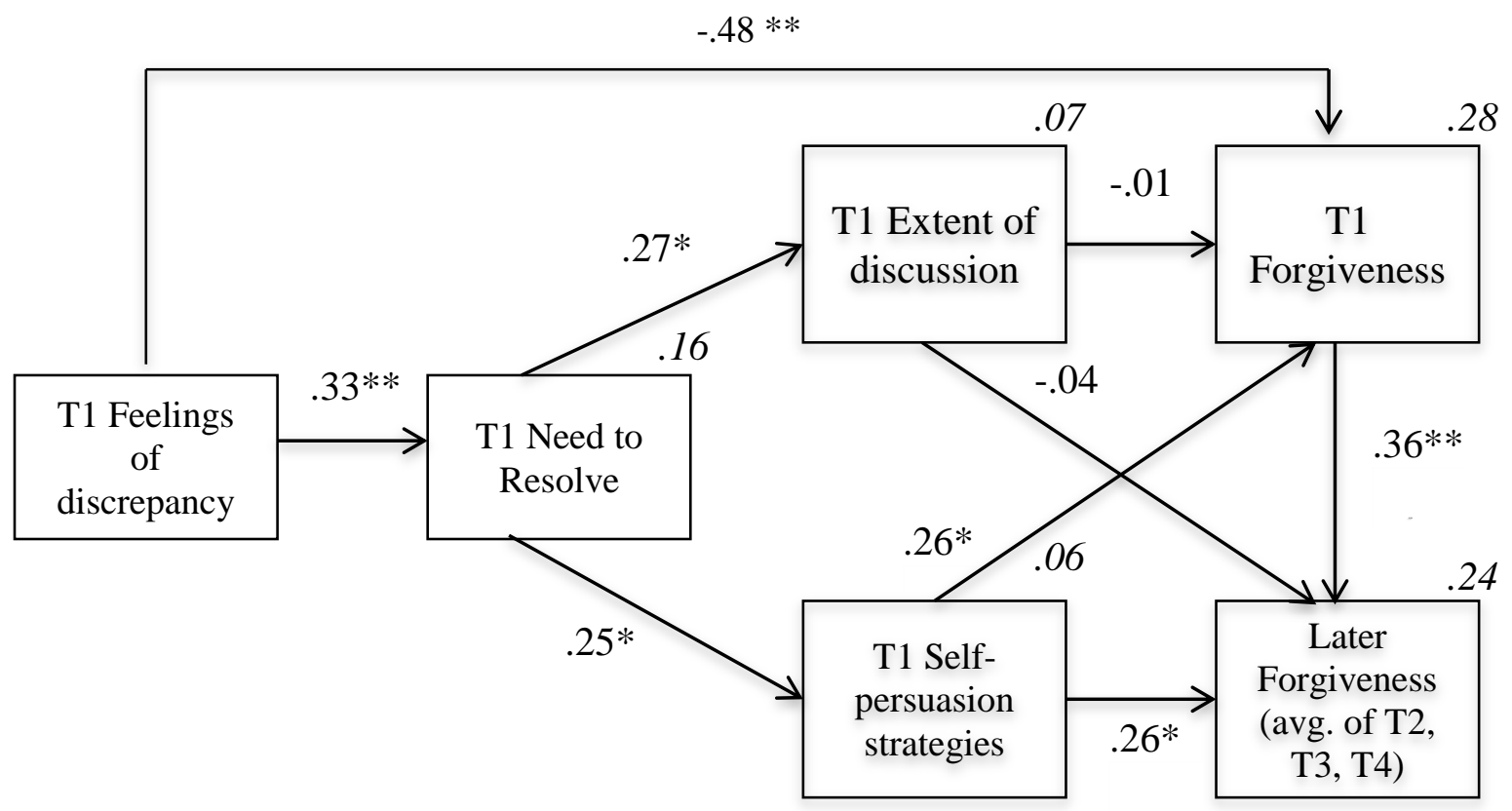

Figure 8. Modified model for Study $3, \chi^{2}(6)=6.85, p=.335, \mathrm{CFI}=.98$, NNFI $=.96$, and RMSEA $=.05(90 \% \mathrm{CI}:<.001, .18)$. The model controls for time since the transgression, perceived relationship quality, and perceived transgression severity. Rectangles represent measured variables (error terms are excluded from the figure). Italicized values on the endogenous variables represent the percentage of variance explained by predictors in the variable (squared multiple correlations). Path coefficients are the standardized regression weights.

$* * p<.01$. * $p=.05$. 
Indirect effects were tested following the recommendations of Preacher and Hayes (2008). The statistical significance of the indirect effects were computed using bootstrapping techniques. Bootstrapping is a non-parametric method in which the computer program repeatedly samples from the original dataset, usually thousands of times, using random sampling with replacement. The indirect effect is computed in each of the random samples, and a sampling distribution of the indirect effect is generated along with a confidence interval and an estimate of the indirect effect. An indirect effect is considered statistically significant at $p<.05$ if the $95 \%$ confidence interval does not include zero (i.e., the interval does not span from a negative to a positive value; see Preacher \& Hayes, 2004, 2008). Confidence intervals generated from bootstrapping offer a more accurate estimate of the indirect effect for small-to-moderate sample sizes relative to the Sobel test, which is better suited for large sample sizes with normal distributions (Shrout \& Bolger, 2002). In addition, testing indirect effects with bootstrapping allows multiple mediators to be tested simultaneously (as opposed to testing each mediator separately) as well as a comparison of the sizes of each specific indirect effect in the model (see Preacher \& Hayes, 2008). Preacher and Hayes (2008) recommend that testing multiple mediation should involve two components: first, researchers should examine the total indirect effect to see whether the set of mediators in the model transmits the effect of the predictor to the outcome variable; second, researchers should examine the indirect effect of each mediator in the model while considering the contributions of the other mediators in the model. Further, a significant total indirect effect is not necessary in order to test the specific indirect effects as it is possible to find significant specific indirect effects without a significant total indirect effect. Therefore, in the present research, it is 
possible to test whether discussion and strategies as a set of mediators account for the relation between need to resolve and forgiveness, and to test the significance of discussion and strategies as mediators separately (while controlling for the influence of the other) and comparing the magnitude of their effects. Indirect effects in the present research were tested using SPSS 19.0.

The total indirect effect from need to resolve to forgiveness at Time 1 via discussion and strategies was not significant. However, the specific indirect effect of need to resolve to forgiveness at Time 1 via strategies was significant. The indirect effect was not significant via discussion (see Table 10).

Similarly, the total indirect effect from need to resolve to later forgiveness via discussion and strategies was not significant. Again, however, the specific indirect effect of need to resolve to later forgiveness via strategies was significant. The specific indirect effect via discussion was again not significant (see Table 11). Thus, the use of selfpersuasion strategies mediated the relation from need to resolve to both Time 1 and later forgiveness. 
Table 10

Study 3 Bootstrapping Results for Tests of Indirect Effects of Need to Resolve on Forgiveness via Discussion and Strategies for Forgiveness at Time 1

\begin{tabular}{lccc}
\hline \multicolumn{1}{c}{ Indirect Effect } & $\begin{array}{c}\text { Unstandardized } \\
\text { Estimate }\end{array}$ & \multicolumn{2}{c}{$\begin{array}{c}\text { BC 95\% C.I. } \\
\text { (Unstandardized Estimate) }\end{array}$} \\
\cline { 3 - 4 } Total Indirect Effect & .0310 & -.0112 & Upper \\
Indirect effect via discussion & .0021 & -.0297 & .0518 \\
Indirect effect via strategies & .0289 & .0018 & .0934 \\
Discussion vs. strategies & .0268 & -.0134 & .0988 \\
\hline
\end{tabular}

Note. BC, bias corrected; Number of bootstrapping resamples: 5000. 
Table 11

Study 3 Bootstrapping Results for Tests of Indirect Effects of Need to Resolve on Forgiveness via Discussion and Strategies for Changes in Later Forgiveness

\begin{tabular}{lccc}
\hline \multicolumn{1}{c}{ Indirect Effect } & $\begin{array}{c}\text { Unstandardized } \\
\text { Estimate }\end{array}$ & \multicolumn{2}{c}{$\begin{array}{c}\text { BC 95\% C.I. } \\
\text { (Unstandardized Estimate) }\end{array}$} \\
\cline { 3 - 4 } & & Lower & Upper \\
\hline Total Indirect Effect & .0422 & -.0250 & .1638 \\
Indirect effect via discussion & -.0134 & -.1011 & .0243 \\
Indirect effect via strategies & .0556 & .0024 & .1811 \\
Discussion vs. strategies & .0691 & -.0040 & .2256 \\
\hline
\end{tabular}

Note. BC, bias corrected; Number of bootstrapping resamples: 5000. 
The data collected in Study 3 can also be examined using latent growth curve modeling (LGM). The SEM analyses that we reported were used to test whether the components in the deliberate self-persuasion process predict mean levels of change in forgiveness at the start of the study and later in the study (Times 2, 3, and 4). On the

other hand, LGM can capture an individual's forgiveness trajectory (intraindividual change) as well as individual differences in forgiveness trajectories (interindividual change; Acock \& Li, n.d.; Byrne, 2010; Duncan \& Duncan, 2009). In addition, predictors can also be added to latent growth curve models to examine which predictors have the greatest effects on the rate of change in levels of forgiveness. We conducted analyses using LGM to test intra- and inter-individual changes in forgiveness trajectories. The results from these analyses, however, did not add much to our current analysis of the data. Thus, we do not discuss the LGM results here, but they are presented in Appendix D.

\section{Cross-lagged Panel Correlations}

It is possible, at least theoretically, that forgiveness might encourage deliberate self-persuasion strategies - the opposite direction of influence to the one hypothesized in the current model. This alternative perspective was investigated by computing crosslagged panel correlations using repeated measures of strategies and forgiveness: Time 1 measures for strategies and forgiveness and an aggregate of Time 2, 3, and 4 measures for strategies and forgiveness. These cross-lagged correlations showed that Time 1 strategies predicted later forgiveness (controlling for Time 1 forgiveness), $\beta=.19, p=$ .04 , but Time 1 forgiveness did not predict later use of strategies (controlling for Time 1 
strategies), $\beta=-.20, p=.28$. This pattern of cross-lagged correlations provides some support for our interpretation of the deliberate self-persuasion model of forgiveness.

\section{Discussion}

The purpose of Study 3 was to examine the relations among the components of deliberate self-persuasion as interpersonal transgressions unfold. Unlike Study 1, participants in the present study nominated transgressions that, on average, occurred in the recent past. The pattern of results from the data collected at Time 1 suggested a model of forgiveness that was similar to Study 1. Feelings of discrepancy were positively related to need to resolve, and need to resolve was positively related to discussion and strategies. For forgiveness responses at Time 1, the relation between need to resolve and forgiveness was indirectly related via strategies, but not via discussion. As well, there was a direct relation between feelings of discrepancy and forgiveness, suggesting that more ambivalence was associated with less forgiveness toward the transgressor. Thus, the present study generally replicated the findings from Study 1, but there was also evidence for strategies as a mediator between need to resolve and forgiveness and a direct relation between discrepancy and forgiveness. Although greater feelings of discrepancy led to less forgiveness, when participants were motivated to resolve the discrepancy and used self-persuasion strategies to do so, more forgiveness was elicited.

Another purpose of Study 3 was to examine whether the components of deliberate self-persuasion predicted changes in forgiveness. Based on our tests of the indirect and modified indirect models, both the use of strategies and forgiveness at Time 1 predicted changes in later forgiveness (see Figures 7 and 8). This suggests that the more self- 
persuasion strategies were used and the more forgiving participants were at Time 1 , the larger their increases in forgiveness were, on average, over the course of the study.

\section{General Discussion}

\section{Summary of Findings}

The present set of studies provides some tentative but converging evidence for a deliberate self-persuasion model of forgiveness. We proposed that when people are transgressed against by someone close to them, the transgression can lead to a discrepancy between how they currently feel and how they want to feel about the close other, and that they can be motivated to resolve those feelings of discrepancy. We hypothesized that the discrepancy could be resolved interpersonally, by discussing the transgression, or intrapersonally, by engaging in a variety of mental strategies, both leading to a more desirable evaluation of the close other, which would, in turn, influence forgiving responses. Thus, we expected people's motivation to resolve the discrepancy to influence forgiving responses indirectly, via discussing the transgression and using selfpersuasion strategies.

To summarize, Study 1 examined participants' recollections of a past transgression in which their romantic partner was the transgressor. The results showed that participants who experienced greater feelings of discrepancy toward their partner after the transgression were also more motivated to resolve those feelings, and, in turn, greater need to resolve feelings of discrepancy was associated with more willingness to discuss the transgression but not more use of self-persuasion strategies. Nonetheless, participants' use of strategies, but not discussion, predicted forgiving responses, such that greater use of strategies was associated with more forgiving responses. The results 
indicated that neither talking about the transgression nor engaging in self-persuasion mediated the relation between need to resolve and forgiving responses.

In Study 2, participants imagined their responses to a hypothetical transgression committed by their romantic partner. Similar to Study 1, participants who expected to feel more discrepancy toward their partner following the transgression also expected more need to resolve those feelings. Need to resolve was in turn associated with greater likelihood of discussing the transgression with their partner, but not with the use of selfpersuasion strategies, and neither discussion nor strategies mediated the relation between resolve and forgiving responses. Once again, strategies was a significant predictor of forgiveness. The results from Study 2 also suggested that our conceptualization of forgiveness may be oversimplified, such that feelings of discrepancy and need to resolve may have not only indirect effects on forgiveness, but direct effects as well. In addition, feelings of discrepancy may affect forgiveness independently from motivation to resolve those feelings.

In Study 3, participants reported, over a three-week period, their reactions to a current transgression committed by their romantic partner. The results from participants' initial responses (at Time 1) showed that greater feelings of discrepancy due to the transgression were associated with more need to resolve those feelings. In turn, more need was associated with more discussion of the transgression and with more use of deliberate self-persuasion strategies. Additionally, although discussion did not predict forgiveness, self-persuasion strategies predicted forgiveness and significantly mediated the relation between need to resolve and forgiveness. The results also indicated that feelings of discrepancy may be negatively associated with forgiveness without mediation 
by the motivation to resolve the discrepancy. Finally the results from the tests of the modified indirect model showed that participants' initial use of strategies, but not discussion, was associated with significant increases in forgiving responses later in the study.

\section{Contributions and Implications}

The primary goal of the present research was to examine a deliberate selfpersuasion model of forgiveness - that is, whether people can convince themselves to forgive someone who transgressed against them. The results from the present studies support the idea that after people are hurt by their romantic partners, they can be aware of feelings of discrepancy toward their partner and can feel a need to resolve the discrepancy - factors that are hypothesized to be necessary for deliberate self-persuasion to occur (see Maio \& Thomas, 2007). However, even when people are motivated to resolve their ambivalent attitudes toward their partner, they may not necessarily engage in deliberate self-persuasion strategies, but may use other tactics, such as talking to their partner about the transgression.

In Studies 1 and 2, participants recalled a past transgression and imagined a hypothetical scenario, respectively, in which their romantic partner transgressed against them. In both studies, there was no significant relation between need to resolve and the use of deliberate self-persuasion strategies, but there was a significant relation between need to resolve and discussion. Perhaps Study 1 involved transgressions that happened long enough in the past that participants had difficulty recalling their use of deliberate self-persuasion strategies, whereas it was easier for them to recall conversations with

their partner. In Study 2, the hypothetical nature of the transgression may have elicited 
self-focused goals, which occur immediately after the transgression and often involve affective reactions, rather than relationship-focused goals, which occur after some passage of time and involve pro-relationship motivations (e.g., via self-persuasion).

In contrast, Study 3 instructed participants to think about a current transgression. At Time 1, the more participants expressed a need to resolve the transgression, the more they discussed the transgression with their partner and the more they reported using selfpersuasion strategies. Perhaps the latter finding reflected that people were actually working through the transgression when they completed the questionnaires, which made it easier for them to recall their use of deliberate self-persuasion strategies (unlike Study 1, where participants recalled transgressions further back in the past). Also, the timing of the transgression in Study 3 (within the past week) may have provided sufficient time for our participants to shift from self-focused to relationship-focused goals, thereby activating self-persuasion strategies (unlike the hypothetical situation in Study 2, which may have elicited self-focused goals).

Importantly, across all three studies, strategies consistently predicted forgiving responses. This consistent relation between use of self-persuasion strategies and forgiveness is encouraging for a self-persuasion perspective on forgiveness. It is interesting that reported discussion of the transgression did not predict forgiveness in any study, which implies that people's decisions to forgive were not based so much on their discussions with their partner as on how they perceived the transgression and their partner (resulting from self-persuasion strategies). It should also be noted, however, that the measures of discussion in the present studies assessed the quantity of discussion rather than the quality of that discussion (e.g., whether participants had discussed the 
transgression, rather than the constructiveness of the discussion). Perhaps quality is more important than quantity, and different measures would provide more support for the benefits of discussion in the forgiveness process.

Study 3 examined whether the use of self-persuasion strategies was associated with changes in forgiveness over time. In our tests of the indirect and modified indirect models, the results demonstrated that participants' initial use of strategies (at Time 1) was associated with greater increases in later forgiveness of their partner (average of forgiveness at Times 2, 3, and 4), holding constant forgiveness at Time 1 . This finding is also encouraging for a self-persuasion perspective on forgiveness.

To our knowledge, this is the first set of studies to empirically test a deliberate self-persuasion model of forgiveness. The findings from the present research extend the forgiveness literature by presenting a different conceptualization of forgiveness. Researchers have discussed what forgiveness entails, such as victims' letting go of their resentment and negative feelings toward the perpetrator, and what forgiveness does not entail, such as excusing or condoning (e.g., Aquino et al., 2003). However, the present research suggests that forgiveness may be dependent, in part, on individuals' need to resolve the discrepancy between their current feelings toward the transgressor and how they want to feel about the transgressor, mediated by the use of deliberate selfpersuasion. Specifically, in Study 3, stronger need to resolve the discrepancy was associated with greater use of deliberate self-persuasion strategies, which in turn was associated with greater immediate and delayed forgiveness of the perpetrator. 
We have provided some evidence that one way to satisfy the need to resolve feelings of discrepancy is by using self-persuasion strategies. However, other strategies may serve a similar purpose. For example, interventions that have typically been used to promote forgiveness have tended to focus on empathy or self-enhancement (for a review, see Lundahl, Taylor, Stevenson, \& Roberts, 2008; see also McCullough et al., 1997; Sandage \& Worthington, 2010). Empathy-focused interventions ask victims to think about instances when they have been hurt by someone and to think about the lessons they learned from the transgressions. Then they are asked to think about instances in which they were the perpetrator of a harm and have been forgiven by the victim, which is intended to elicit feelings of gratitude and humility, so they might forgive their own perpetrator. Self-enhancement interventions ask victims to focus on the personal benefits of forgiveness, such as improving their social life, their relationship with the perpetrator, and their emotional and physical health. Both of these types of interventions fit with our analysis of forgiveness, in that victims are encouraged to use strategies that might reduce the discrepancy between their current and desired attitudes towards their transgressor.

\section{Limitations and Directions for Future Research}

In the present research, our attempts to demonstrate causal effects of feelings of discrepancy and need to resolve on the mediators (i.e., discussion and strategies) and outcome variables (i.e., forgiveness) were unsuccessful. Thus, our correlational results are open to alternative interpretations involving different causal paths. For example, the reverse causal path is plausible: perhaps people's feelings of discrepancy and need to resolve those feelings are dependent, at least in part, on the extent to which they have already forgiven the perpetrator for the harm. In future studies, we plan to develop more 
effective experimental manipulations of feelings of discrepancy and need to resolve to provide more direct support for our model. However, it may be the case that feelings of discrepancy and need to resolve are difficult to manipulate, especially when it comes to interpersonal harms. People's recollections of such harms may elicit strong emotional experiences that make it difficult to reduce feelings of discrepancy toward the transgressor. Further, most people may be highly motivated to resolve feelings of discrepancy when the transgressor is close to them, which could work against attempted manipulations of need to resolve.

In the current studies, we inquired about the extent to which participants discussed the transgression with their partner and used deliberate self-persuasion strategies as ways of resolving their ambivalent feelings toward their partner. However, individuals may use other strategies, and there may be other factors that can reduce the discrepancy between current and desired attitudes to promote forgiveness of the perpetrator. For example, as discussed earlier, people can increase their empathy towards their partner or think about how forgiveness benefits themselves (e.g., McCullough et al., 1997; Sandage \& Worthington, 2010). Further, our current studies examined only one interpersonal factor that could influence forgiveness: the extent to which participants discussed the transgression with their partner. Other interactions between the victim and the perpetrator are also potentially important, such as the extent to which the perpetrator made amends or sincerely apologized for the harm, or interactions between the victim and third parties, which can lead to more desirable attitudes toward the perpetrator. In future research, we plan to examine how these other strategies and interpersonal factors can influence the extent to which people use deliberate self-persuasion strategies. 
Finally, it would be interesting to examine whether our model of forgiveness applies to other types of close relationships. Our studies focused exclusively on transgressions within romantic relationships, but the model could potentially extend to other close relationships (e.g., friends and family members). There may be differences in the extent to which individuals engage in deliberate self-persuasion based on the relationship type. For example, relationships that are difficult to end (e.g., parent-child relationships) may be especially likely to elicit self-persuasion strategies following a transgression.

\section{Conclusions}

In romantic relationships, individuals often make themselves vulnerable by attaching their needs and goals to the goodwill of their partners. Inevitably, there will be times when partners fail to meet the expectations of individuals, and these instances can lead to feelings of ambivalence toward the partner. The current research provides insight into how individuals can resolve these feelings of ambivalence in order to facilitate forgiveness. Our findings are compatible with the idea that individuals can sometimes resolve these ambivalent feelings by using deliberate self-persuasion strategies-tactics that can help individuals reach their desired attitudes about their partner- to promote forgiveness. Although our research leaves many unanswered questions, it is a first step in exploring deliberate self-persuasion in the forgiveness process. 


\section{References}

Acock, A. C., \& Li, F. (n.d.). Latent growth curve analysis: A gentle introduction. Retrieved from: http://oregonstate.edu/dept/hdfs/papers/lgcgeneral.pdf

Albert, S. (1977). Temporal comparison theory. Psychological Review, 84, 485-503.

Aquino, K., Grover, S. L., Goldman, B., \& Folger, R. (2003). When push doesn't come to shove: Interpersonal forgiveness in workplace relationships. Journal of Management Inquiry, 12, 209-216.

Aronson, E. (1999). The power of self-persuasion. American Psychologist, 54, 875-884.

Aronson, E., \& Mills, J. (1959). The effect of severity of initiation on liking for a group. The Journal of Abnormal and Social Psychology, 59, 177-181.

Ashton, M. C., Paunonen, S. V., Helmes, E., \& Jackson, D. N. (1998). Kin altruism, reciprocal altruism, and the Big Five personality factors. Evolution and Human Behavior, 19, 243-255.

Baron, R. M. \& Kenny, D. A. (1986). The moderator-mediator variable distinction in social psychological research: Conceptual, strategic and statistical considerations. Journal of Personality and Social Psychology, 51, 1173-1182.

Baumeister, R. F., Stillwell, A. M., \& Heatherton, T. F. (1995). Personal narratives about guilt: Role in action control and interpersonal relationships. Basic and Applied Social Psychology, 17, 173-198.

Baumeister, R. F., Stillwell, A., \& Wotman, S. R. (1990). Victim and perpetrator accounts of interpersonal conflict: Autobiographical narratives about anger. Journal of Personality and Social Psychology, 59, 994-1005.

Bentler, P. M. \& Bonett, D. G. (1980). Multivariate analysis with latent variables: Causal modeling. Annual Review of Psychology, 31, 419-456. 
Berry, J. W., Worthington, E. L., Jr., Parrott, Les, III, O'Connor, L. E., \& Wade, N. G. (2001). Dispositional forgivingness: Development and construct validity of the Transgression Narrative Test of Forgivingness (TNTF). Personality and Social Psychology Bulletin, 27, 1277-1290.

Boon, S. D., \& Sulsky, L. M. (1997). Attributions of blame and forgiveness in romantic relationships: A policy-capturing study. Journal of Social Behavior \& Personality, $12,19-44$.

Bradfield, M., \& Aquino, K. (1999). The effects of blame attributions and offender likeableness on forgiveness and revenge in the workplace. Journal of Management, $25,607-631$.

Brown, R. P. (2003). Measuring individual differences in the tendency to forgive: Construct validity and links with depression. Personality and Social Psychology Bulletin, 29, 759-771.

Browne, M. W. \& Cudeck, R. (1992). Alternative ways of assessing model fit. Sociological Methods and Research, 21, 230-258.

Burnette, J. L., Davis, D. E., Green, J. D., Worthington, E. L., Jr., \& Bradfield, E. (2009). Insecure attachment and depressive symptoms: The mediating role of rumination, empathy, and forgiveness. Personality and Individual Differences, 46, 276-280.

Byrne, B. M. (2010). Structural equation modeling with AMOS: Basic concepts, applications, and programming ( $2^{\text {nd }}$ ed.). New York: Routledge.

Carver, C. S., \& Scheier, M. F. (1998). On the self-regulation of behavior. New York: Cambridge University Press.

Cialdini, R. B. (1984). Influence. New York: William Morrow and Company. 
Collins, N. L. (1996). Working models of attachment: Implications for explanation, emotion, and behavior. Journal of Personality and Social Psychology, 71, 810-832.

Coyle, C. T., \& Enright, R. D. (1997). Forgiveness intervention with postabortion men. Journal of Consulting and Clinical Psychology, 65, 1042-1046.

Duncan, T. E., \& Duncan, S. C. (2009). The ABC's of LGM: An introductory guide to latent growth curve modeling, Social and Personality Psychology Compass, 3, 979991.

Fagenson, E. A., \& Cooper, J. (1987). When push comes to power: A test of power restoration theory's explanation for aggressive conflict escalation. Basic and Applied Social Psychology, 8, 273-293.

Fan, X., Thompson, B. \& Wang, L. (1999). Effects of sample size, estimation methods, and model specification on structural equation modeling fit indexes. Structural Equation Modeling, 6, 56-83.

Festinger, L. (1962). A theory of cognitive dissonance. Stanford, CA: Stanford University Press.

Fincham, F. D. (2000). Family violence: A challenge for behavior therapists. Behavior Therapy, 31, 685-693.

Fincham, F. D. (2000). The kiss of the porcupines: From attributing responsibility to forgiving. Personal Relationships, 7, 1-23.

Finkel, E. J., Rusbult, C. E., Kumashiro, M., \& Hannon, P. A. (2002). Dealing with betrayal in close relationships: Does commitment promote forgiveness? Journal of Personality and Social Psychology, 82, 956-974. 
Fletcher, G. J. O., Simpson, J. A., \& Thomas, G. (2000a). Ideals, perceptions, and evaluations in early relationship development. Journal of Personality and Social Psychology, 79, 933-940.

Fletcher, G. J. O., Simpson, J. A., \& Thomas, G. (2000b). The measurement of perceived relationship quality components: A confirmatory factor analytic approach. Personality and Social Psychology Bulletin, 26, 340-354.

Freedman, S. R., \& Enright, R. D. (1996). Forgiveness as an intervention goal with incest survivors. Journal of Consulting and Clinical Psychology, 64, 983-992.

Gonzales, M. H., Manning, D. J., \& Haugen, J. A. (1992). Explaining our sins: Factors influencing offender accounts and anticipated victim responses. Journal of Personality and Social Psychology, 62, 958-971.

Gottman, J. M. (1994). What predicts divorce? The relationship between marital processes and marital outcomes. Hillsdale, NJ, England: Lawrence Erlbaum Associates, Inc.

Hannon, P. A., Rusbult, C. E., Finkel, E. J., \& Kamashiro, M. (2010). In the wake of betrayal: Amends, forgiveness, and the resolution of betrayal. Personal Relationships, 17, 253-278.

Higgins, E. T., \& Spiegel, S. (2004). Promotion and prevention strategies for selfregulation: A motivated cognition perspective. In R. F. Baumeister \& K. D. Vohs (Eds.), Handbook of self-regulation: Research, theory, and applications (pp. 171187). New York: Guilford.

Hilton, D. J. (1990). Conversational processes and causal explanation. Psychological Bulletin, 107, 65-81. 
Kachadourian, L. K., Fincham, F., \& Davila, J. (2005). Attitudinal Ambivalence,

Rumination, and Forgiveness of Partner Transgressions in Marriage. Personality and Social Psychology Bulletin, 31, 334-342.

Kammrath, L., \& Dweck, C.S. (2006). Voicing conflict: Preferred conflict strategies among incremental and entity theorists. Personality and Social Psychology Bulletin, $32,1497-1508$.

Karremans, J. C., Van Lange, P. A. M., Ouwerkerk, J. W., \& Kluwer, E. S. (2003). When forgiving enhances psychological well-being: The role of interpersonal commitment. Journal of Personality and Social Psychology, 84, 1011-1026.

Kearns, J. N., \& Fincham, F. D. (2005). Victim and Perpetrator Accounts of Interpersonal Transgressions: Self-Serving or Relationship-Serving Biases? Personality and Social Psychology Bulletin, 31, 321-333.

Kelley, H. H., Holmes, J. G., Kerr, N. L., Reis, H. T., Rusbult, C. E., \& Van Lange, P. A. M. (2003). An atlas of interpersonal situations. New York: Cambridge University Press.

Kelley, H. H., \& Thibaut, J. W. (1978). Interpersonal relations: A theory of interdependence. New York: Wiley.

Knudson, R. M., Sommers, A. A., \& Golding, S. L. (1980). Interpersonal perception and mode of resolution in marital conflict. Journal of Personality and Social Psychology, $38,751-763$.

Kremer, J. F., \& Stephens, L. (1983). Attributions and arousal as mediators of mitigation's effect on retaliation. Journal of Personality and Social Psychology, 45, 335-343. 
Leary, M. R., Springer, C., Negel, L., Ansell, E., \& Evans, K. (1998). The causes, phenomenology, and consequences of hurt feelings. Journal of Personality and Social Psychology, 74, 1225-1237.

Lundahl, B. W., Taylor, M. J., Stevenson, R., \& Roberts, K. D. (2008). Process-based forgiveness interventions: A meta-analytic review. Research on Social Work Practice, 18, 465-478.

Maio, G. R., Fincham, F. D., \& Lycett, E. J. (2000). Attitudinal ambivalence toward parents and attachment style. Personality and Social Psychology Bulletin, 26, 14511464.

Maio, G. R., \& Thomas, G. (2007). The Epistemic-Teleologic Model of Deliberate SelfPersuasion. Personality and Social Psychology Review, 11, 1-22.

Maio, G. R., Thomas, G., Fincham, F. D., \& Carnelley, K. B. (2008). Unraveling the role of forgiveness in family relationships. Journal of Personality and Social Psychology, 94(2), 307-319.

McCullough, M. E. (2001). Forgiveness: Who does it and how do they do it? Current Directions in Psychological Science, 10, 194-197.

McCullough, M. E., Fincham, F. D., \& Tsang, J. (2003). Forgiveness, forbearance, and time: The temporal unfolding of transgression-related interpersonal motivations. Journal of Personality and Social Psychology, 84, 540-557.

McCullough, M. E., \& Hoyt, W. T. (2002). Transgression-related motivational dispositions: Personality substrates of forgiveness and their links to the Big Five. Personality and Social Psychology Bulletin, 28, 1556-1573. 
McCullough, M. E., Rachal, K. C., Sandage, S. J., Worthington, E. L., Jr., Brown, S. W., \& Hight, T. L. (1998). Interpersonal forgiving in close relationships: II. Theoretical elaboration and measurement. Journal of Personality and Social Psychology, 75, 1586-1603.

McCullough, M. E., \& Root, L. M. (2005). Forgiveness as change. In E. L. Worthington, Jr. (Ed.), Handbook of forgiveness (pp. 91-107). New York: Routledge.

McCullough, M. E., Root, L. M., \& Cohen, A. D. (2006). Writing about the benefits of an interpersonal transgression facilitates forgiveness. Journal of Consulting and Clinical Psychology.Special Issue: Benefit-Finding, 74, 887-897.

McCullough, M. E., Worthington, E. L., Jr., \& Rachal, K. C. (1997). Interpersonal forgiving in close relationships. Journal of Personality and Social Psychology, 73, 321-336.

McNulty, James K. (2011). The dark side of forgiveness: The tendency to forgive predicts continued psychological and physical aggression in marriage. Personality and Social Psychology Bulletin, 37(6), 770-783.

McNulty, James K. (2010). When positive processes hurt relationships. Current Directions in Psychological Science, 19(3), 167-171.

Murray, S. L. (1999). The quest for conviction: Motivated cognition in romantic relationships. Psychological Inquiry, 10, 23-34.

Murray, S. L., \& Holmes, J. G. (1993). Seeing virtues in faults: Negativity and the transformation of interpersonal narratives in close relationships. Journal of Personality and Social Psychology, 65, 707-722. 
Neff, L. A., \& Karney, B. R. (2003). The Dynamic Structure of Relationship Perceptions: Differential Importance as a Strategy of Relationship Maintenance. Personality and Social Psychology Bulletin, 29, 1433-1446.

Ohbuchi, K., Kameda, M., \& Agarie, N. (1989). Apology as aggression control: Its role in mediating appraisal of and response to harm. Journal of Personality and Social Psychology, 56, 219-227.

Olson, J. M., \& Stone, J. (2005). The influence of behavior on attitudes. In D. Albarracin, B. T. Johnson, \& M. P. Zanna (Eds.), Handbook of attitudes and attitude change (pp. 223-271). Mahwah, NJ: Erlbaum.

Petty, R. E., \& Wegener, D. T. (1999). The elaboration likelihood model: Current status and controversies. In S. Chaiken, \& Y. Trope (Eds.), Dual-process theories in social psychology. (pp. 37-72). New York: Guilford Press.

Pratkanis, A. R., \& Aronson, E. (1992). Age of propaganda: The everyday use and abuse of persuasion. New York: W H Freeman/Times Books/ Henry Holt \& Co.

Preacher, K. J., \& Hayes, A. F. (2008). Asymptotic and resampling strategies for assessing and comparing indirect effects in multiple mediator models. Behavior Research Methods, 40, 879-891.

Preacher, K. J., \& Hayes, A. F. (2004). SPSS and SAS procedures for estimating indirect effects in simple mediation models. Behavior Research Methods, Instruments, and Computers, 36, 717-731.

Pronk, T. M., Karremans, J. C., Overbeek, G., Vermulst, A. A., \& Wigboldus, D. H. J. (2010). What it takes to forgive: When and why executive functioning facilitates forgiveness. Journal of Personality and Social Psychology, 98, 119-131. 
Rusbult, C. E., Hannon, P. A., Stocker, S. L., \& Finkel, E. J. (2005). Forgiveness and relational repair. In E. L. Worthington, Jr. (Ed.), Handbook of forgiveness (pp. 185206). New York: Routledge.

Rusbult, C. E., \& Van Lange, P. A. M. (2003). Interdependence, interaction and relationships. Annual Review of Psychology, 54, 351-375.

Sandage, S. J., \& Worthington, E. L., Jr. (2010). Comparison of two group interventions to promote forgiveness: Empathy as a mediator or change. Journal of Mental Health Counseling, 32, 35-57.

Sandage, S. J., \& Worthington, E. L., Jr. (2010). Comparison of two group interventions to promote forgiveness: Empathy as a mediator of change. Journal of Mental Health Counseling, 32, 35-57.

Sanitioso, R., Kunda, Z., \& Fong, G.T. (1990). Motivated recall of autobiographical memories. Journal of Personality and Social Psychology, 59, 229-241.

Shapiro, D. L. (1991). The effects of explanations on negative reactions to deceit. Administrative Science Quarterly, 36, 614-630.

Shrout, P. E., \& Bolger, N. (2002). Mediation in experimental and nonexperimental studies: New procedures and recommendations. Psychological Methods, 7, 422-445.

Simpson, J. A., Ickes, W., \& Blackstone, T. (1995). When the head protects the heart: Empathic accuracy in dating relationships. Journal of Personality and Social Psychology, 69, 629-641.

Smolen, R. C., \& Spiegel, D. A. (1987). Marital locus of control as a modifier of the relationship between the frequency of provocation by spouse and marital satisfaction. Journal of Research in Personality, 21, 70-80. 
Soanes, C., \& Stevenson, A. (Eds.). (2008). Concise Oxford English Dictionary $\left(11^{\text {th }}\right.$ edition). New York: Oxford Universtiy Press.

Stillwell, A. M., \& Baumeister, R. F. (1997). The construction of victim and perpetrator memories: Accuracy and distortion in role-based accounts. Personality and Social Psychology Bulletin, 23, 1157-1172.

Tangney, J. P., Wagner, P. E., Hill-Barlow, D., Marschall, D. E., \& Gramzow, R. (1996). Relation of shame and guilt to constructive versus destructive responses to anger across the lifespan. Journal of Personality and Social Psychology, 70, 797-809.

Thibaut, J. W., \& Kelley, H. H. (1959). The social psychology of groups. New York: Wiley.

Van Lange, P. A. M., \& Rusbult, C. E. (1995). My relationship is better than-and not as bad as-yours is: The perception of superiority in close relationships. Personality and Social Psychology Bulletin, 21, 32-44.

Wegner, D. M., Erber, R., \& Zanakos, S. (1993). Ironic processes in the mental control of mood and mood-related thought. Journal of Personality and Social Psychology, 65, 1093-1104.

Zechmeister, J. S., \& Romero, C. (2002). Victim and offender accounts of interpersonal conflict: Autobiographical narratives of forgiveness and unforgiveness. Journal of Personality and Social Psychology, 82, 675-686. 
Appendices

Appendix A: Measures for Study 1

Manipulation Check for Transgression Severity

1. How severe was the offense your partner committed?

$(1=$ not severe at all, $7=$ extremely severe $)$

2. How serious was the offense your partner committed?

$(1=$ not serious at all, $7=$ extremely serious $)$

3. How painful was the offense your partner committed?

$(1=$ not painful at all, $7=$ extremely painful $)$

4. How harmful was the offense your partner committed?

$(1=$ not harmful at all, 7 = extremely harmful $)$

\section{Forgiveness Measures}

\section{Single-Item Measure of Forgiveness}

To what extent have you forgiven your partner?

( 1 = I have not forgiven at all, $7=$ I have completely forgiven $)$ 


\section{Transgression-Related Interpersonal Motivations (TRIM) Inventory}

Below is a set of questions about the offense that your partner committed. Please indicate your current thoughts and feelings about your partner, who hurt you. Use the following scale to indicate your agreement with each of the questions.

1

Strongly disagree

Disagree

3

Neutral
4

Agree
5

Strongly agree

1. I__ll make my partner pay.

2. __ I keep as much distance between us as possible.

3. Ev__ Even though my partners' actions hurt me, I still have good will for him/her.

4. __ I wish that something bad would happen to my partner.

5. __ I live as if my partner doesn't exist, isn't around.

6. _ I I want us to bury the hatchet and move forward with our relationship.

$7 . \quad$ I _ _ _ don't trust my partner.

8. Despite what my partner did, I want us to have a positive relationship again.

9. __ I want my partner to get what he/she deserves.

10. __ I find it difficult to act warmly toward my partner.

11. __ I avoid my partner.

12. ___ Although my partner hurt me, I put the hurt aside so we could resume our relationship.

13. I'm going to get even.

14. __ I forgive my partner for what he/she did to me.

15. I I cut off the relationship with my partner.

16. I__ I have released my anger so I could work on restoring our relationship to health.

17. _ I want to see my partner hurt and miserable.

18. _ I I withdraw from my partner. 


\section{Discussion of Transgression}

1. If you and your partner discussed the transgression, who initiated the conversation? (you, partner, someone else, please specify:

2. In how much detail did you and your partner discuss the offense? $(1=$ not detailed at all, $7=$ Extremely detailed $)$

3. Did your partner apologize for the transgression? (yes, no)

\section{Feelings of Discrepancy towards Partner (FD) / Need to resolve (NR)}

How did you feel about your partner immediately after he/she committed the offense?

Please use the scale below and select the number that best represents your response.

$\begin{array}{ccccccc}1 & 2 & 3 & 4 & 5 & 6 & 7 \\ \text { Strongly } & \text { Disagree } & \begin{array}{c}\text { Disagree } \\ \text { somewhat }\end{array} & \text { Neutral } & \text { Agree } & \text { Agree } & \text { Strongly } \\ \text { somewhat } & & & \text { agree }\end{array}$

1. It It was difficult to see my partner the same way after what he/she did. (FD)

2. ___ It was stressful to have both positive and negative feelings about my partner. (FD)

3. ___ It was important to me that my partner and I talked about what happened so our relationship could get back to normal. (NR)

4. __ What my partner did really bothered me. $(F D)$

5. ___ I experienced conflicting thoughts and feelings about my partner. (FD)

6. ___ It was important for me to change things, for the better, between my partner and I. $(N R)$

7. _ I I wanted to stay away from my partner and spend time with my partner at the same time. $(F D)$

8. __ It was important to me to 'fix' the way things were between us. (NR)

9. __ It was important for me to know how our future would be affected by what happened. $(N R)$ 


\section{Deliberate Self-Persuasion Strategies}

Instructions: The following questions ask you about thoughts that you may have had immediately after the transgression. Please use the following scale to rate the extent to which you had each thought in response to the transgression.

1

2

3

Not at all
4

5

6

1. I thought about my partner's good qualities. (attitudinal concentration)

2. I thought about my partner's good qualities that were unrelated to the transgression. (attitudinal concentration)

3. I thought about times when my partner treated me well. (attitudinal concentration)

4. I tried to forget the transgression. (attitudinal suppression)

5. I tried to reinterpret the transgression in a more positive way. (motivated interpretation)

6. I tried to "put myself in my partner's shoes." (motivated hypothesis testing?) 
Appendix B: Measures for Study 2

\section{Article}

Instructions: Please read the article below carefully. After you read the article, we will ask you evaluate certain aspects about the article to understand how researchers can effectively communicate information about relationships.

As great as relationships can be, they can sometimes be a major source of our stresses when things don't run smoothly. Although problems are very common in close relationships, it's how you resolve these problems that will determine the quality of your relationship.

\section{[Low need to resolve condition]}

Dr. Sandra Fitzpatrick is a clinical psychologist who runs a private practice in New York City and is a part-time instructor in the Clinical program at New York University. She specializes in couple's therapy and meets with over 100 couples each year to help them build healthier relationships. All too frequently, Dr. Fitzpatrick sees the dangers with couples arguing about every conflict in their relationship. "Many people believe that honesty is the best policy, and sometimes this is true, but other times it's not. Sometimes, when people are dealing with issues, bringing them into the open can create tension and unhappiness in the relationship." She goes on to add, "When people feel like they have been 'hurt' by their partners, they tend to have biased perceptions of the situation. They may see the situation in a more selfcentered way and are unable to take into account situational factors that might have led to their partner's behavior. Because of this, it's often times safer to let things go and not discuss the conflict at all." Dr. Fitzpatrick and other clinicians agree that, compared with people in less healthy relationships, those who are in healthy and stable relationships have a better understanding of when to confront issues with their partners. When people can let go of conflicts, it shows that they trust their partners.

\section{[High need to resolve condition]}

Dr. Sandra Fitzpatrick is a clinical psychologist who runs a private practice in New York City and is a part-time instructor in the Clinical program at New York University. She specializes in couple's therapy and meets with over 100 couples each year to help them build healthier relationships. All too frequently, Dr. Fitzpatrick sees the dangers with couples being unable to resolve the conflicts in their relationship. "Many people believe that honesty is the best policy, and this is absolutely true. When people are dealing with issues, it is extremely important for both partners to communicate their needs and expectations to each other." She goes on to add, "When people feel like they have been 'hurt' by their partners, they tend to have biased perceptions of the situation. They may see the situation in a more self-centered way and are unable to take into account situational factors that might have led to their partner's behavior. Because of this, it's better for people to discuss their conflicts and communicate clearly with their partner, so that a similar situation does not happen in the future." Dr. Fitzpatrick and other clinicians agree that, compared with people in less healthy relationships, those who are in healthy and stable relationships are better at resolving issues with their partners. When people try to resolve conflicts, it shows that they trust their partners. 
Please rate the content of the article that you just read by answering the questions below:

1. Do you think the article is easy to understand? $(1=$ not at all, $7=$ extremely $)$

2. Do you think the article is well-written? $(1=$ not at all, $7=$ extremely $)$

3. Do you think the article is effective? $(1=$ not at all, $7=$ extremely $)$

\section{Hypothetical Scenario}

Instructions: In the next part of the study, we ask you to imagine a hypothetical scenario between you and your partner. We would like you to imagine your thoughts and feelings if you were actually in the scenario described. Your responses to the scenario will help us understand the kinds of communication styles people use in relationships.

\section{Scenario:}

Imagine that your partner offers to drop off a scholarship application for you at the post office by the deadline for submission. A week later, you get a letter from the scholarship granting agency saying that your application could not be considered because it was postmarked after the deadline and they had a very strict policy about this. Your partner said that he or she ran into old friend, went to dinner, and lost track of time. When he or she remembered the package, it was close to closing time at the post office, and he or she would have needed to rush frantically to get there; he or she decided that deadlines usually aren't that strictly enforced, so he or she waited until the next morning to deliver the package.

Please imagine carefully that this event really happened. Please read the scenario one more time and think about it carefully. 


\section{Salience Manipulation}

\section{[High salience condition]}

We would like to learn more about how you would respond to your partner if the scenario were to actually occur. Please read the statements below and indicate how much you agree with each statement using the scale below:

\begin{tabular}{|c|c|c|c|c|c|c|}
\hline 1 & 2 & 3 & 4 & 5 & 6 & 7 \\
\hline $\begin{array}{l}\text { Strongly } \\
\text { disagree }\end{array}$ & Disagree & $\begin{array}{l}\text { Disagree } \\
\text { somewhat }\end{array}$ & Neutral & $\begin{array}{c}\text { Agree } \\
\text { somewhat }\end{array}$ & Agree & $\begin{array}{c}\text { Strongly } \\
\text { agree }\end{array}$ \\
\hline
\end{tabular}

1. My partner's behaviour would be different from my expectations of him or her.

2. What I would have wanted my partner to do and what he did were very different.

3. I would believe that my partner did not work hard enough to meet my expectations.

4. I would feel more negatively toward my partner than I want to.

5. I would feel like my partner did not live up to my expectations.

6. I would feel as though my partner valued his needs more than my needs.

7. My partner would have failed to meet my standards.

8. I would feel like my partner did not do everything he or she could to help me get the scholarship application in on time.

9. I would feel like my partner did not live up to my standards of what it means to be a 'good partner.'

10. What happened would show that my partner doesn't understand my needs as well as I thought.

\section{[Low salience condition]}

We would like to learn more about your general communication style in order to understand how you interact with people in your environment. Please answer the questions below.

1. How often do you use text messaging? $(1=$ never, $7=$ very frequently $)$

2. How often do you use instant messaging? $(1=$ never, $7=$ very frequently $)$

3. How often do you use email? $(1=$ never, $7=$ very frequently $)$

4. How often do you use facebook? $(1=$ never, $7=$ very frequently $)$

5. How often do you tweet? $(1=$ never, $7=$ very frequently $)$

6. How often do you blog? $(1=$ never, $7=$ very frequently $)$

7. How often do you make phone calls from your cell phone? $(1=$ never, $7=$ very frequently $)$

8. How often do you make phone calls from a landline? $(1=$ never, $7=$ very frequently $)$

9. How often do you use a webcam for face-to-face communication? $(1=$ never, $7=$ very frequently)

10. How often do you use short forms (e.g., LOL, BRB, BTW) in your written communication? ( $1=$ never, 7 = very frequently) 


\section{Manipulation Checks: Feelings of Discrepancy towards Partner (FD) / Need to resolve (NR)}

How would you feel about your partner after you found out that your scholarship application would not be considered? Please use the scale below and select the number that best represents your response.

$\begin{array}{ccccccc}1 & 2 & 3 & 4 & 5 & 6 & 7 \\ \text { Strongly } & \text { Disagree } & \begin{array}{c}\text { Disagree } \\ \text { somewhat }\end{array} & \text { Neutral } & \text { Agree } & \text { Agree } & \text { Strongly } \\ \text { disagree } & & & \text { somewhat } & & \text { agree }\end{array}$

1. __ It would be difficult to see my partner the same way after what he/she did. $(F D)$

2. __ It would be stressful to have both positive and negative feelings about my partner. $(F D)$

3. I _ It would be important to me that my partner and I talked about what happened so our relationship could get back to normal. (NR)

4. ___ My partner's actions would really bother me. (FD)

5. I I I would experience conflicting thoughts and feelings about my partner. $(F D)$

6. I _ It would be important for me to discuss what happened with my partner in order to make things better. $(N R)$

7. _ I would want to stay away from my partner and spend time with my partner at the same time. $(F D)$

8. __ It would be important for me to 'fix' the way things are between us by talking about what happened. (NR)

9. I _ It would be important for me to know how our future would be affected by what happened. (NR)

10. __ My partner's behaviour would be different from what I expect from him or her. $(F D)$ 


\section{Deliberate Self-Persuasion Strategies}

Instructions: Below are some statements that describe how someone might react to the scenario that you imagined. Please read each statement carefully and indicate the likelihood that you would engage in each of the behaviours using the scale below:

$\begin{array}{ccccc}1 & 2 & 3 & 4 & 5 \\ \text { Never } & \text { Rarely } & \begin{array}{c}\text { About half } \\ \text { the time }\end{array} & \text { Usually } & \text { Always }\end{array}$

\section{Teleologic Strategies}

1. I would "take my mind off things" by thinking about something else. (distraction)

2. I would distract myself with other tasks to avoid thinking about what happened. (distraction)

3. I would simply try not to think about what happened. (suppression)

4. I would try to ignore what happened. (suppression)

5. I would focus on all of the good things that my partner has done for me. (concentration)

6. I would think about my partner's positive qualities. (concentration)

7. I would avoid thinking about other instances in which my partner had hurt or upset me. (preemption)

\section{Epistemic Strategies}

1. I would explain my partner's behaviour in a more positive way. (motivated interpretation)

2. I would associate my partner's behaviour with some of their positive qualities (e.g., your partner was honest for telling you why he or she wasn't able to send out your application on time). (motivated integration)

3. I would consider the situation that my partner was in at the time (i.e., running into and catching up with a good friend he or she hadn't seen in a long time) to explain his or her behaviour. (attribution to benign causal factors)

4. I would think of other instances when I asked my partner for a favour and he or she did it for me without any problems. (motivated hypothesis testing)

5. I would try to "see the good" in my partner by comparing him or her to some of my other less valued friends. (changing comparators)

6. I would try to place more emphasis on the positive qualities and less emphasis on the negative qualities of our relationship. (changing dimensions)

7. I tried to place less emphasis on the negative qualities of our relationship. (changing dimensions) 


\section{Discussion of Transgression}

1. What is the likelihood that you would confront your partner about his or her behaviour (i.e., failing to mail your application on time)? (1 = not likely at all, $7=$ extremely likely)

2. What is the likelihood that you would bring up what happened (i.e., not being considered for the scholarship) with your partner? $(1=$ not likely at all, 7 = extremely likely)

3. In how much detail would you talk to your partner about his or her behaviour (i.e., failing to mail your application on time $) ?(1=$ no detail at all, $7=$ in extreme detail $)$

\section{Forgiveness Measures}

1. To what extent would you want to forgive your partner? $(1=$ not at all, $7=$ very much $)$

2. What is the likelihood that you would actually forgive your partner? $(1=$ not likely at all, $7=$ very likely $)$

3. How long do you think it would take for you to fully forgive your partner? $(1=$ not long at all, $7=$ an extremely long time $)$

\section{Attitudinal Measure of Forgiveness}

Instructions: Please indicate the extent to which you agree with each of the statements below in response to the transgression that you imagined using the scale below.

$-3$

Strongly

disagree
$-2 \quad-1$

0

1. I would easily forgive my partner.

2. I would see my partner as positively as before.

3. I would hold a grudge against my partner.

4. ___ I would see my partner more negatively than I did before.

5. __ I would have difficulty forgiving my partner.

6. ___ I would never see my partner as positively as before he or she wronged me.

$7 . \quad$ _ _ I would not hold a grudge against my partner.

8. ___ I would not see my partner more negatively than I did before. 


\section{Transgression-Related Interpersonal Motivations (TRIM) Inventory}

Below is a set of questions about the offense that you were asked to imagine. Please indicate your current thoughts and feelings about your partner if he or she were to commit the offense you imagined. Use the following scale to indicate your agreement with each of the questions.

1

Strongly disagree
2

Disagree
3

Neutral
4

Agree
5

Strongly agree

1. I would make my partner pay.

2.___ I would keep as much distance between us as possible.

3. Even though my partner's actions hurt me, I would still have good will for him/her.

4.___ I would wish that something bad happens to my partner.

5._ I would live as if my partner doesn't exist, isn't around.

6.__ I would want us to bury the hatchet and move forward with our relationship.

$7 . \quad$ I w wouldn't trust my partner.

8.___ Despite what my partner did, I would want us to have a positive relationship again.

9.___ I would want my partner to get what he/she deserves.

10. _ I would find it difficult to act warmly toward my partner.

11.__ I would avoid my partner.

12.___ Although my partner hurt me, I would put the hurt aside so we could resume our relationship.

13.___ I would get even.

14.__ I would forgive my partner for what he/she did to me.

15.__ I would cut off the relationship with my partner.

16.___ I would have released my anger so I could work on restoring our relationship to health.

17.__ I would want to see my partner hurt and miserable.

18.__ I would withdraw from my partner.

\section{Transgression Severity}

To what extent do think the hypothetical scenario would have the potential to harm your relationship with your partner? ( $1=$ no harm at all, $7=$ extremely harmful $)$ 
Appendix C: Measures for Study 3

\section{Transgression Description}

Please provide the initials of your romantic partner.

We would like for you to describe an event in which your romantic partner wronged you within the last week. That is, we would like you to describe an interpersonal hurt or transgression committed by your partner that you experienced between 1 and 7 days ago. Try to visualize in your mind the events and the interactions you had with your partner. In your description of the event, please try to include as many details as you are comfortable providing.

Your responses to this survey will be content-analyzed to assess certain dimensions of wrongful acts. Thus, your honest reporting of the incident is greatly appreciated. Please remember that your answers are completely confidential and will not be associated with your name.

Please think of a keyword or short phrase (2-3 words) for the transgression you described. We will remind you of the transgression that you described by referring to the keyword or short phrase when we send you emails for the follow-up sessions. Please write down a meaningful keyword or short phrase that will help you remember the transgression you described. 


\section{Feelings of Discrepancy towards Partner (FD) / Need to resolve (NR)}

How do you feel about your partner after what he or she did to you? Please use the scale below and select the number that best represents your response.

$\begin{array}{ccccccc}1 & 2 & 3 & 4 & 5 & 6 & 7 \\ \text { Strongly } & \text { Disagree } & \text { Disagree } & \text { Neutral } & \text { Agree } & \text { Agree } & \text { Strongly } \\ \text { disagree } & & \text { somewhat } & & \text { somewhat } & & \text { agree }\end{array}$

1. I _ It is difficult to see my partner the same way after what he/she did. (FD)

2. I _ It is stressful to have both positive and negative feelings about my partner. (FD)

3. _ It is important to me that my partner and I talk about what happened so our relationship could get back to normal. (NR)

4. __ My partner's actions really bother me. (FD)

5. — I experience conflicting thoughts and feelings about my partner. (FD)

6. __ It is important for me to discuss what happened with my partner in order to make things better. (NR)

7. __ I want to stay away from my partner and spend time with my partner at the same time. (FD)

8. I _ It is important for me to 'fix' the way things are between us by talking about what happened. (NR)

9. __ It is important for me to know how our future would be affected by what happened. (NR)

10. __ My partner's behaviour is different from what I expect from him or her. (FD) 


\section{Deliberate Self-Persuasion Strategies}

Instructions: Below are some statements that describe how someone might react after they were harmed by their partner. Please read each statement carefully and indicate the extent to which you engaged in each of the behaviours since the event happened using the scale below:

$\begin{array}{ccccc}1 & 2 & 3 & 4 & 5 \\ \text { Never } & \text { Rarely } & \begin{array}{c}\text { About half } \\ \text { the time }\end{array} & \text { Usually } & \text { Always }\end{array}$

\section{Teleologic Strategies}

1. I tried to "take my mind off things" by thinking about something else. (distraction)

2. I distracted myself with other tasks to avoid thinking about what happened. (distraction)

3. I simply tried not to think about what happened. (suppression)

4. I tried to ignore what happened. (suppression)

5. I focused on all of the good things that my partner has done for me. (concentration)

6. I thought about my partner's positive qualities. (concentration)

7. I tried to avoid thinking about other instances in which my partner had hurt or upset me. (preemption)

\section{Epistemic Strategies}

1. I tried to explain my partner's behaviour in a more positive way. (motivated interpretation)

2. I tried to associate my partner's behaviour with some of their positive qualities (e.g., if a friend forgot to do something important for you, he or she was honest about it). (motivated integration)

3. I tried to consider the situation that my partner was in at the time to explain his or her behaviour. (attribution to benign causal factors)

4. I tried to think of past instances that show the good qualities of my partner. (motivated hypothesis testing)

5. I tried to "see the good" in my partner by comparing him or her to some of my other less valued family or friends. (changing comparators)

6. I tried to place more emphasis on the positive qualities of our relationship. (changing dimensions)

7. I tried to place less emphasis on the negative qualities of our relationship. (changing dimensions) 


\section{Discussion of Transgression}

1. To what extent have you and your partner talked about what happened?

$(1=$ not at all, $7=$ very much $)$

2. In how much detail did you and your partner discuss the offense?

$(1=$ not detailed at all, $7=$ Extremely detailed $)$

\section{Attitudinal Measure of Forgiveness}

Instructions: Please indicate the extent to which you agree with each of the statements

below in response to the transgression that you described using the scale provided.

$\begin{array}{ccccccc}-3 & -2 & -1 & 0 & +1 & +2 & +3 \\ \begin{array}{c}\text { Strongly } \\ \text { disagree }\end{array} & \text { Disagree } & \begin{array}{c}\text { Slightly } \\ \text { disagree }\end{array} & \begin{array}{c}\text { Neither agree } \\ \text { or disagree }\end{array} & \begin{array}{c}\text { Slightly } \\ \text { agree }\end{array} & \text { Agree } & \text { Strongly agree }\end{array}$

1. ___ I would easily forgive my partner.

2. ___ I would see my partner as positively as before.

3. __ I would hold a grudge against my partner.

4. ___ I would see my partner more negatively than I did before.

5. ___ I would have difficulty forgiving my partner.

6. ___ I would never see my partner as positively as before he or she wronged me.

$7 . \quad$ _ _ I would not hold a grudge against my partner.

8. ___ I would not see my partner more negatively than I did before. 


\section{Transgression-Related Interpersonal Motivations Inventory (TRIM-18)}

Please indicate the extent to which you agree with each of the statements below in response to the transgression that you described using the scale provided.

$\begin{array}{ccccccc}-3 & -2 & -1 & 0 & +1 & +2 & +3 \\ \begin{array}{l}\text { Strongly } \\ \text { disagree }\end{array} & \text { Disagree } & \begin{array}{l}\text { Slightly } \\ \text { disagree }\end{array} & \begin{array}{c}\text { Neither agree Slightly agree } \\ \text { or disagree }\end{array} & \text { Agree } & \text { Strongly agree }\end{array}$

1. I__ I'll make my partner pay.

2. I I keep as much distance between us as possible.

3. Even though my partners' actions hurt me, I still have good will for him/her.

4. __ I wish that something bad would happen to my partner.

5. __ I live as if my partner doesn't exist, isn't around.

6. _ I I want us to bury the hatchet and move forward with our relationship.

$7 . \quad$ I I don't trust my partner.

8. Despite what my partner did, I want us to have a positive relationship again.

9. _ I want my partner to get what he/she deserves.

10. __ I find it difficult to act warmly toward my partner.

11. _ I I avoid my partner.

12. ___ Although my partner hurt me, I put the hurt aside so we could resume our relationship.

13. I_ I'm going to get even.

14. __ I forgive my partner for what he/she did to me.

15. I I I cut off the relationship with my partner.

16. __ I have released my anger so I could work on restoring our relationship to health.

17. _ I want to see my partner hurt and miserable.

18. I I I withdraw from my partner.

\section{Transgression Severity and Event Date}

1. When this incident occurred, to what extent did you think that it had the potential to seriously harm your relationship with your partner? $(1=$ no harm to our relationship at all, $7=$ extremely harmful to our relationship)

2. When did the event occur? Please be as specific as you can.

month (e.g., January, February)

day (e.g., 1, 2, 16, 30)

year (e.g., 2010) 
Appendix D: Latent Growth Curve (LGM) Modeling for Study 3

We first tested a simple latent growth curve model by examining forgiveness responses at each of the four time points. As depicted in Figure 9, the intercept represents the mean level of forgiveness at the start of the study and the slope represents the rate of change in forgiveness over the three-week period. The paths from the intercept to forgiveness at each time point are set to 1 , which establishes the initial or constant level of forgiveness as if there was no growth over the three-week period. The paths from the slope to forgiveness at each time point are set to $0,1,2$, and 3 respectively to establish a linear growth curve as each measure was separated by a 1-week time period. And finally, the intercept and slope are allowed to be correlated in the model to test whether there is a relation between initial forgiveness and the rate of change in forgiveness. 


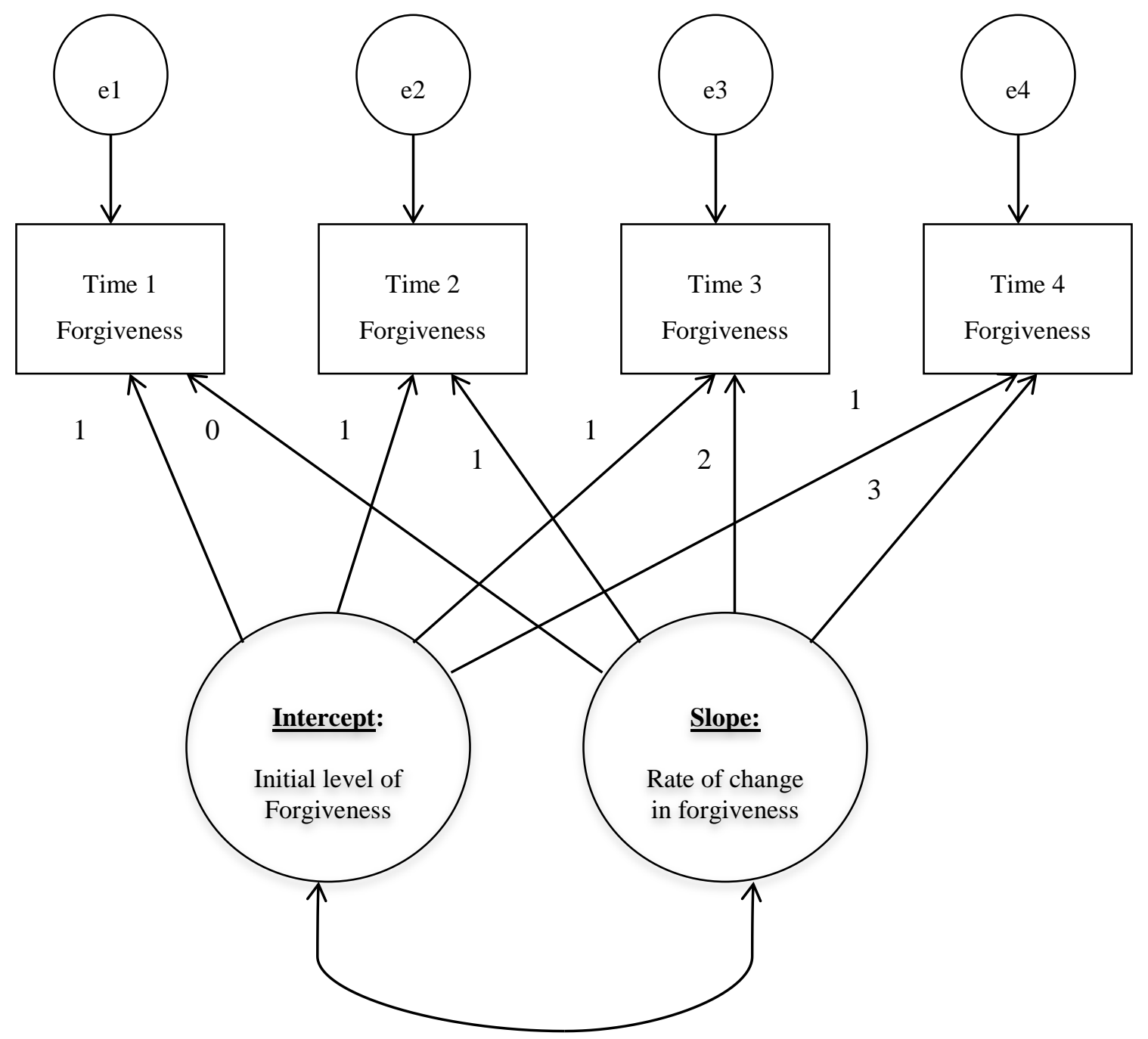

Figure 9. Simple latent growth curve model. 
A test of the model as shown in Figure 9 indicated that the model was an acceptable fit, $\chi^{2}(5)=9.21, p=.10, \mathrm{CFI}=.98, \mathrm{NNFI}=.98$, and $\mathrm{RMSEA}=.12(90 \% \mathrm{CI}$ : $<.001, .24)$. The results indicated that the mean intercept value was $1.36(p<.001)$, and the mean rate of change in forgiveness was $.06(p=.13)$ over the course of the study. Thus, the intercept was significantly different from zero, but the slope was not. The correlation between initial levels of forgiveness and the rate of change in forgiveness was not significant $(r=.28, p=.15$ ), which indicates that forgiveness at the start of the study was not related to the increase in forgiveness over the three-week period. The model, however, indicated that there were strong individual differences in the variances of the intercept $(v a r=.79, p<.001)$ and the slope scores $(v a r=.05, p=.01)$. Given these differences, we examined whether the variables in our model of deliberate self-persuasion predicted individual differences in levels of forgiveness at the start of the study and the rate at which forgiveness changed over time. Thus, we tested whether feelings of discrepancy, need to resolve, discussion, and strategies at Time 1 predicted individual differences in the intercept and slope of forgiveness (see Figure 10).

A test of the model as illustrated in Figure 10, indicated that the model was an acceptable fit, $\chi^{2}(16)=24.44, p=.08, \mathrm{CFI}=.97, \mathrm{NNFI}=.95$, and $\mathrm{RMSEA}=.10(90 \%$ CI: <.001, .17). Results indicated that feelings of discrepancy significantly predicted initial levels of forgiveness $(\beta=-.81, p<.001)$, such that greater feelings of discrepancy was relaed to lower levels of forgiveness at the start of the study. However, none of the other predictors explained the variation of the intercept or slope of forgiveness ( $p s>.15$ ). 


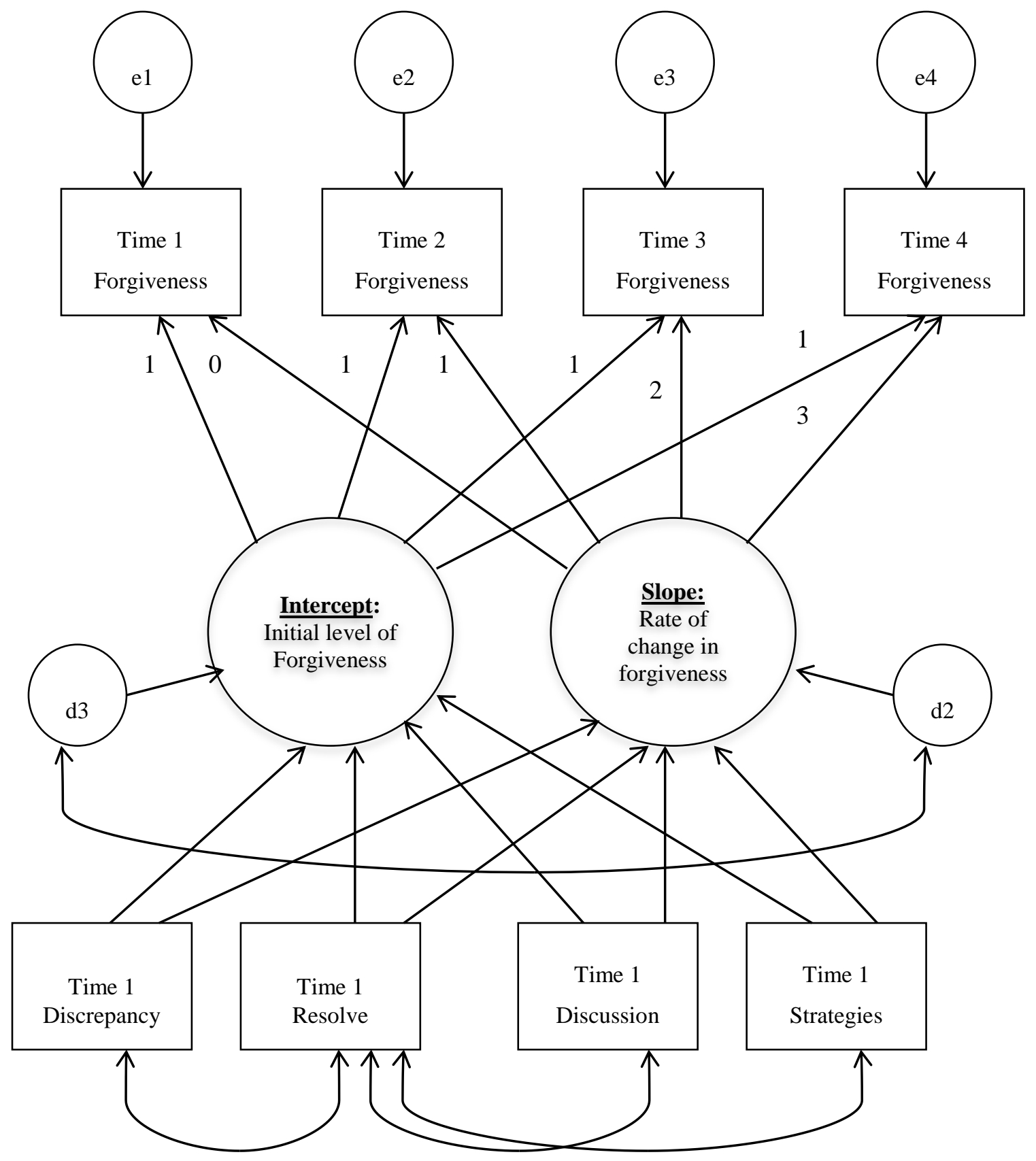

Figure 10. Hypothesized latent growth curve model with feelings of discrepancy, need to resolve, discussion, and strategies at Time 1 as predictors. 
We conducted another test of the model (as shown in Figure 10), but this time partialing out perceived transgression severity, number of days since the transgression occurred, and relationship quality from the forgiveness measures and the predictors in the model. The model was an acceptable fit, $\chi^{2}(16)=23.12, p=.11, \mathrm{CFI}=.96$, NNFI $=.92$, and RMSEA $=.09(90 \%$ CI: <.001, .16). Results indicated that feelings of discrepancy significantly predicted initial forgiveness $(\beta=-.54, p<.001)$, and the use of deliberate self-persuasion strategies predicted initial forgiveness $(\beta=.30, p=.03)$ indicating that less feelings of discrepancy and greater use of strategies were both related to more forgiveness at the start of the study among participants. No other significant paths were observed $(p s>.15)$. As in Studies 1 and 2, we reasoned that it is important to take into account the effects of perceived transgression severity, number of days since the transgression occurred, and relationship quality in the forgiveness process. Thus, the latent growth curve model that accounts for these variables seems to be the best representation of the data.

The findings from the LGM analysis indicate that forgiveness at the start of the study differed significantly from zero. However, the rate of change in forgiveness over the course of the study was not significantly different from zero. The LGM analysis also showed that both ambivalence and use of strategies predicted differences in initial levels of forgiveness among participants, such that less ambivalence and greater use of strategies was associated with higher levels of forgiveness. 
Appendix E : Ethics Approval Forms for Studies 1, 2, and 3

\author{
Department of Psychology \\ The University of Western Ontario \\ Room 7418 Social Sciences Centre \\ London, Ontario, Canada N6A $5 \mathrm{C} 2$ \\ Telephone: (519) 661-2067 Fax: (519) 661-3961
}

Psychology 4850E Use of Human Subjects Ethics Approval Notice

\begin{tabular}{|l|l|l|l|}
\hline $\begin{array}{l}\text { Review } \\
\text { Number }\end{array}$ & 4850E Approval\# HE09-16 & $\begin{array}{c}\text { Approval } \\
\text { Date }\end{array}$ & $\begin{array}{l}\text { October 13, } \\
2009\end{array}$ \\
\hline $\begin{array}{l}\text { Student } \\
\text { Investigator }\end{array}$ & Lisa Gallen & April 8, \\
\hline \\
Supervisor & Irene Cheung and James Olson & \\
\hline & & \\
Thesis Title & Recalling events in romantic relationships
\end{tabular}

This form indicates that your Psychology $4850 \mathrm{E}$ honors thesis research protocol has received ethics approval from the Psychology 4850E Course Coordinator (Bill Roberts) and through him from the University of Western Ontario Department of Psychology Research Ethics Board (PREB).

This approval shall remain valid until the end date noted above.

It is assumed that there will be no significant changes to the research protocol approved here, unless these changes are further approved by the Psychology 4850E Course Coordinator. Significant changes that would require further approval are particularly those that involve increased risk to participants' safety or privacy or might expose participants to unexpected or adverse experiences. In any of these cases, a revised research protocol should be submitted to the Psychology 4850E Course Coordinator for consideration before any further participants are tested.

You may take this signed form to Daniella Chirila, the Psychology Research Pool Coordinator, in Room 7416 SSC, and she will arrange access for you to the Research Pool. Please provide Daniella with a copy of your poster, your email address, and an indication of how many participant credits you will use.

William A. Roberts Ph.D.

Psychology 4850E Course Coordinator 
Department of Psychology The University of Western Ontario Room 7418 Social Sciences Centre, London, ON, Canada N6A 5C1

Telephone: (519) 661-2067Fax: (519) 661-3961

Use of Human Subjects - Ethics Approval Notice

\begin{tabular}{|r|l|l|l|}
\hline Review Number & $\mathbf{1 0} 1012$ & Approval Date & 101006 \\
\hline Principal Investigator & Jim Olson/Irene Cheung & End Date & 110430 \\
\hline Protocol Title & Watching videos and communicating in romantic relationships \\
\hline Sponsor & n/a & \\
\hline
\end{tabular}

This is to notify you that The University of Western Ontario Department of Psychology Research Ethics Board (PREB) has granted expedited ethics approval to the above named research study on the date noted above.

The PREB is a sub-REB of The University of Western Ontario's Research Ethics Board for Non-Medical Research Involving Human Subjects (NMREB) which is organized and operates according to the Tri-Council Policy Statement and the applicable laws and regulations of Ontario. (See Office of Research Ethics web site: http://www.uwo.ca/research/ethics/)

This approval shall remain valid until end date noted above assuming timely and acceptable responses to the University's periodic requests for surveillance and monitoring information.

During the course of the research, no deviations from, or changes to, the protocol or consent form may be initiated without prior written approval from the PREB except when necessary to eliminate immediate hazards to the subject or when the change(s) involve only logistical or administrative aspects of the study (e.g. change of research assistant, telephone number etc). Subjects must receive a copy of the information/consent documentation.

Investigators must promptly also report to the PREB:

a) changes increasing the risk to the participant(s) and/or affecting significantly the conduct of the study;

b) all adverse and unexpected experiences or events that are both serious and unexpected;

c) new information that may adversely affect the safety of the subjects or the conduct of the study.

If these changes/adverse events require a change to the information/consent documentation, and/or recruitment advertisement, the newly revised information/consent documentation, and/or advertisement, must be submitted to the PREB for approval.

Members of the PREB who are named as investigators in research studies, or declare a conflict of interest, do not participate in discussion related to, nor vote on, such studies when they are presented to the PREB.

Clive Seligman Ph.D.

Chair, Psychology Expedited Research Ethics Board (PREB)

The other members of the 2009-2010 PREB are: David Dozois, Bill Fisher, Riley Hinson and Steve Lupker

CC: UWO Office of Research Ethics

This is an official document. Please retain the original in your files 


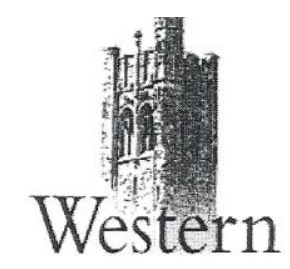

Department of Psychology The University of Western Ontario Room 7418 Social Sciences Centre, London, ON, Canada N6A 5C1

Telephone: (519) 661-2067Fax: (519) 661-3961

Use of Human Subjects - Ethics Approval Notice

\begin{tabular}{|r|l|r|l|}
\hline Review Number & 101029 & Approval Date & 101026 \\
\hline Principal Investigator & Jim Olson/Irene Cheung & End Date & 110430 \\
\hline Protocol Title & Reactions to events in romantic relationships \\
\hline Sponsor & n/a & \\
\hline
\end{tabular}

This is to notify you that The University of Western Ontario Department of Psychology Research Ethics Board (PREB) has granted expedited ethics approval to the above named research study on the date noted above.

The PREB is a sub-REB of The University of Western Ontario's Research Ethics Board for Non-Medical Research Involving Human Subjects (NMREB) which is organized and operates according to the Tri-Council Policy Statement and the applicable laws and regulations of Ontario. (See Office of Research Ethics web site: http://www.uwo.ca/research/ethics/)

This approval shall remain valid until end date noted above assuming timely and acceptable responses to the University's periodic requests for surveillance and monitoring information.

During the course of the research, no deviations from, or changes to, the protocol or consent form may be initiated without prior written approval from the PREB except when necessary to eliminate immediate hazards to the subject or when the change(s) involve only logistical or administrative aspects of the study (e.g. change of research assistant, telephone number etc). Subjects must receive a copy of the information/consent documentation.

Investigators must promptly also report to the PREB:

a) changes increasing the risk to the participant(s) and/or affecting significantly the conduct of the study;

b) all adverse and unexpected experiences or events that are both serious and unexpected;

c) new information that may adversely affect the safety of the subjects or the conduct of the study.

If these changes/adverse events require a change to the information/consent documentation, and/or recruitment advertisement, the newly revised information/consent documentation, and/or advertisement, must be submitted to the PREB for approval.

Members of the PREB who are named as investigators in research studies, or declare a conflict of interest, do not participate in discussion related to, nor vote on, such studies when they are presented to the PREB.

Clive Seligman Ph.D.

is

Chair, Psychology Expedited Research Ethics Board (PREB)

The other members of the 2010-2011 PREB are: Mike Atkinson (Introductory Psychology Coordinator), David Dozois, Vicki Esses, Riley Hinson Albert Katz (Department Chair), and Tom O'Neill (Graduate Student Representative) 
Curriculum Vitae

\section{Irene Cheung}

\section{Education}

Ph.D., Social Psychology, University of Western Ontario, 2012

M.Sc., Social Psychology, University of Western Ontario, 2007

B.A. (Honours), Applied Studies and Psychology Co-op, University of Waterloo, 2005

\section{Awards and Scholarships}

- Social Sciences and Humanities Research Council (SSHRC), Doctoral Fellowship, 2008$2011, \$ 60,000$

- Graduate Thesis Research Award, University of Western Ontario, 2008, \$500

- Convention Travel Grant, Canadian Psychological Association, 2007, \$150

- Social Sciences and Humanities Research Council (SSHRC), Master's Scholarship, 2006-2007, \$17,500

- Western Graduate Research Scholarship, University of Western Ontario, 2005-2010, $\$ 16,500$

- Graduate Teaching Award Nominee, University of Western Ontario, 2005, 2007, 2008

- Ontario Graduate Scholarship, 2005-2006, \$15,000

- Natural Sciences and Engineering Research Council (NSERC), Undergraduate Student Research Award, 2002, \$4000

- Arts Faculty Scholarship, University of Waterloo, 2000, \$1000

\section{Research Interests}

- Interpersonal Forgiveness

- Social Justice

- Time Perception

- Affective Forecasting

- Moral Exclusion 


\section{Publications}

Cheung, I., \& Olson, J. M. (in press). Sometimes it's easier to forgive my transgressor than your transgressor: Effects of subjective temporal distance on forgiveness for harm to self or close other. Journal of Applied Social Psychology.

Konrath, S. H., \& Cheung, I. (in press). The fuzzy reality of perceived harms. Commentary in Response to target article "Cognitive Systems of Revenge and Forgiveness" by Michael E. McCullough, Robert Kurzban, and Benjamin A. Tabak To appear in Behavioral and Brain Sciences.

Hafer, C. L., Conway, P. J., Cheung, I., Malyk, D., \& Olson, J. M. (in press). The relation between identification with a target and the perceived importance of justice.

Maio, G. R., Olson, J. M., \& Cheung, I. (in press). Attitudes in social behavior. In H. Tennen \& J. Suls (Eds.), The handbook of psychology $\left(2^{\text {nd }}\right.$ ed.), Volume 5: Personality and social psychology.

Olson, J. M., Cheung, I., Conway, P., Hutchison, J., \& Hafer, C. L. (2011). Distinguishing two meanings of moral exclusion: Irrelevance of fairness vs. rationalized harm-doing. Social Justice Research.

Olson, J. M., Hafer, C. L., Cheung, I., \& Conway, P. J. (2010). Explorations into the scope of justice: A deservingness perspective. In A. C. Kay, D. R. Bobocel, M. P. Zanna, \& J. M. Olson (Eds.). The psychology of justice and legitimacy: The Ontario Symposium (Vol. 11, pp. 125-149). New York: Psychology Press.

Lam, K. C. H., Buehler, R., McFarland, C., Ross, M., \& Cheung, I. (2005). Culture and affective forecasting. Personality and Social Psychology Bulletin, 31, 1296-1309.

\section{Research Reports}

Gorman, G., Tieu, T.-T., \& Cheung, I. (2011). The essential skills and pathways project: Final report. Prepared for the Ontario Ministry of Training, Colleges and Universities.

\section{Manuscripts in Preparation}

Bennett-AbuAyyash, C., Cheung, I., \& Olson, J. M. Lay perceptions of prejudice.

Cheung, I., Conway, P. J., Hafer, C. L., Kawiuk, C., Fernando, J. P., \& Olson, J. M. Support for harm-doing: The roles of deservingness and fairness.

Conway, P., Cheung, I., Maxwell-Smith, M., \& Seligman, C. Are election outcomes predicted by procedural justice or moral conviction?

Conway, P., Cheung, I. \& Olson, J. M. No benefit of the doubt? Perceivers fail to excuse ego-depleted immoral behaviour. 


\section{Selected Conference Talks \& Poster Presentations}

Lopes, B. K., Cheung, I., \& Wilson, A. E. (2012, January). Forgiveness in Close Friendships: The Role of Past Transgression Resolution and Subjective Temporal Distance on Forgiveness of Future Transgressions. Poster presented at the 13th annual meeting of the Society for Personality and Social Psychology, San Diego, CA, USA.

Cheung, I., Conway, P., Fernando, J. P, Kawiuk, C., Hafer, C. L., \& Olson, J. M. (2011, January). Justice in Harm-Doing: Examining Deservingness and Exclusion in the Treatment of Minorities and Terrorist Suspects. Poster presented at the 12th annual meeting of the Society for Personality and Social Psychology, San Antonio, TX, USA.

Cheung, I., Conway, P., Kawiuk, C., Hafer, C. L., \& Olson, J. M. (2010, August). Support for harsh treatment of terrorist suspects: The roles of deservingness and fairness. Poster presented at the 13th biennial meeting of the International Society for Justice Research, Banff, Alberta, Canada.

Cheung, I., Gorman, G., \& Olson, J. M. (2010, January). Reactions to injustice: The role of explicit and implicit self-esteem. Poster presented at the 11th annual meeting of the Society for Personality and Social Psychology, Las Vegas, NV, USA.

Cheung, I., Conway, P. J., Maxwell-Smith, M., \& Seligman, C. (2009, June). Happiness and the outcome of the 2008 Canadian Federal Election. Symposium presentation, $70^{\text {th }}$ annual meeting of the Canadian Psychological Association convention, Montreal, Quebec, Canada.

Cheung, I., \& Olson, J. M. (2009, May). Psychological distancing and forgiveness: The roles of visual perspective and subjective time. Poster presented at the $21^{\text {st }}$ annual meeting of the Association for Psychological Science, San Francisco, CA, USA.

Cheung, I., \& Olson, J. M. (2008, June). When interpersonal harms feel far away: Examining the role of psychological time and apology in forgiveness. Symposium presentation, $69^{\text {th }}$ annual meeting of the Canadian Psychological Association convention, Halifax, Nova Scotia, Canada.

Cheung, I., Olson, J. M., Conway, P. J, \& Hafer, C. L. (2008, February). Psychological factors affecting the treatment of others. Poster presented at the 9th annual meeting of the Society for Personality and Social Psychology, Albuquerque, NM, USA.

Cheung, I., Olson, J. M., \& Hafer, C. L. (2007, August). Similarity and utility as determinants of punishment for illegal behaviour. Poster presented at the 11th meeting of the Ontario Symposium, Waterloo, Ontario, Canada.

Cheung, I., \& Olson, J. M. (2007, June). Forgiving others: The relation between subjective temporal distance and forgiveness. Poster presented at the 68th annual meeting of the Canadian Psychological Association convention, Ottawa, Ontario, Canada.

Cheung, I., \& Olson, J. M. (2007, May). Forgiving others: The relation between subjective temporal distance and forgiveness. Informal paper presented at the Annual WaterlooWestern Meeting, Waterloo, Ontario, Canada. 


\section{Selected Conference Talks \& Poster Presentations (continued)}

Cheung, I., Olson, J. M., \& Hafer, C. L. (2007, January). How we treat others: Understanding the role of perceived deservingness. Poster presented at the 8th annual meeting of the Society for Personality and Social Psychology, Memphis, TN, USA.

Lam, K. C. H., Buehler, R., McFarland, C., Ross, M., \& Cheung, I. (2005, January). Cultural differences in affective forecasting: The role of focalism. Poster presented at the 6th annual meeting of the Society for Personality and Social Psychology, New Orleans, LA, USA.

Lam, K. C. H., Linardatos, L., Cheung, I., Wilson, A. E., \& Ross, M. (2003, June). Testing temporal self-appraisal theory with older adults. Poster presented at the 64th annual meeting of the Canadian Psychological Association convention, Hamilton, Ontario, Canada.

\section{Teaching Experience}

- Instructor, Research Methods in Psychology, King's University College at the University of Western Ontario, Winter 2012

- Instructor, Industrial and Organizational Psychology, Wilfrid Laurier University, Fall 2011

- Co-Instructor, Psychology of Persuasion, University of Western Ontario, Winter 2012

- Co-Instructor, Psychological Aspects of Life Skills, University of Western Ontario, Summer 2011

- Honors Thesis Supervisor, Topic: Interpersonal Forgiveness, University of Western Ontario, 2010

- Honors Thesis Co-Supervisor, Topic: Interpersonal Forgiveness, University of Western Ontario, 2009

- Lab Instructor, Research Methods in Social Psychology, University of Western Ontario, 2010

- Lab Instructor, Statistics for Psychology, University of Western Ontario, 2008

- Lab Instructor, Research Methods in Psychology, University of Western Ontario, 2005, 2006, 2007

- Guest Lecturer, Research Methods in Social Psychology, University of Western Ontario, Oct. 2010

- Guest Lecturer, Culture and Psychology, University of Waterloo, Feb. 2007

- Teaching Assistant, Research Methods in Psychology, University of Western Ontario, 2009

- Teaching Assistant, Social Psychology, University of Western Ontario, Spring 2008

- Teaching Assistant, Cultural Psychology, University of Waterloo, 2004

\section{Teaching Interests}

Attitudes and Persuasion

I/O Psychology

Interpersonal Relations

Introduction to Psychology

Psychological Aspects of Life Skills
Research Methods

Social Cognition

Social Justice

Social Psychology

Statistics 


\section{Other Professional Activities}

- Webmaster, Social and Personality Section, Canadian Psychological Association, June 2010present

- Abstract Reviewer, Social and Personality Section, Canadian Psychological Association, 2010, 2011

- Co-organizer, Annual Waterloo-Western Conference, 2010, 2011

- Research Assistant for Michael Dixon and Kevin Harrigan, University of Waterloo, August 2009

- Project Title: Effectiveness of a Brief Educational Intervention and ATM-relocation in Reducing Erroneous Cognitions and Over-Expenditure during Slot Machine Play in a Sample of Problem, At Risk, and Non-Problem Gamblers

- Student Organizing Committee, Ontario Symposium: The Science of the Couple, August 2009

- Graduate Student Campus Representative, Canadian Psychological Association, 2008-2009

- Social Psychology Brownbag Coordinator, University of Western Ontario, 2007-2008

- Student Representative, Social Psychology Area Committee, University of Western Ontario, 2006-2007

- Member, Technology and Social Research Committee, University of Western Ontario, 20052008

- Student Organizer, Festschrift for Melvin J. Lerner, University of Waterloo, 2002

- Research Assistant \& Lab Co-ordinator for Michael Ross, University of Waterloo, 2001-2005

\section{Ad-hoc Reviewer}

- European Journal of Social Psychology

- Personal Relationships 